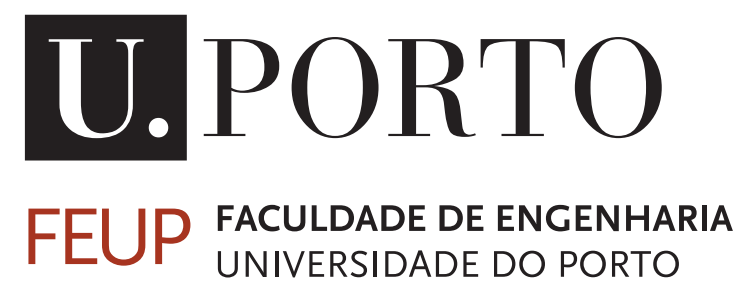

\title{
Impact of environmental concerns on the capacity-pricing problem in the car rental business
}

Fábio Queirós

FINAL VERSION

Mestrado Integrado em Engenharia Eletrotécnica e de Computadores

Supervisor: Beatriz Brito Oliveira

October 21, 2020 
(C) Fábio Queirós, 2020 


\section{Resumo}

Uma das principais decisões que uma uma empresa de car rental deve tomar diz respeito à definição do tamanho e do mix da frota, ou seja, a capacidade de atendimento da procura. Essa procura é altamente imprevisível e sensível ao preço, portanto, a definição dos preços cobrados influencia as decisões de capacidade. Além disso, as decisões de capacidade também estão ligadas a outras estratégias da empresa para atender à procura, como oferta de upgrades, downgrades, realização de transferências em vazio entre estações e recurso ao leasing adicional de veículos. Além disso, a decisão de aceitar ou rejeitar um pedido de reserva é complexa. Os pedidos de reserva podem ser aceites por ordem de chegada, desde que haja capacidade para o realizar (veículos disponíveis) ou, por outro lado, um pedido pode ser rejeitado, mesmo havendo capacidade para o realizar, guardando assim essa capacidade para um pedido futuro mais rentável financeiramente. Tipicamente, este tipo de problemas podem ser descritos em modelos matemáticos que tentam otimizar, usualmente, os lucros obtidos. Contudo, os resutados financeiros não devem ser o único foco de preocupação. As alterações climáticas são um grande problema que a humanidade terá que enfrentar e medidas devem ser tomadas o quanto antes para evitar medidas mais drásticas no futuro.

Posto iso, este trabalho visa a incorporação de preocupações ambientais num modelo matemático referente ao problema de integração das decisões de capacidade e de preços no negócio do car rental, resultando então num modelo bi-objetivo. O método Life Cycle Assessment é aplicado não só aos veículos mas também ao combustível, para definição dos parâmetros ambientais e do objetivo correspondente. São considerados 4 tipos de veículos: veículos de combustão interna, híbridos, híbridos plug-in e veículos elétricos.

Vários métodos de solução de problemas multi-objetivo são abordados e o método epsilon constraint é desenvolvido e aplicado a este problema e modelo matemático bi-objetivo. Os resultados obtidos permitem concluir que a fonte de energia elétrica é preponderante nos resultados ambientais enquanto a utilização de incentivos à utilização de veículos elétricos não se traduz num decréscimo nas emissões de $\mathrm{CO}_{2}$. Os resultados ambientais e financeiros tendem a seguir alterações na procura e uma pequena variação de preços influencia quase linearmente os resultados financeiros. O orçamento disponível prova ser essencial na capacidade do modelo em aceitar pedidos de reserva enquanto os resultados ambientais dependem essencialmente do tamanho da frota. Os resultados mostram uma predisposição a comprar veículos em vez de recorrer ao seu leasing, enquanto que as transferências em vazio mostram não ser muito comuns. Por fim, analisando todas as curvas de Pareto, conclui-se que, em média, com um decréscimo de $16.10 \%$ nos resultados financeiros, é possível obter um decréscimo de $65.33 \%$ nos resultados ambientais. 


\section{Abstract}

One of the main decisions that a car rental company has to make regards the definition of the fleet size and mix, i.e., the capacity to meet demand. This demand is highly unpredictable and pricesensitive, thus, the definition of prices charged influences capacity decisions. In addition to this, capacity decisions are also linked to other company strategies to meet demand such as offering upgrades, downgrades, performing empty transfers between stations, and resorting to additional vehicle leasing. Moreover, the decision to accept or reject a rental request is complex. Rental requests can be accepted on a first-come, first-served basis, as long as there is the capacity to carry it out (vehicles available) or, on the other hand, a request can be rejected, even if there is the capacity to carry it out, thus keeping that capacity for a more profitable further rental request. Typically, these types of problems can be described in mathematical models that try to optimize, usually, the profits obtained. However, financial results should not be the only focus of concern. Climate change is a major problem that humanity will have to face and measures must be taken as soon as possible to avoid more drastic measures in the future.

That said, this work aims to incorporate environmental concerns into a mathematical model related to the capacity-pricing problem in the car rental business, resulting in a bi-objective model. The Life Cycle Assessment method is applied not only to vehicles but also to fuel, to define environmental parameters and the corresponding objective. Four types of vehicles are considered: internal combustion engine vehicles, hybrids, hybrids plug-in, and electric vehicles.

Several methods of solving multi-objective problems are addressed and the epsilon constraint method is developed and applied to this problem and to the bi-objective mathematical model. The results obtained allow us to conclude that the source of electric energy is significant in the environmental results while the use of incentives for using electric vehicles does not translate into a decrease in $\mathrm{CO}_{2}$ emissions. Environmental and financial results tend to follow changes in demand and a small variation in prices influences financial results almost linearly. The available budget proves to be essential in the model's capacity to accept rental requests while environmental results depend essentially on the size of the fleet. The results show a predisposition to buy vehicles instead of resorting to its leasing, while empty transfers are not very common. Finally, analysing all Pareto fronts, it is concluded that, on average, with a decrease of $16.10 \%$ in financial results, it is possible to obtain a decrease of $65.33 \%$ in environmental results. 


\section{Agradecimentos}

A primeira palavra de agradecimento é dirigida à Prof. Beatriz Brito Oliveira, minha orientadora nesta dissertação. Agradeço, primeiramente, por me ter confiado a realização desta dissertação e, de seguida, por todo o apoio que me foi dado durante todos estes meses de trabalho. A prontidão demonstrada na resposta a dúvidas ou problemas que inevitavelmente surgem sempre durante a realização de uma dissertação foi, de facto, algo notável e que tem de ser reconhecido, antes de mais. Obrigado, mesmo!

De seguida, agradecer à minha família por todo o suporte ao longo destes meses. Devido à pandemia, grande parte do trabalho desenvolvido nesta dissertação foi realizado em casa, junto da minha família. Assim, mais que nunca, o carinho e o bom ambiente familiar foram essenciais para manter o foco no trabalho.

Por último, agradecer aos meus amigos. Eles que são um analgésico para os dias menos bons e que foram essencias para manter a sanidade mental em dias tão complicados. Recordo todas as vídeo-chamadas feitas durante o estado de emergência que, de alguma forma, ajudaram a amenizar a tristeza por a pandemia me ter retirado o último cortejo, a última queima e a possibilidade de festejar o meu aniversário com eles.

Queria deixar também uma nota de agradecimento ao Bruno Nogueira por, num momento particularmente difícil para todos, ter sido a companhia diária de muitos portugueses e provar que é possível haver Natal em maio.

Fábio Queirós 
"The most important thing is to try and inspire people so that they can be great in whatever they want to do."

Kobe Bryant 


\section{Contents}

1 Literature Review 1

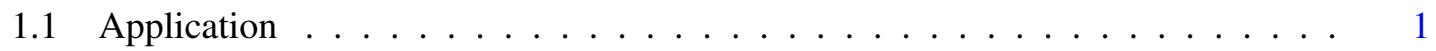

1.1.1 Car Rental . . . . . . . . . . . . . . . . . . . 1

1.1.2 Environmental Impacts . . . . . . . . . . . . . . . . . . . . . 4

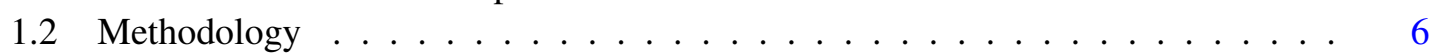

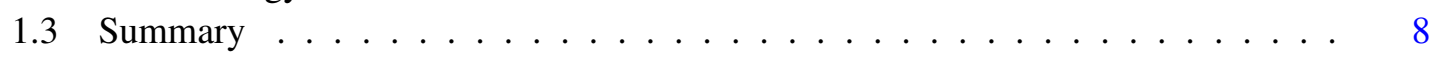

2 Bi-objective Mathematical Model 9

2.1 Indices and Parameters . . . . . . . . . . . . . . . . . . . . . . 9

2.2 Decision Variables . . . . . . . . . . . . . . . . . . . . 11

2.3 Objective Functions . . . . . . . . . . . . . . . . . . . . . . 12

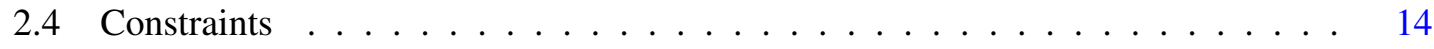

3 Environmental Parameters Definition $\quad 19$

3.1 Production and Disposal . . . . . . . . . . . . . . . . . . . . . . . 19

3.2 Fuel and Utilization . . . . . . . . . . . . . . . . . . . . . . . . . 20

3.3 Other Parameters . . . . . . . . . . . . . . . . . . . . . 22

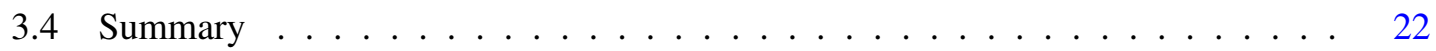

4 Solution Method 25

4.1 Single Objective Function Method . . . . . . . . . . . . . . . . . . . . . 25

4.2 Weighted Sum Method . . . . . . . . . . . . . . . . . 25

4.3 Epsilon Constraint Method . . . . . . . . . . . . . . . . . . . . 26

5 Tests and Analyses 27

5.1 Analysis of Instance Characteristics _ . . . . . . . . . . . . . . . . . 28

5.2 Methodological Tests . . . . . . . . . . . . . . . . . 30

5.3 Analyses and Insights . . . . . . . . . . . . . . . . . . . . . . 36

5.3.1 Incentives for Using Electric Vehicles . . . . . . . . . . . . . . . . 37

5.3.2 Use of Renewable Sources of Energy . . . . . . . . . . . . . . . . . . . . . 40

5.3 .3 Electric Vehicles Disposal . . . . . . . . . . . . . . . . . . 43

5.3 .4 Fuel Production . . . . . . . . . . . . . . . . . . . . . . . . 44

5.3 .5 Homogeneous Fleets . . . . . . . . . . . . . . . . . . . 46

5.3.6 Total Demand Variation . . . . . . . . . . . . . . . . . . . . . . 49

5.3 .7 Demand Variation by Group . . . . . . . . . . . . . . . . . . . 52

5.3 .8 Market Competition . . . . . . . . . . . . . . . . . . . 54

5.3 .9 Available Budget . . . . . . . . . . . . . . . . . . . . 57

5.4 Summary . . . . . . . . . . . . . . . . . . . . . . 60 
6 Conclusions and Future Work

A Methodological Tests Results 65 


\section{List of Figures}

1.1 Pareto front solution set $[22] \ldots \ldots \ldots \ldots \ldots$

1.2 Feasible region and directions of objective functions $[26] \ldots \ldots$

5.1 Distribution of check-out time period . . . . . . . . . . . . . . . . . . . . . . 29

5.2 Distribution of check-in time period . . . . . . . . . . . . 30

5.3 Distribution of rental requests duration . . . . . . . . . . . . . 30

5.4 Average iteration time for different scale factors . . . . . . . . . . . . . . . 33

5.5 Average gap for different scale factors . . . . . . . . . . . . . . 33

5.6 Average iteration time depending on the number of rentals . . . . . . . . . 34

5.7 Average iteration time depending on the number of vehicle groups . . . . . . . . 34

5.8 Average iteration time depending on the epsilon size $\ldots \ldots \ldots . \ldots 35$

5.9 Total time per instance depending on the epsilon size . . . . . . . . . . . 35

5.10 Incentives for using electric vehicles: Pareto front . . . . . . . . . . . . . . 37

5.11 Incentives for using electric vehicles: Environmental impacts decomposition . . . 38

5.12 Incentives for using electric vehicles: Revenues . . . . . . . . . . . . . . . 39

5.13 Incentives for using electric vehicles: Costs decomposition . . . . . . . . . . . 39

5.14 Incentives for using electric vehicles: Acceptance rate . . . . . . . . . . . . . . . 40

5.15 Use of renewable sources of energy: Pareto front . . . . . . . . . . . . . . 41

5.16 Use of renewable sources of energy: Environmental impacts decomposition . . . 42

5.17 Use of renewable sources of energy: Environmental impacts decomposition (ex-

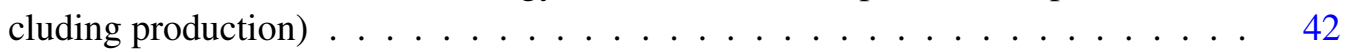

5.18 Electric vehicles disposal: Pareto front . . . . . . . . . . . . . . . . 43

5.19 Fuel Production: Pareto front . . . . . . . . . . . . . . . . . . . . 45

5.20 Fuel Production: Environmental impacts decomposition (excluding production) . 46

5.21 Homogeneous fleets: Pareto front . . . . . . . . . . . . . . . . . 47

5.22 Homogeneous fleets: Revenues . . . . . . . . . . . . . . . . . . . . . 47

5.23 Homogeneous fleets: Acceptance rate . . . . . . . . . . . . . . . . . . . 48

5.24 Homogeneous fleets: Environmental impacts decomposition . . . . . . . . . . . 48

5.25 Homogeneous fleets: Environmental impacts decomposition (excluding production) 49

5.26 Total demand variation: Pareto front . . . . . . . . . . . . . . . 50

5.27 Total demand variation: Rental requests . . . . . . . . . . . . . . . . . . . . 50

5.28 Total demand variation: Acceptance rate . . . . . . . . . . . . . . . 51

5.29 Demand variation by group: Pareto front . . . . . . . . . . . . . . . . 53

5.30 Demand variation by group: Groups required . . . . . . . . . . . . . 53

5.31 Demand variation by group: Environmental impacts decomposition . . . . . . 54

5.32 Demand variation by group: Environmental impacts decomposition (excluding

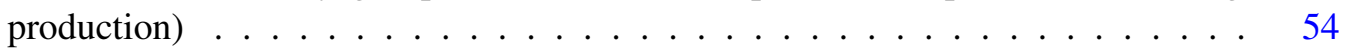

5.33 Market competition: Pareto front . . . . . . . . . . . . . . . . 55 
5.34 Market competition: Revenues . . . . . . . . . . . . . . . . . . 56

5.35 Market competition: Costs decomposition . . . . . . . . . . . . . 56

5.36 Market competition: Rental requests . . . . . . . . . . . . . . . . . . . 57

5.37 Available budget: Pareto front . . . . . . . . . . . . . . . . 58

5.38 Available budget: Revenues . . . . . . . . . . . . . . . . . . . . . 58

5.39 Available budget: Costs decomposition . . . . . . . . . . . . . . . . . . . 59

5.40 Available budget: Environmental impacts decomposition . . . . . . . . . . . 59

5.41 Available budget: Rental requests . . . . . . . . . . . . . . . . . 60 


\section{List of Tables}

3.1 Emissions from energy production . . . . . . . . . . . . . . 20

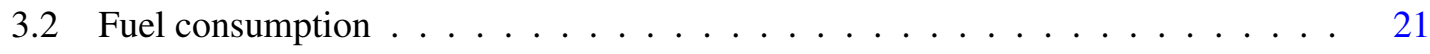

3.3 Environmental parameters ................... 23

5.1 Instances main characteristics . . . . . . . . . . . . . . . . . . . . 28

5.2 Results of solving a single objective function at a time . . . . . . . . . . 31

5.3 Results of the weighted sum method . . . . . . . . . . . . . . . 31

5.4 Results of the epsilon constraint method . . . . . . . . . . . . . . . 32

5.5 Instances utilized . . . . . . . . . . . . . . . . . . . 36

5.6 Purchased vehicles by group . . . . . . . . . . . . . . . . . . 40

5.7 Emissions variation ...................... 41

5.8 Purchased vehicles for the same environmental impact . . . . . . . . . . . . 44

5.9 Purchased vehicles at final iteration . . . . . . . . . . . . . . . . . . 4 44

5.10 Total demand variation: Emissions variation . . . . . . . . . . . . . 51

5.11 Total demand variation: Financial results variation . . . . . . . . . . . . . 51

5.12 Financial results variations . . . . . . . . . . . . . . . . 55

6.1 GHGs global warming potential [21] . . . . . . . . . . . . . . . 64

6.2 Emissions associated with fuel combustion, over $100 \mathrm{~km} \mathrm{[33]} \mathrm{.} \mathrm{.} \mathrm{.} \mathrm{.} \mathrm{.} \mathrm{.} \mathrm{.} \mathrm{.} \mathrm{.} 64$

6.3 Multiplication of GWP by the emissions . . . . . . . . . . . . . . . 64

A.1 Instances data and number of iterations tested . . . . . . . . . . . . . . . 66

A.2 Epsilon constraint method - financial objective function results (1) . . . . . . . 67

A.3 Epsilon constraint method - financial objective function results (2) . . . . . . 68

A.4 Epsilon constraint method - environmental objective function results . . . . . . . 69 


\title{
Abbreviations and Symbols
}

\author{
ACC Adaptive Cruise Control \\ BEV Battery Eectric Vehicle \\ CAGR Compound Annual Growth Rate \\ GHG Greenhouse Gas \\ GA Genetic Algorithm \\ GWP Global Warming Potential \\ ICE Internal Combustion Engine \\ INLP Integer Non-Linear Programming Model \\ LCA Life Cycle Assessment \\ MIP Mixed-Integer Programming \\ MOO Multi-Objective Optimization \\ OF Objective Function \\ PHEV Plg-in Hybrid Electric Vehicle \\ PTW Plant-to-wheel \\ SUV Sport Utility Vehicle \\ TTW Tank-to-wheel \\ WTT Well-to-tank \\ WTW Well-to-Wheel \\ YMS Yield Management System
}





\section{Chapter 1}

\section{Literature Review}

The literature review is divided into two main parts: Application and Methodology. The first one focuses on two different themes. Firstly, the car rental business is explained. Its growth is addressed alongside the predictions for the future and some particularities of car rental are exploited such as pools, rentals, capacity-pricing relation, among others. The second part of the section focuses on the environmental aspects and has the goal of supporting the development of a realistic environmental objective function for this sector. Herein a very comprehensive approach is taken not only to the car but also to the fuel. The Life Cycle Assessment (LCA) is introduced and exhaustive analyses are carried out on all the pollution existing in individual transportation by car.

Lastly, the Methodology section focuses on the optimization of multi-criteria problems. Four optimization methods are exploited: solving the model considering only one criterion at a time, using a weighted sum approach to convert a multi-objective into single-objective problems, epsilon constraint method, and NSGA-II which is a genetic algorithm that can solve multi-objective problems. These methods were selected because they represent common ways of solving the problem and are progressive in terms of complexity. Examples of practical applications of these same methods are also shown.

\subsection{Application}

This section is divided into two parts as follows. Firstly, the car rental business is explained in Section 1.1.1. After that, the environmental impacts of mobility sector are exploited in Section 1.1.2.

\subsubsection{Car Rental}

The car rental business is a relevant sector within the current mobility systems, which has been significantly growing in the past years. In 2018, the fleet had an average growth of $1.2 \%$ while the revenue gains have grown $4.83 \%$, in U.S [6, 7]. In addition to this, Market Research Future has published a research report about the global car rental market that foresees a massive hike for this market with 14\% CAGR (Compound Annual Growth Rate) between 2018 and 2023 [8]. All these 
details highlight not only the importance of car rental in the present but, above all, the importance of it in the future. That said, it is important to understand how the car rental business operates.

In brief, the car rental business consists of renting cars from the fleet for a pre-defined period that can be short term ( 1 day) to long term ( 1 month or more). The rental stations are usually aggregated in pools - groups of stations that share the same fleet. These stations are used by the drivers to pick up or leave the car. Also, there is flexibility between the pools, which means the pool design can be frequently reshuffled in order to e.g. fulfill a seasonal demand on a specific location [29].

A car rental fleet is composed by rental groups - cars of different types (e.g. sport utility vehicle (SUV), compact, hybrid, battery electric car (BEV), etc.), and the size of the fleet is mainly determined by the company's strategy and the available investment. In addition to this, the size of the fleet is neither steady nor a one-time decision. In fact, the vehicle acquisition and removal from a fleet play a very important part on the company's financial results and is considerably flexible.

Another relevant management decision regards the fleet distribution. This decision takes particular relevance since the majority of the operational costs in car rental depend on the idle fleet [29]. Even so, there is a certain flexibility associated with these decisions due to the incoming pick-ups and returns (can occur in different stations at different times). To overcome this possible mismatch between fleet availability and demand in certain locations and keep the fleet distribution balanced, it is possible the use of empty transfers of the vehicles between stations. This is typically done by a driver in two ways, depending on the number of cars to move: driving a specific car or driving a set of cars by truck.

The task of assigning a specific vehicle to a booking request is also included in the fleet management. This task intertwines with the scheduling of the planned maintenance and is of utmost importance to the efficient interaction between them. Also, there are other details linked to the booking request that require an analysis. A rental request is characterized by the following: desired rental group, check-in and check-out station, and check-in and check-out date. This way, it is likely that there will be situations of unavailability of the intended vehicle group. To avoid a lost sale, car rental companies usually offer an upgrade or a downgrade although the latter one is only used as a last resort and not all companies do it. The first one consists of offering an upper vehicle group for the price of the originally desired one. The downgrade consists on the possibility of getting a "worse" vehicle group with a discount [29].

Moreover, uncertainty also plays an important role and greatly affects the car rental fleet management. Firstly, the demand is highly difficult to predict and, as already said above, the idle fleet represents the majority of the operational costs. Besides, the unplanned vehicle maintenance and repair or the delayed car return by a client highly affects the availability of the fleet. There is then uncertainty regarding the available capacity forecast.

Summing up, the car rental fleet management problems include several decisions on the following topics:

- Clustering locations into pools; 
- Fleet size and composition;

- Fleet distribution among rental stations;

- Acceptance of rental requests;

- Assigning rentals to vehicles.

Considering the topics above, the ones with relation to the capacity problem regards the fleet size and composition, distribution among rental stations, and the acceptance of rental requests.

The acceptance of rental requests is a very critical decision since it is firmly linked to the revenue stream. Therefore, the decision to accept or reject a booking request should be always made in order to optimise the revenue. Some companies may fulfill all the requests by arriving in order as long as they have available capacity. Other companies may reject a rental request, even though there is available capacity, in order to save the vehicle for a more profitable further request. This optimisation is not trivial and some companies use mathematical models to support the decision. A literature review of some of these models was performed and presented below.

Guerriero et al. modelled and solved a car rental revenue stream optimisation problem [16]. An innovative integer programming model was devised with the inclusion of car rental business particularities such as multi-day rentals and non-cascading upgrades. The developed model allows the determination of the appropriate number of cars to be rented and incorporates the possibility of implementing upgrades.

Another similar support system can be found in [13] where Hertz (wholly owned subsidiary of Ford) developed its yield management system (YMS) to help decide the availability of several combinations such as car types, rental periods, pickup and return locations, and temporary insurance and refueling options. The YMS supports models that solve the closely-related problems of pricing, fleet planning, and fleet deployment.

In [30], Oliveira et al. tackle the integration of capacity and pricing problems for car rental companies proposing a mathematical model that defines it and developing a matheuristic approach to solving it. This mathematical model is particularly relevant for this work since it will be used as a starting point for the development of the bi-objective mathematical model presented in Chapter 2. Oliveira et al. extend the model proposed in [30] to consider uncertainty in demand and competitor prices, thus presenting the stochastic car rental capacity-pricing problem [31]. They also proposed a co-evolutionary matheuristic to solve it. This matheuristic is based on a co-evolutionary genetic algorithm where parallel populations of solutions and scenarios co-evolve. This matheuristic provides a set of good solutions and there is no need for information regarding the probability distribution. The decision-maker only needs to establish an upper and lower bound for the uncertain parameters.

One of the main contributions of this work is the integration of environmental concerns with the mathematical model first proposed in [30]. For that, it is important to understand how these environmental issues can relate to car rental. 


\subsubsection{Environmental Impacts}

The growing environmental concerns make it imperative to adapt the way of organizing and managing a business. It is important not only to consider financial aspects but also environmental ones, and this should be transverse to all sectors of industry. The mobility sector is one in which it is particularly important to address these concerns due to its contribution to pollution. An example of this integration is found in [36] where environmental and financial impacts of adopting alternative vehicle technologies and relocation strategies in station-based one-way carsharing are measured.

Taking a closer look at the environmental impacts associated with the individual transportation sector, it is important to understand that they are not only present in the vehicle utilization phase, going far beyond that. Commonly, a life cycle assessment (LCA) methodology is applied in related matters. It is possible to apply the LCA methodology to the mobility sector and for this case, in particular, to study the vehicle cycle [20,21].

The whole vehicle cycle is divided into two parts: the fuel cycle, which considers the production, processing, and use of the fuel, and the vehicle cycle. The latter one contains the following steps, in which energy is consumed and emissions are generated:

- Vehicle material production - The energy used to produce and the respective emissions from the materials (e.g. aluminum, steel, plastic, etc.);

- Vehicle assembly — The energy consumption and emissions during the assembly;

- Vehicle distribution - The energy required and emissions for transportation from the assembly line to the dealership;

- Vehicle maintenance - Energy required and emissions during the maintenance and repair over the vehicle lifetime;

- Vehicle disposal - Energy used for dismantling vehicles for disposal or recycling.

This approach is taken into account in [21] where average consumption and emission of greenhouse gas (GHG) are estimated as $91.1 \mathrm{GJ}$ and 11.5 ton per vehicle. These values are calculated regarding a mid-size passenger conventional vehicle. Moreover, this paper provides some significant outcomes:

- The vehicle material production process is significantly energy-intensive;

- The vehicle assembly process is significantly emission-intensive;

- The energy consumption and and GHG emissions in vehicle distribution, maintenance and disposal are small compared to the overall vehicle cycle impacts.

All these conclusions are relevant to the further definition of the environmental objective function. 
Extending the analysis from the emissions point of view to the entire vehicle cycle is not enough. There is still an essential missing part of this analysis - the fuel. Since it varies depending on the type of vehicle - battery electric vehicle (BEV), internal combustion engine (ICE), hybrid or plug-in hybrid electric vehicles (PHEV) - the fuel cycle will also be different for each type of vehicle. The fuel cycle is divided into three parts $[14,18]$ :

- Tank-to-wheel (TTW) - Vehicle onboard energy consumption to move the wheels;

- Well-to-tank (WTT) - All steps to fill the onboard full tank (feedstock extraction, transport, storage, processing, distribution, etc.);

- Well-to-wheel (WTW) - Aggregation of WTT and TTW.

The Well-to-wheel approach is difficult to apply since it is hard to quantify the emissions associated with feedstock extraction, transport, storage, among others [12]. Instead, it is common to use a simpler approach: Plant-to-wheel (PTW) [14, 11]. It estimates only the emissions associated with the use of fuel.

From a TTW standpoint, an electric vehicle does not produce either pollutant or greenhouse gas. Nevertheless, the electricity generation mix will be decisive on the WTT emissions quantification. On the other hand, a conventional internal combustion engine (ICE) vehicle pollutes on both stages and is not so dependent on the electricity generation mix as the BEVs. These considerations will also be important to the analyses carried out further in this work.

Donateo et al. proposed three approaches to improve the efficiency of conventional vehicles, and thus reduce the vehicle cycle environmental impacts [14].

- Automotive light weighting - reducing the total weight of the vehicle through the use of lighter materials;

- Adoption of low energy-intensive and low emission-intensive materials;

- Substitution of coal as main process fuel for environment friendly sources.

Ribeiro et al. proved the efficiency of the second approach where a car component which is part of the brake system has been modified. That modification implied the use of a new multimaterial injection moulding process and the consumption of recycled materials and that scenario proved to be less pollutant [33].

Simões et al. applied the first solution where three different car multimedia solution chassis were studied. It was found a decrease in the environmental impact in all-new designs, mostly because of weight reduction and decrease of the number of parts [35].

Considering only the fuel cycle, PHEVs and BEVs not only have the advantage of being less polluting than conventional ones, but they also have lower fuel costs. Despite that, the financial aspect is still a barrier against the adoption of electric vehicles [32]. The same article also shows that, on the one hand, the willingness to take a chance on new technologies significantly increases 
the likelihood of adopting electric vehicles. On the other hand, the environmental concerns and impacts of using more energy-efficient cars do not have such a significant relationship. Moreover, this article also shows that people are not still convinced of the reliability and cost savings of electric cars. Eventually, from a client standpoint, this fact can make these vehicles more interesting for renting rather than buying them.

In addition to this, the batteries are a critic point due to their cost, short life cycle, and long charging times [14]. Also, the utilization of auxiliaries (e.g. lights, radio, air conditioning, etc.) reduces considerably the vehicle range ( $21 \%$ more consumption).

Despite all the inherent limitations already mentioned, electric vehicles have the potential to contribute to a path less dependent on fossil fuels, and at least in some countries, these concerns have been taken into account. For instance, the Swedish local authorities are obligated through legislation to substitute fossil-fuelled vehicles [37]. Also, in 2017 more than half of Norways new car sales were electric or hybrid [32]. This is due to the following factors: strong policy incentives, low electricity prices and high fuel prices, and relatively well developed re-charging infrastructures.

\subsection{Methodology}

Multi-objective optimization (MOO) is present in numerous sectors and is used to solve many different problems. A particularly interesting application for this work, since it relates to the sector under study, is verified in [34] where an electric vehicle with an adaptive cruise control (ACC) function is chosen as an object to study the car-following process. A multi-objective optimization algorithm for ACC system is proposed in order to optimize safety, tracking, comfort, and energy consumption. It is important to first understand what is multi-objective optimization and how it can be achieved.

The main goal of MOO is to depict the Pareto-optimal front - Figure 1.1. The Pareto front is formed by the solutions in which any change in any of the decision variables aimed at improving a particular performance index will produce a deterioration in some of the other performance indices.

Solving a MOO model considering only one criterion at a time is the most simple method to do it. For example, in [27] the three pillars of sustainability are addressed as objective functions: economic, environmental, and social. The impacts of a sustainable supply chain are calculated and analysed for each one.

Another possible to solve this MOO is the assignment of weights to each one of the objectives and combines them linearly into a single algebraic expression - the weighted sum method. It continues to be used extensively not only to provide multiple solution points by varying the weights consistently but also to provide a single solution point that considers the multiple objectives [25]. Despite that, this method requires an important input since the definition of the weights is needed. Moreover, it is also important to remark that if the functions are in different units (e.g. euros and 


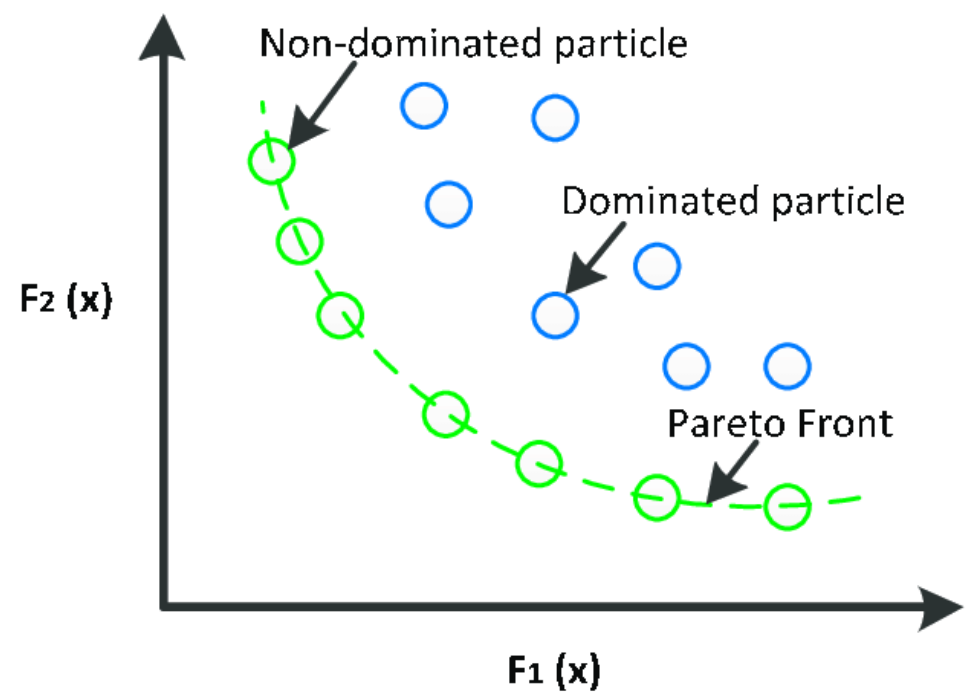

Figure 1.1: Pareto front solution set [22]

grams), weights must consider the order of magnitude of each one so that the final impact is balanced. Although there are many different approaches to define the weights, these are just different ways of organizing the preferences and priorities [24]. Marler et al. focus on the mathematical characteristics of the function instead of proposing another algorithm for translating preferences into weights [25]. Moreover, it is also mentioned that the understanding of these fundamentals is useful in setting the weights directly (without the use of an additional algorithm). Another important conclusion to retrieve from this literature is that although the weighted sum method is easy to use, it provides only a linear approximation of the Pareto front.

The utilization of genetic algorithms (GA) is another possible way to optimize these multiobjective models. For instance, a GA is applied in [23] to solve a problem of automatic parking by a back-wheel drive vehicle. This approach dealt with a dynamic multi-objective optimization problem, which is extremely hard to be dealt with analytically. Despite that, the GA allowed to obtain a simple and efficient solution.

Another example of genetic algorithm utilization to solve a multi-objective problem is the NSGA-II, one of the most recognized GAs. It is widely used in a myriad of fields for multiobjective problems and also has good results [17]. In the same article, based on a multi-parent crossover operator, the experimental results have shown such an operator has better global search capabilities and maintain the diversity of the population. It shows that it is always possible to try to improve the efficiency of these methods since its performance highly depends on the problem and context.

Another common method to solve MOO is using the Epsilon constraint method. Considering, for example, a bi-objective mathematical model, this method turns one of the objectives into a constraint $O F<=$ Epsilon in which Epsilon is progressively changed, in order to build an approximation to the Pareto front - Figure 1.2. 


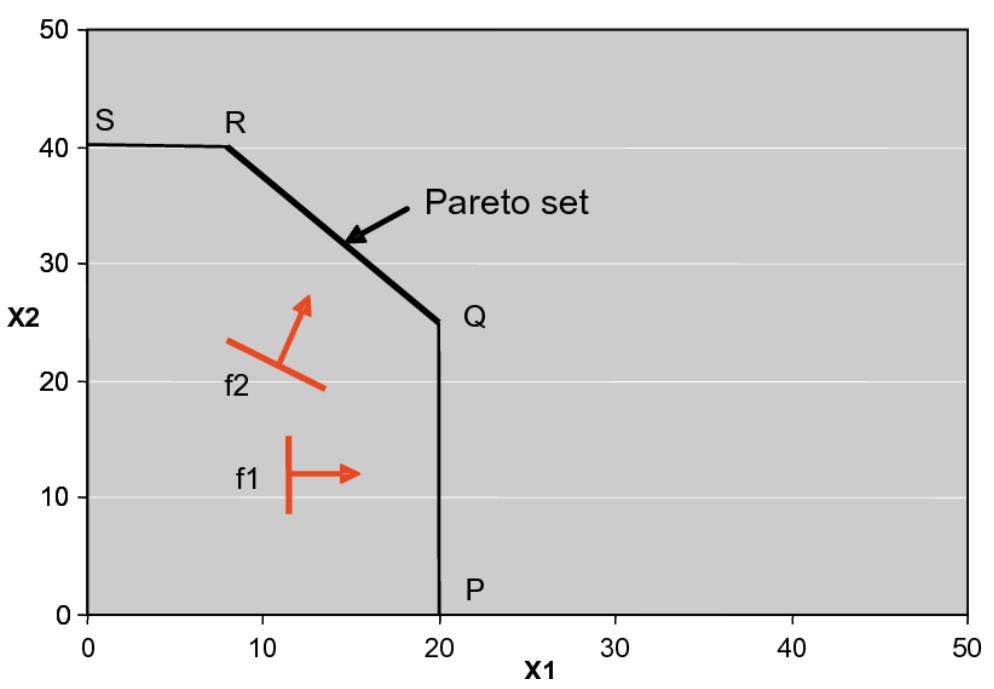

Figure 1.2: Feasible region and directions of objective functions [26]

Aghaei et al. proposed a new multi-objective model for electricity market clearing considering both voltage and dynamic security aspects of the power system. To solve this multi-criteria problem, an augmented epsilon constraint method is proposed. Once more, the scope of this type of method is proven [9].

\subsection{Summary}

Summing up, this literature review focuses on three different themes. Firstly, the car rental business is explained alongside its growth predictions. Some particularities of car rental are exploited such as pools, rentals, capacity-pricing relation, among others. Then it focuses on the environmental aspects of this business. Herein a very comprehensive approach is taken not only to the car but also to the fuel and the Life Cycle Assessment (LCA) is introduced.

Lastly, the Methodology section focuses on the optimization of multi-criteria problems. Several optimization methods are exploited: solving the model considering only one criterion at a time, using a weighted sum approach to convert a multi-objective into single-objective problems, epsilon constraint method, and NSGA-II which is a genetic algorithm that can solve multiobjective problems. These methods were selected because they represent common ways of solving the problem and are progressive in terms of complexity, the effort required, and performance potential. 


\section{Chapter 2}

\section{Bi-objective Mathematical Model}

In this chapter, the bi-objective mathematical model is presented and explained. This model was developed from the one proposed in [30]. In order to improve the efficiency of that model, some adjustments were made to linearize it. After that, the environmental components were added resulting in a new decision variable, a new objective function and some additional constraints.

Several parameters were added to the model, essentially related to emissions from vehicles, trucks, and fuel. The inclusion of emissions related to trucks is a change from the original model because the original considered an approximation, not differentiating when an empty transfer was made by a truck that loads several cars or the cars being driven individually - which has a quite different environmental impact. Regarding the decision variables, the changes made are related with two main purposes: the linearization of the model and the inclusion of the possibility of empty transfers by truck. As far as the objective functions concerns, the changes that lead to the model linearization are presented and explained. At the same time, the new objective function representing environmental impacts is introduced. Finally, new constraints are added, mostly related to fixing maximum and minimum capacities of empty transferred vehicles by truck so that the number of trucks needed is calculated. The remaining modifications in constraints are the result of the model linearization.

For a better distinction between the parameters already existing in the original model and the new or adapted ones, asterisks are used in the next section. More specifically, the changed parameters are followed by an asterisk $\left(^{*}\right)$ while the new parameters are followed by two asterisks (**). No special notation was applied to the unchanged parameters.

This chapter is thus divided into four sections: indices and parameters, decision variables, objective functions and constraints.

\subsection{Indices and Parameters}

$t, t^{\prime}=\{0, \ldots, T\} \quad$ Index for the set $\mathscr{T}$ of time periods, where $t=0$ represents the initial conditions of the time horizon (season) and "overlaps" with $t=T$ for the previous season 


\begin{tabular}{|c|c|}
\hline$g, g 1, g 2=\{1, \ldots, G\}$ & Index for the set $\mathscr{G}$ of vehicle groups \\
\hline$s, s 1, s 2, c=\{1, \ldots, S\}$ & Indices for the set $\mathscr{S}$ of rental locations \\
\hline$r=\{1, \ldots, R\}$ & $\begin{array}{l}\text { Index for the set } \mathscr{R} \text { of rental types (characterized by check-out and check- } \\
\text { in location and time period, and vehicle group requested) }\end{array}$ \\
\hline sout $_{r}$ & Check-out location of rental type $r$ \\
\hline $\sin _{r}$ & Check-in location of rental type $r$ \\
\hline dout $_{r}$ & Check-out time period of rental type $r$ \\
\hline $\operatorname{din}_{r}$ & Check-in time period of rental type $r$ \\
\hline$g r_{r}$ & Vehicle group requested by rental type $r$ \\
\hline$\alpha^{* *}$ & $\begin{array}{l}\text { Estimated distance }(\mathrm{km}) \text { traveled by a vehicle per time period during the } \\
\text { rental period }\end{array}$ \\
\hline$\beta^{* *}$ & $\begin{array}{l}\text { Estimated distance }(\mathrm{km}) \text { traveled by a vehicle during the time at rental } \\
\text { service }\end{array}$ \\
\hline$a=\{0, \ldots, A\}$ & $\begin{array}{l}\text { Index for the set } \mathscr{A} \text { of antecedences allowed (number of time periods be- } \\
\text { tween the rental request and the start of the rental), where } a=0 \text { represents } \\
\text { a "walk-in" customer }\end{array}$ \\
\hline$p=\{1, \ldots, P\}$ & Index for the set $\mathscr{P}$ of price levels allowed \\
\hline$P R I_{p g}$ & $\begin{array}{l}\text { Pecuniary value associated with price level } p \text { for vehicle group } g \text { (for } \\
\text { example, for group } g=2 \text {, price level } p=1 \text { has a pecuniary value of } \\
P R I_{1,2}=20 € \text { ) }\end{array}$ \\
\hline$D E M_{\text {rap }}$ & Demand for rental type $r$, at price level $p$, with antecedence $a$ \\
\hline $\operatorname{COS}_{g}$ & $\begin{array}{l}\text { Buy cost of a vehicle of group } g \text {. The value considered is the net cost: } \\
\text { purchase gross cost minus salvage value derived from its sale after one } \\
\text { year }\end{array}$ \\
\hline$L E A_{g}$ & Leasing cost (per time unit) of a vehicle of group $g$ \\
\hline$O W N_{g}$ & Ownership cost (per time unit) of a vehicle of group $g$ \\
\hline$L P_{g}$ & Leasing period for a vehicle of group $g$ \\
\hline$P I_{g}$ ** & Environmental impacts related with the production of a vehicle of group \\
\hline$F C_{g} * *$ & Fuel consumption $(1 / \mathrm{km}$ or $\mathrm{kWh} / \mathrm{km})$ of a vehicle of group $g$ \\
\hline$F P_{g}^{* *}$ & $\begin{array}{l}\text { Emissions }\left(\mathrm{gCO}_{2} / \mathrm{kWh} \text { or } \mathrm{gCO}_{2} / \mathrm{l}\right) \text { related with the fuel production for a } \\
\text { vehicle of group } g\end{array}$ \\
\hline$U T_{g} * *$ & Emissions $\left(\mathrm{gCO}_{2} / \mathrm{km}\right)$ related with driving a vehicle of group $g$ \\
\hline$D I_{g} * *$ & Environmental impacts related with the disposal of a vehicle of group $g$ \\
\hline$P Y U$ & Penalty charged for each upgrade \\
\hline$U P G_{g 1 g 2}$ & $\begin{array}{l}\text { Whether a vehicle of group } g 1 \text { can be upgraded to a vehicle of group } g 2 \\
(=1) \text { or not }(=0)\end{array}$ \\
\hline$T T_{s 1 s 2}$ & Transfer time from location $s 1$ to location $s 2$ \\
\hline$d_{s 1 s 2} * *$ & Distance $(\mathrm{km})$ between locations $s 1$ and $s 2$ \\
\hline$T C_{g s 1 s 2}$ & Transfer cost of a vehicle of group $g$ from location $s 1$ to location $s 2$ \\
\hline
\end{tabular}




$\begin{array}{ll}M A X T^{* *} & \text { Maximum number of cars transferred by one truck } \\ M I N T^{* *} & \text { Minimum number of cars transferred by one truck } \\ U T^{T * *} & \text { Emissions }\left(\mathrm{gCO}_{2} / \mathrm{km}\right) \text { related with driving one truck transporting vehi- } \\ & \text { cles } \\ B U D & \text { Total budget for the purchase of vehicles } \\ M & \text { Big-M large enough coefficient }\end{array}$

\section{Other sets:}
$\mathscr{R}^{g^{-}} \quad$ Rental types that do not require group $g$
$\mathscr{R}_{s t}^{i n} \quad$ Rental types whose check-in is at location $s$ at time $\in[t-1, t[$
$\mathscr{R}_{\text {st }}^{\text {out }} \quad$ Rental types whose check-out is at location $s$ at time $\in[t-1, t[$
$\mathscr{R}_{t}^{u s e} \quad$ Rental types that require a vehicle to be in use at $t$ (i.e., dout $\langle t \wedge \operatorname{din} \geq t$ )

\section{Inputs from previous seasons (previous decision periods):}
$I N X_{g s}^{O} \quad$ Initial number of owned $(O)$ vehicles of group $g$ located at $s$, at the beginning of the season $(t=0)$
$O N Y_{\text {gts }}^{L / O} \quad$ Number of owned $(O)$ or leased $(L)$ vehicles of group $g$ on on-going empty trans- portation (previously decided), being transferred to location $s$, arriving at time $t$
$O N U_{g t s}^{L / O} \quad$ Number of owned $(O)$ or leased $(L)$ vehicles of group $g$ on on-going rentals (pre- viously decided), being returned to location $s$ at time $t$

\subsection{Decision Variables}

The decision variables are mainly related with the acquisition of vehicles - both by leasing and for the owned fleet - and the prices definition for each different rental type. The owned vehicles are considered to be available at the beginning of the time horizon while the leased vehicles can become available during shorter periods of time throughout the time horizon. For a better understanding of the results obtained, other decision variables are considered to help track the vehicles over the time horizon considered.

A rental type is characterized by a check-out and check-in location and time period, and the vehicle group requested. The number of fulfilled rentals requested includes the rental type, the antecedence of the request, the required group and the price level. In the previous model, the price level was not included. This change allows the model to be linear, as shown in the next section.

The last decision variable is related with the number of trucks used to perform empty transfers. Although not present in the original model, it is necessary when considering the environmental impact since the emissions produced by a truck are different than the ones produced by a car. 
$w_{g s}^{O} \quad$ Number of vehicles of group $g$ acquired for the owned fleet available at $t=0$ in location $s$

$w_{g t s}^{L} \quad$ Number of vehicles of group $g$ acquired by leasing to be available at time $t$ in location $S$

$q_{\text {rap }}=1$ if price level $p$ is charged for rental type $r$ with antecedence $a ;=0$ otherwise Number (stock) of leased $(L)$ or owned $(O)$ vehicles of group $g$ located at $s$ at time $t$ Number of leased $(L)$ or owned $(O)$ vehicles of group $g$ empty transferred by truck $(T)$ or driver $(D)$ at time $t$ from location $s 1$ to location $s 2$

$u_{\text {ragp }}^{L / O} * \quad$ Number of fulfilled rentals requested as rental type $r$ with antecedence $a$ that are served by a leased $(L)$ or owned $(O)$ vehicle of group $g$ at a price level $p$

$f_{g t}^{L / O} \quad$ Auxiliary variable: total leased $(L)$ or owned $(O)$ fleet of group $g$ at time $t$

$z_{s 1 s 2 t}{ }^{* *} \quad$ Number of trucks used to transfer cars from $s 1$ to $s 2$ at time $t$

\subsection{Objective Functions}

Equation 2.1 represents the financial objective function and consists of the following elements: revenues from the fulfilled rentals, buying costs, leasing costs, ownership costs, empty transfer costs and penalties for upgrades.

Firstly, the revenues from the fulfilled rentals are calculated multiplying the total number of fulfilled rentals served by a leased or owned vehicle with the pecuniary value associated with the price level and the group requested. In the original model, as the number of fulfilled rentals did not include the price level, it was multiplied by the binary decision variable $\left(q_{\text {rap }}\right)$ with the value of 1 when the specific price level was charged or 0 otherwise. The multiplication of these two decision variables rendered the model non-linear. This multiplication is no longer necessary since the number of rentals fulfilled already includes the price level, rendering the model linear, requiring some changes in the constraints.

Secondly, the costs are calculated with significant differences between the owned and the leased cars. Owned cars are considered to be available at the beginning of the time horizon and continue available throughout the entire time horizon. Therefore, acquisition costs are a one-time cost. With a different process, the costs for the leased vehicles are calculated multiplying the leasing cost per time unit and the number of vehicles acquired by leasing during a certain period. Ownership costs only apply to owned vehicles.

Afterwards, empty transfer costs are represented. This element considers several aspects such as the group transferred, the initial and final stations and whether or not a truck is used.

Finally, the last element of the objective function concerns upgrading costs, included in order to guarantee that upgrades only exists when there are no available vehicles from the required group. 


$$
\begin{array}{r}
\max \sum_{r=1}^{R} \sum_{a=1}^{A} \sum_{g=1}^{G} \sum_{p=1}^{P}\left(\left(u_{\text {ragp }}^{L}+u_{\text {ragp }}^{O}\right) P R I_{p g}\right)-\sum_{g=1}^{G}\left(\sum_{s=1}^{S} w_{g s}^{O}\right) C O S_{g}-\sum_{g=1}^{G}\left(\sum_{t=1}^{T} f_{g t}^{L}\right) L E A_{g} \\
-\sum_{g=1}^{G}\left(\sum_{t=1}^{T} f_{g t}^{O}\right) O W N_{g}-\sum_{s 1=1}^{S} \sum_{s 2=1}^{S} \sum_{g=1}^{G}\left(\sum_{t=1}^{T}\left(y_{s 1 s 2 g t}^{L, T}+y_{s 1 s 2 g t}^{L, D}+y_{s 1 s 2 g t}^{O, T}+y_{s 1 s 2 g t}^{O, D}\right)\right) T C_{g s 1 s 2} \\
-\sum_{g=1}^{G} \sum_{r \in \mathscr{R}^{-}} \sum_{a=1}^{A} \sum_{p=1}^{P}\left(u_{\text {ragp }}^{L}+u_{\text {ragp }}^{O}\right) P Y U
\end{array}
$$

Equation 2.2 aims to represent the environmental impacts (in $\mathrm{gCO}_{2}$ ) and comprises the following elements: production and disposal impacts, fuel, vehicle and truck utilization impacts and empty transfer emissions. All these phases were selected according to the LCA method, aiming to assess all direct and indirect environmental impacts across the full life cycle of a vehicle, as stated in the literature review.

The first element of the objective function defines the impacts related with both production and disposal. These two impacts are only affected by the vehicle group, therefore there is no distinction between owned or leased vehicles.

Secondly, regarding the fuel impact, the multiplication of the fuel consumption by the fuel production results in the emissions in $\mathrm{gCO}_{2} / \mathrm{km}$. Moreover, it is important to understand the differences between owned and leased vehicles. For that, the estimated distance travelled by a vehicle during the time at rental service $(\beta)$ is considered for owned vehicles. As far as leased cars are concerned, the ratio between the leasing period and the time horizon duration are considered to deliver more consistent and coherent results. This way, for example, a vehicle leased for half the time horizon, will have an estimated travelled distance, and consequent fuel consumption, of half of the owned car which is available in the fleet throughout all time horizon. All estimated distances, both for owned and leased vehicles, are summed up and multiplied by the emissions previously mentioned, obtaining the final emissions in $\mathrm{gCO}_{2}$.

Afterwards, the emissions due to vehicle utilization are calculated. For that, a distance travelled by a vehicle per rental day is estimated $(\alpha)$. This estimation is multiplied by the rental duration (the difference between the check-in and check-out time periods) and summed up the distance between the check-in and check-out locations, thus obtaining an approximation of the total distance travelled by a vehicle in a given rental. This distance is multiplied by the emissions related with driving a vehicle of a certain group and by the number of fulfilled rentals.

Finally, the last two elements consider the empty transfer impacts. The total number of trucks utilized to perform empty transfers multiplied by the emission values of utilizing a truck multiplied by the distance between the initial and final stations describes the empty transfer emissions when performed by a truck. Empty transfer emissions performed by a driver are calculated in a similar way. The main difference between the two situations is the value of the utilization emissions, since in the empty transfer by a driver the vehicle group is considered as the car itself is being driven, unlike with the truck transfer. The sum of the emissions resulting from both leased and owned 
vehicles transferred by a driver is also considered.

$$
\begin{aligned}
\min \sum_{g=1}^{G} & \sum_{s=1}^{S}\left(P I_{g}+D I_{g}\right)\left(w_{g s}^{O}+\sum_{t=1}^{T} w_{g t s}^{L}\right)+\sum_{g=1}^{G} F C_{g} F P_{g} \sum_{s=1}^{S} \beta\left(w_{g s}^{O}+\frac{L P_{g}}{T} \sum_{t=1}^{T} w_{g t s}^{L}\right) \\
& +\sum_{r=1}^{R} \sum_{g=1}^{G}\left[\sum_{a=1}^{A} \sum_{p=1}^{P}\left(u_{\text {ragp }}^{L}+u_{\text {ragp }}^{O}\right)\right]\left[U T_{g}\left(d_{\text {sin }_{r}, \text { sout }_{r}}+\left(\text { din }_{r}-\text { dout }_{r}\right) \alpha\right)\right] \\
& +\sum_{s 1=1}^{S} \sum_{s 2=1}^{S}\left(\sum_{t=1}^{T} z_{s 1 s 2 t}\right) U T^{T} d_{s 1 s 2}+\sum_{s 1=1}^{S} \sum_{s 2=1}^{S} \sum_{g=1}^{G}\left(\sum_{t=1}^{T}\left(y_{s 1 s 2 g t}^{L, D}+y_{s 1 s 2 g t}^{O, D}\right)\right) U T_{g} d_{s 1 s 2}
\end{aligned}
$$

\subsection{Constraints}

Equations 2.3-2.7 calculate the stock of available vehicles of a specific group, in a specific location, at a specific time. Firstly, Equations 2.3 deal with the stock of owned vehicles of each group, in a specific location, at a given time period except the initial one. To do so, the stock of owned vehicles from the previous period is summed with the arrivals of vehicles on on-going empty transportation and rentals from the previous season. The arrival of vehicles that were being employed in rentals during this season and meanwhile returned to this specific location is also considered and the number of vehicles meanwhile used in rentals that started in this season are subtracted. Then, the number of vehicles being empty transferred and meanwhile arrived at the specific location are summed while the number of vehicles empty transferred to another locations are subtracted.

Equations 2.4 and 2.5 represent a similar situation yet applied to the leased vehicles. The main difference to the owned ones is that the leasing can occur at any time throughout the time horizon so the vehicles can be added or removed from the fleet at any time. In Equations 2.4 the acquisition of leased vehicles is summed while in Equations 2.5 its removal is subtracted. Another important note resides on the validation of these constraints: the first equations are valid for any period lower or equal than the leasing period, and the second are valid only for time periods greater than the leasing time.

Equations 2.6 and 2.7 calculate the number of stock available at the beginning of the season $(\mathrm{t}=0)$. The owned fleet consists on the sum of the owned vehicles from the previous season and the new ones purchased. The leased fleet is considered to be initially empty. 


$$
\begin{aligned}
& \text { s.t. } x_{g t s}^{O}=x_{g, t-1, s}^{O}+O N Y_{g t s}^{O}+O N U_{g t s}^{O} \\
& +\sum_{r \in \mathscr{R}_{s, t}^{\text {in }}} \sum_{a=1}^{A} \sum_{p=1}^{P} u_{r, a, g, p}^{O}-\sum_{r \in \mathscr{R}_{s, t}^{\text {out }}} \sum_{a=1}^{A} \sum_{p=1}^{P} u_{r, a, g, p}^{O} \\
& +\sum_{c=1}^{S}\left(y_{c, s, g, t-T T_{c s}-1}^{O, T}+y_{c, s, g, t-T T_{c s}-1}^{O, D}\right) \\
& -\sum_{c=1}^{S}\left(y_{s, c, g, t-1}^{O, T}+y_{s, c, g, t-1}^{O, D}\right) \quad \forall g, t>0, s \\
& x_{g t s}^{L}=x_{g, t-1, s}^{L}+O N Y_{g t s}^{L}+O N U_{g t s}^{L} \\
& +\sum_{r \in \mathscr{R}_{s, t}^{\text {in }}} \sum_{a=1}^{A} \sum_{p=1}^{P} u_{r, a, g, p}^{L}-\sum_{r \in \mathscr{R}_{s, t}^{\text {out }}} \sum_{a=1}^{A} \sum_{p=1}^{P} u_{r, a, g, p}^{L} \\
& +\sum_{c=1}^{S}\left(y_{c, s, g, t-T T_{c s}-1}^{L, T}+y_{c, s, g, t-T T_{c s}-1}^{L, D}\right) \\
& -\sum_{c=1}^{S}\left(y_{s, c, g, t-1}^{L, T}+y_{s, c, g, t-1}^{L, D}\right) \\
& +w_{g, t-1, s}^{L} \quad \forall g, 0<t \leq L P_{g}, s \\
& x_{g t s}^{L}=x_{g, t-1, s}^{L}+O N Y_{g t s}^{L}+O N U_{g t s}^{L} \\
& +\sum_{r \in \mathscr{R}_{s, t}^{\text {in }}} \sum_{a=1}^{A} \sum_{p=1}^{P} u_{r, a, g, p}^{L}-\sum_{r \in \mathscr{R}_{s, t}^{\text {out }}} \sum_{a=1}^{A} \sum_{p=1}^{P} u_{r, a, g, p}^{L} \\
& +\sum_{c=1}^{S}\left(y_{c, s, g, t-T T_{c s}-1}^{L, T}+y_{c, s, g, t-T T_{c s}-1}^{L, D}\right) \\
& -\sum_{c=1}^{S}\left(y_{s, c, g, t-1}^{L, T}+y_{s, c, g, t-1}^{L, D}\right) \\
& +w_{g, t-1, s}^{L}-w_{g, t-L P_{g}-1, s}^{L} \quad \forall g, t>L P_{g}, s \\
& x_{g 0 s}^{O}=I N X_{g s}^{O}+w_{g s}^{O} \quad \forall g, s \\
& x_{g 0 s}^{L}=0 \quad \forall g, s
\end{aligned}
$$

Equations 2.8 ensure that, at a given time and location, the sum of the number of fulfilled rentals and empty transfers starting at that location and time are limited by the total stock of vehicles available. Equations 2.9 guarantee that the number of fulfilled rentals is limited by the demand for the rental type, at a chosen price level. This constraint has also undergone considerable changes when compared with the original model. Previously, since the sum of the fulfilled rentals did not include the price level, it was necessary to sum a factor, $M\left(1-q_{\text {rap }}\right)$, to the demand. This way, when the price level was chosen, this portion would be null, thus limiting the number of fulfilled rentals 
to the demand, and otherwise this constraint would not limit the aggregated (per price level) rentals fulfilled. In this model, as the chosen price is already included in the number of fulfilled rentals, it is only necessary to multiply the demand by the binary variable regarding the choice or not of the price level. Thus, in cases where the price level is chosen, the number of fulfilled rentals is limited to the demand. Otherwise, the number of fulfilled rentals is null.

$$
\begin{array}{cc}
\sum_{r \in \mathscr{R}_{\text {st }}^{\text {out }}} \sum_{a=1}^{A} \sum_{p=1}^{P} u_{\text {ragp }}^{L / O}+\sum_{c=1}^{S} y_{\text {scgt }}^{L / O, T / D} \leq x_{\text {gts }}^{L / O} & \forall g, t, s \\
\sum_{g=1}^{G}\left(u_{\text {ragp }}^{L}+u_{\text {ragp }}^{O}\right) \leq D E M_{\text {rap }} \times q_{\text {rap }} & \forall r, a, p
\end{array}
$$

The decision of offering upgrades or not is presented in Equations 2.10. If the upgrade between groups is allowed, a large enough coefficient is utilized so the upgrades can be performed even with a significant number of rental requests.

$$
\sum_{a=1}^{A} \sum_{p=1}^{P}\left(u_{\text {ragp }}^{L}+u_{\text {ragp }}^{O}\right) \leq U P G_{g_{r}, g} \times M \quad \forall r, g
$$

To ensure that the investment in owned fleet does not exceed the available budget, Equation 2.11 assures that the number of purchased vehicles multiplied by their cost is lower or equal than the budget available.

$$
\sum_{s=1}^{S} \sum_{g=1}^{G} w_{g s}^{O} \operatorname{COS}_{g} \leq B U D
$$

Equations 2.12 assure that only one price is chosen per rental type and antecedence.

$$
\sum_{p=1}^{P} q_{r a p}=1 \quad \forall r, a
$$

An auxiliary variable representing the total fleet was created to facilitate building the objective function. In Equations 2.13, the total fleet is described as the sum of the stock of vehicles at all stations and the ones currently being used either in rentals or empty transfers.

$$
\begin{gathered}
f_{g t}^{L / O}=\sum_{s=1}^{S} x_{g t s}^{L / O}+\sum_{r \in \mathscr{R}_{t}^{u s e}} \sum_{a=1}^{A} \sum_{p=1}^{P} u_{r, g, a, p}^{L / O} \\
+\sum_{s 1=1}^{S} \sum_{s 2=1}^{S} \sum_{t^{\prime}=\max \left\{0, t-T T_{s 1 s 2}\right\}}^{t-1} y_{s 1, s 2, g, t^{\prime}}^{L / O, T}+y_{s 1, s 2, g, t^{\prime}}^{L / O, D} \quad \forall g, t
\end{gathered}
$$

Equations 2.14 ensure that the total number of vehicles empty transferred by truck is bigger or equal than the number of trucks utilized multiplied by the minimum number of cars that a truck can carry. In a similar way, Equations 2.15 ensure that the trucks capacity is not exceeded. These equations allow to calculate the number of trucks needed to transfer the vehicles, in accordance 
with their maximum capacity and ensuring that there is a minimum amount of vehicles that render the use of the truck reasonable. Equations 2.14 and 2.15 represent new constraints in the model.

$$
\begin{array}{ll}
\sum_{g=1}^{G}\left(y_{s 1 s 2 g t}^{T, O}+y_{s 1 s 2 g t}^{T, L}\right) \geq M I N T \times z_{s 1 s 2 t} & \forall s 1, s 2, t \\
\sum_{g=1}^{G}\left(y_{s 1 s 2 g t}^{T, O}+y_{s 1 s 2 g t}^{T, L}\right) \leq M A X T \times z_{s 1 s 2 t} \quad \forall s 1, s 2, t
\end{array}
$$

Lastly, Equations 2.16 represent the domain of the decision variables.

$$
\begin{aligned}
q_{\text {rap }} \in\{0,1\} & \forall r, a, p \\
w_{\text {gts }}^{L} \in \mathbb{Z}_{0}^{+} & \forall g, t, s \\
w_{g s}^{O} \in \mathbb{Z}_{0}^{+} & \forall g, s \\
y_{s 1 s 2 g t}^{L / O, T / D} \in \mathbb{Z}_{0}^{+} & \forall s 1, s 2, g, t \\
x_{\text {gts }}^{L / O} \in \mathbb{Z}_{0}^{+} & \forall g, t, s \\
u_{\text {ragp }}^{L / O} \in \mathbb{Z}_{0}^{+} & \forall r, a, g, p \\
f_{\text {gt }}^{L / O} \in \mathbb{Z}_{0}^{+} & \forall g, t
\end{aligned}
$$




\section{Chapter 3}

\section{Environmental Parameters Definition}

In this chapter, all the steps taken into account for the definition of the environmental parameters used in the model presented in Chapter 2 are explained. These parameters include several elements from both vehicle and fuel cycles and are clustered into two main sections:

- Production and disposal;

- Fuel and utilization.

Although they are not environmental impacts themselves, parameters such as the maximum (minimum) number of cars transferred by one truck and the estimated distance travelled by a vehicle per time period and during the time at rental service are necessary for the implementation of the model. These parameters are presented and explained in this chapter as well.

Regarding the vehicles characterized by these parameters, the following four groups are considered: internal combustion engine (ICE), hybrid, plug-in hybrid electric vehicles (PHEV), and battery electric vehicles (BEV). These vehicle groups were chosen because they represent the main vehicle groups currently in the automotive market. These are also the groups considered in the analyses later described in Chapter 4.

Lastly in this chapter, a table with the summary of this matter is presented for a better perception.

\subsection{Production and Disposal}

As already referred in the literature review, the production phase (materials production and assembly) is significantly pollutant compared to the overall vehicle cycle impacts. On the other hand, the disposal impact is almost negligible when compared with the production one. Even so, it is important to include it since impact of the disposal of the electric batteries goes beyond the energy consumption itself. Almarzooqi et al. tackle the management of used lithium ion batteries [10]. The same paper emphasizes the need of appropriate disposal methods of lithium batteries in response to the expected large number of lithium batteries to be recycled. 
The production and disposal impacts are then calculated from data retrieved from [21]. Here, the material production is obtained considering the different car components (Ferrous, Aluminum, Copper, etc.) alongside the respective weight. Moreover, the assembly energy consumption is estimated as a linear function of the vehicle mass of $19.75(\mathrm{MJ} / \mathrm{kg})$. A vehicle with the mass of $1324 \mathrm{~kg}$ is considered.

The disposal energy consumption is also estimated as a linear function of the vehicle mass of $370(\mathrm{~kJ} / \mathrm{kg})$. Considering the vehicle mass of $1324 \mathrm{~kg}$ and converting the energy from joules (J) to kilowatt hour $(\mathrm{kWh})^{1}$, the total energy required is estimated as follows:

- Production - $24826 \mathrm{kWh}$;

- Disposal — $0.136 \mathrm{kWh}$.

It is then necessary to know the $\mathrm{CO}_{2}$ emissions due to energy production. For that, the report of International Energy Association (IEA) published in $2019^{2}$ was consulted [19]. The main results of the report, used in this dissertation, are presented in Table 3.1. Considering the World values (485 $\mathrm{gCO}_{2} / \mathrm{kWh}$ ), the production and disposal emissions are calculated as $12040610 \mathrm{gCO}_{2}$ and $65.96 \mathrm{gCO}_{2}$ respectively. These emissions are considered equal for all vehicle groups.

Table 3.1: Emissions from energy production

\begin{tabular}{|c|c|}
\hline Region & Emissions $\left(\mathrm{gCO}_{2} / \mathrm{kWh}\right)$ \\
\hline Africa & 568 \\
\hline America & 353 \\
\hline Asia & 610 \\
\hline Europe & 303 \\
\hline Oceania & 651 \\
\hline World & 485 \\
\hline
\end{tabular}

\subsection{Fuel and Utilization}

In the mathematical model, the fuel component is divided into two: fuel production and fuel consumption. Firstly, it is important to notice the units of these two parameters. While the fuel

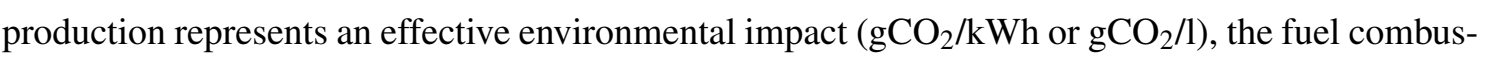
tion only represents the consumption of the same fuel by a certain vehicle of a certain group $(1 / \mathrm{km}$ or $\mathrm{kWh} / \mathrm{km})$. This way, the intended environmental impact $\left(\mathrm{gCO}_{2} / \mathrm{km}\right)$ is obtained multiplying both elements as in the environmental objective function.

The difference between a hybrid and a plug-in hybrid electric vehicle (PHEV) is an important matter needed to be fully understood since it is linked to the fuel utilization of the vehicle. Both vehicles have an electrical and an internal combustion engine but, unlike hybrids, the PHEVs

\footnotetext{
${ }^{1} 1 \mathrm{MJ}=0.277778 \mathrm{kWh}$

${ }^{2}$ Although published in 2019, the data retrieved regards 2017.
} 
can be connected to an outside electrical source for charging its battery. This way, the PHEV fuel source can be either electrical or through oil products (petrol or diesel). Therefore, as for the fuel production concerns, this impact is estimated as $750 \mathrm{gCO}_{2} / 1$ for both ICE and hybrid vehicles. Regarding the battery electric vehicles (BEV), the World average emissions from energy production presented in Table 3.1 are utilized - $485 \mathrm{gCO}_{2} / \mathrm{kWh}$. Regarding the PHEV, as their fuel source can be either electric or fossil, it is particularly challenging to define their consumption. To do so, the electric and total autonomy of ten PHEV were analysed [3]. It was thus concluded that about $5 \%$ of the total autonomy of the vehicles is due to the electric motor. Due to the lack of more straightforward indicators, autonomy was selected as a proxy of utilization. Therefore, considering $5 \%$ of the fuel being from an electric source and the rest being petrol, the production of fuel is then estimated as $1074 \mathrm{gCO}_{2} / 1$ for the PHEV.

As for the fuel consumption and utilization emissions, it is an intrinsic characteristic of each vehicle. Therefore, the types of vehicles selected and their respective consumption and utilization emissions are expressed in Table 3.2. The vehicles were chosen giving preference to vehicles typically used in conventional transportation and of the same brand, to be as comparable between them as possible. The BEV chosen was a Daimler AG which is the vehicle considered in an article previously referenced in the literature review. The data relating to Toyota vehicles were retrieved from the official brochures available on the official website [5, 4]. Regarding the BEV, its consumption is estimated as $0.194 \mathrm{kWh} / \mathrm{km}$ and its utilization does not imply the emission of any greenhouse gas [14].

Table 3.2: Fuel consumption

\begin{tabular}{|c||ccc|}
\hline Car type & Model & Fuel consumption & Utilization \\
\hline \hline ICE & Toyota Yaris 1.5 VVT-iE & $0.060(1 / \mathrm{km})$ & $135\left(\mathrm{gCO}_{2} / \mathrm{km}\right)$ \\
Hybrid & Toyota Yaris 1.5 Hybrid e-CVT & $0.048(1 / \mathrm{km})$ & $108\left(\mathrm{gCO}_{2} / \mathrm{km}\right)$ \\
PHEV & Toyota Prius 1.8 Plug-in e-CVT & $0.013(1 / \mathrm{km})$ & $28\left(\mathrm{gCO}_{2} / \mathrm{km}\right)$ \\
BEV & Daimler AG Smart ForTwo Electric Drive & $0.194(\mathrm{kWh} / \mathrm{km})$ & $0\left(\mathrm{gCO}_{2} / \mathrm{km}\right)$ \\
\hline
\end{tabular}

Lastly, the emissions from trucks are calculated taking into account several steps. Since emissions related with driving a truck were not available in any official brochure of any brand, as in the definition of vehicle emissions, a new approach was needed. For that, the emissions associated with the fuel combustion are calculated as $20 \mathrm{kgCO}_{2} / 100 \mathrm{~km}$ - value referring to a passenger petrol car with a consumption of $5.87 \mathrm{kgl} / 100 \mathrm{~km}$ [33]. These consumption values are not, however, in the desired units (the intention is to define the value in units of volume by distance and not mass by distance). For that, the petrol density was consulted $(0.715-0.780 \mathrm{~kg} / \mathrm{l})^{3}$, with the average value being considered [2]. The consumption of the passenger vehicle in the desired units is then obtained $(7.831 / 100 \mathrm{~km})$. The average fuel consumption of a truck is estimated at $28.61 / 100 \mathrm{~km} \mathrm{[1].}$ Combining all these data, the truck emissions are thus calculated as $730 \mathrm{gCO}_{2} / \mathrm{km}$.

\footnotetext{
${ }^{3}$ Density at $15^{\circ} \mathrm{C}$
} 


\subsection{Other Parameters}

Considering the mathematical model proposed in Chapter 2, some parameters must be defined even though they are not directly linked to gas emissions. These parameters are essentially related to the travelled distances by the vehicles and the number of vehicles transported by truck.

The average distance travelled by a vehicle per time period during the rental $(\alpha)$ is estimated as $50 \mathrm{~km}$. This estimate is based on typical daily commuting but also considers typical trips during a more seasonal period such as coming and going to the beach, for example. After consulting directly with a car rental company, the distance travelled by a vehicle during the time at rental service $(\beta)$ is estimated at $60000 \mathrm{~km}$.

The maximum capacity of cars transported by truck is estimated at 8 , representing the capacity of a medium-sized car carrier trailer. To assure efficiency in the empty transfers, the minimum capacity was defined as half of the maximum capacity considered, that is, 4 .

The mathematical model proposed in Chapter 2 comprises several groups of vehicles, each with an associated level, where higher-level vehicles have higher prices and higher purchase, leasing, and ownership costs. The lower the level, the cheaper the costs and lower the prices, respectively. Thus, ICE vehicles are considered to be the lowest level since they are cheaper when compared to the other vehicle groups. Moreover, BEVs are considered to be the highest level because they are more expensive. Concerning both hybrids, PHEVs are considered the second highest class since they are more similar to electric vehicles (they allow charging the batteries through an electrical plug) and, thus, Hybrid vehicles are defined as being the penultimate class. Therefore, from the highest to the lowest group levels, vehicle groups are ordered as follows: BEV, PHEV, Hybrid, and ICE.

\subsection{Summary}

In this chapter, the steps taken into account for the environmental parameters definition were explained. These parameters definition were divided into two main sections.

In the first section, the environmental impacts regarding the production and the disposal of vehicles are estimated. Then, in the second section, the fuel and utilization emissions are discussed. Then, some other parameters regarding the distance travelled by a vehicle at the rental service/per time period as well as the minimum and maximum number of vehicles empty transferred by one truck are presented. The main conclusions retrieved from these analyses are presented in Table 3.3. 
Table 3.3: Environmental parameters

\begin{tabular}{|c|c|c|c|c|c|}
\hline Vehicle group & Production & Disposal & Fuel production & Fuel consumption & Utilization \\
\hline ICE & 12040610 & 65.96 & $750\left(\mathrm{gCO}_{2} / \mathrm{l}\right)$ & $0.060(1 / \mathrm{km})$ & 135 \\
\hline Hybrid & 12040610 & 65.96 & $750\left(\mathrm{gCO}_{2} / \mathrm{l}\right)$ & $0.048(1 / \mathrm{km})$ & 108 \\
\hline PHEV & 12040610 & 65.96 & $1074\left(\mathrm{gCO}_{2} / \mathrm{l}\right)$ & $0.013(1 / \mathrm{km})$ & 28 \\
\hline BEV & 12040610 & 65.96 & $485\left(\mathrm{gCO}_{2} / \mathrm{kWh}\right)$ & $0.194(\mathrm{kWh} / \mathrm{km})$ & 0 \\
\hline Truck & - & - & - & - & 730 \\
\hline Units & $\left(\mathrm{gCO}_{2}\right)$ & $\left(\mathrm{gCO}_{2}\right)$ & $\left(\mathrm{gCO}_{2} / \mathrm{kWh}\right.$ or $\left.\mathrm{gCO}_{2} / \mathrm{l}\right)$ & $(1 / \mathrm{km}$ or $\mathrm{kWh} / \mathrm{km})$ & $\left(\mathrm{gCO}_{2} / \mathrm{km}\right)$ \\
\hline
\end{tabular}




\section{Chapter 4}

\section{Solution Method}

This chapter presents the methods used to solve the bi-objective function present in Chapter 2 . Three methods are covered: single objective function, weighted sum, and epsilon constraint. The methods are explained in this chapter, with the main focus on the epsilon constraint method as it has shown to be the most promising in the literature review. In Chapter 5, methodological tests are carried out on the three methods discussed in this chapter.

\subsection{Single Objective Function Method}

One simple and common approach to solve multi-objective models is to consider only one objective function at a time and retrieve the solution and value obtained. Nevertheless, it is not possible to obtain the desired Pareto front applying this method. In fact, different solutions are usually obtained depending on the objective function selected, which hinders a balanced support to decision-making. It is therefore necessary to have a more advanced method that supports the creation of the Pareto front and, thus, allows for more comprehensive analyses.

\subsection{Weighted Sum Method}

The weighted sum method consists of assigning weights to each one of the objective functions and combining them linearly into a single algebraic expression. This method not only provides multiple solution points by varying the weights consistently, but for each configuration obtains a single solution that considers the multiple objectives. However, the definition of the weights can be particularly challenging, especially in cases where the difference in magnitude of the units is considerable (e.g. euros and grams), as is the case with this model. A simple demonstration of this method is shown below, where $O F_{i}$ represents an objective function and $w_{i}$ represents a weight associated with that same objective function. Considering $N$ objective functions (the objective being the maximization of each one), the objective function presented in Equation 4.1 is obtained. 


$$
\max \sum_{i=1}^{N} w_{i} O F_{i}=w_{1} O F_{1}+w_{2} O F_{2}+w_{3} O F_{3}+w_{4} O F_{4}+(\ldots)+w_{N} O F_{N}
$$

\subsection{Epsilon Constraint Method}

As discussed in the literature review, the epsilon constraint method is a common method used to solve multi-objective problems. This method consists on considering only one of the objective functions as an objective function of the model and using the remaining objective function as a constraint. The objective function (OF) turned into a constraint adopts the form $O F<=$ Epsilon, if the objective is to minimize its value, where the Epsilon value is progressively changed, thus allowing to obtain the Pareto front. In cases where the objective function that is transformed into a constraint must be maximized, it adopts the form $O F>=$ Epsilon. Considering the epsilon constraint with a financial objective function, the implemented algorithm is divided into the following steps:

- Execution of the model considering only the financial component as an objective function and extraction of the corresponding financial and environmental values from that solution;

- Creation of the epsilon vector: predefined sized vector with equidistant values up to the environmental value retrieved from the previous step;

- Running the model through an iterative cycle running through all the values of the epsilon vector. For each iteration, the financial function is considered as an objective function and the environmental objective function turns into a constraint with its value having to be less than or equal to the value in the vector.

The algorithm implemented with the environmental objective function is similar, with only a few differences: in the epsilon vector creation, it is the financial value obtained in the first step that is used. Also, in the last step, the environmental function is the one used as an objective function, with the financial function being defined as a constraint of value greater than or equal to the value in the vector.

In Chapter 5, methodological tests are carried out on these two variants of the epsilon constraint method. 


\section{Chapter 5}

\section{Tests and Analyses}

This chapter presents the analyses conducted to derive realistic and applicable insights from the bi-objective model proposed in Chapter 2 and solved using the method presented in Chapter 4. However, before performing these analyses, it is important to understand what input data is used in the model - the instances - as well as how this data is handled - the performance of the method.

Thus, firstly, the characteristics of the instances used are presented and analysed. This analysis has the objective of understanding the instances in aspects such as the average number of rental days per rental request, the mix of vehicle groups requested, the distribution of the check-out and check-in locations per rental request, among others.

After that, methodological tests are performed. These analyses and tests aim to characterize and validate the method, as well as select the most efficient and fit parametrization to use in subsequent analyses.

Finally, managerial analyses that retrieved relevant insights from the model are presented and the corresponding results are analysed and discussed. These tests are essentially of an environmental and management nature, and are as follows:

- Analysis of the impact of incentives for using electric vehicles;

- Analysis of the impact of using renewable sources of energy;

- Analysis of the impact of electric vehicles disposal;

- Analysis of the impact of fuel production;

- Analysis of the impact of homogeneous fleets;

- Analysis of the impact of total demand variation;

- Analysis of the impact of demand variation by group;

- Analysis of the impact of market competition;

- Analysis of the impact of available budget. 
A summary of the chapter is then presented, where the main conclusions drawn from the analyses carried out are discussed.

\subsection{Analysis of Instance Characteristics}

The dataset of instances used is the literature benchmark for car rental pricing and capacity problems, available in [28]. These instances are presented in Table 5.1 alongside the main characteristics of each one. Also, instances are listed by the increasing size represented as the multiplication of the number of rental requests by the number of vehicle groups.

Each rental request has a certain demand associated with the price level and the antecedence with which the rental request was made. The scale factor affects that demand profile and the available budget by multiplying these parameters by 100 in instances with an odd number. Thus, instances are grouped in pairs in Table 5.1. Instances with an even number represent "scale factors" of 1 while the odd-numbered instances represent "scale factors" of 100. All other parameters, except for the demand profile and the budget, are the same for each pair of instances.

Table 5.1: Instances main characteristics

\begin{tabular}{|c||ccc|}
\hline Instance number & Scale factor & Number of rental requests & Number of vehicle groups \\
\hline \hline $30 / 31$ & $1 / 100$ & 428 & 1 \\
$38 / 39$ & $1 / 100$ & 486 & 1 \\
$24 / 25$ & $1 / 100$ & 517 & 1 \\
$26 / 27$ & $1 / 100$ & 562 & 2 \\
$34 / 35$ & $1 / 100$ & 572 & 2 \\
$42 / 43$ & $1 / 100$ & 831 & 3 \\
$32 / 33$ & $1 / 100$ & 865 & 3 \\
$40 / 41$ & $1 / 100$ & 922 & 3 \\
$16 / 17$ & $1 / 100$ & 924 & 3 \\
$04 / 05$ & $1 / 100$ & 564 & 5 \\
$08 / 09$ & $1 / 100$ & 948 & 3 \\
$10 / 11$ & $1 / 100$ & 724 & 4 \\
$28 / 29$ & $1 / 100$ & 742 & 4 \\
$12 / 13$ & $1 / 100$ & 793 & 4 \\
$36 / 37$ & $1 / 100$ & 1046 & 4 \\
$20 / 21$ & $1 / 100$ & 1141 & 4 \\
$22 / 23$ & $1 / 100$ & 933 & 5 \\
$18 / 19$ & $1 / 100$ & 1182 & 4 \\
$06 / 07$ & $1 / 100$ & 1234 & 5 \\
\hline
\end{tabular}

A total of thirty-eight instances were tested and all original parameters were maintained. In addition, new environmental parameters were included with their values being already defined and explained in Chapter 3. 
One of the main parameters included in the instances is the list of rental requests. A rental request is characterized by a check-out and check-in location and time, and a vehicle group required. Rental requests are analysed in this section in order to better draw conclusions regarding the distribution of the rental check-in and check-out locations, check-in and check-out time period and groups requested.

Regarding the check-out time and location, all instances were analysed individually. For each instance, the data is analysed in percentage of the total number of requests, making it possible to compare data for all instances, even though they have a different number of requests (it varies between the minimum of 428 and the maximum of 1234 rental requests). In Figure 5.1, it is possible to observe that the check-out time periods are significantly concentrated at the beginning of the considered time horizon. In fact, more than $50 \%$ of the total rental requests start within the first three periods. This distribution represents the real behavior of the rental requests coming in a company: there are usually more requests for the next week than for those that follow. Therefore, it is expected that, for example, the size of the initial fleet will be particularly decisive in the number of accepted rentals. Regarding the check-out locations, their distribution appears to be random, not favoring any specific station.

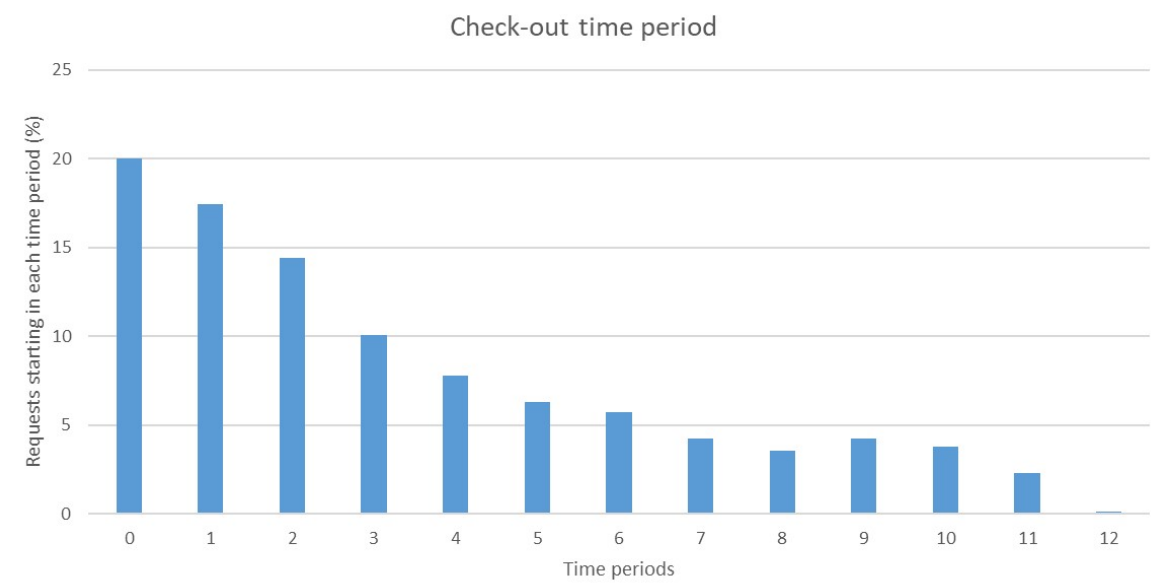

Figure 5.1: Distribution of check-out time period

Similarly, check-in times seem to follow an approximately normal distribution, although slightly shifted to the left. It is also visible that a large part of the vehicle check-ins are made in more central periods, with more than $50 \%$ of these returns concentrated in the interval [2;5], as shown in Figure 5.2. 


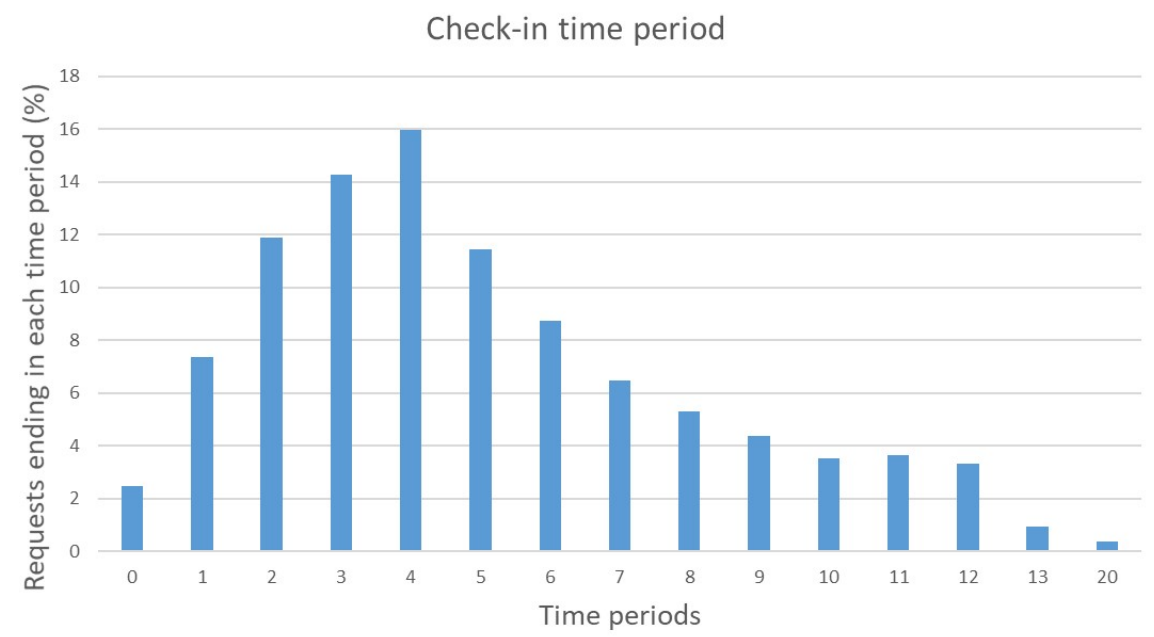

Figure 5.2: Distribution of check-in time period

Figure 5.3 represents the duration of the rentals in number of time periods between vehicle check-out and check-in. It is possible to verify that the requests are mostly short-term. In fact, approximately $15 \%$ of the rental have the same check-in and check-out periods. Also, more than $50 \%$ of the rentals lasts for one or two periods.

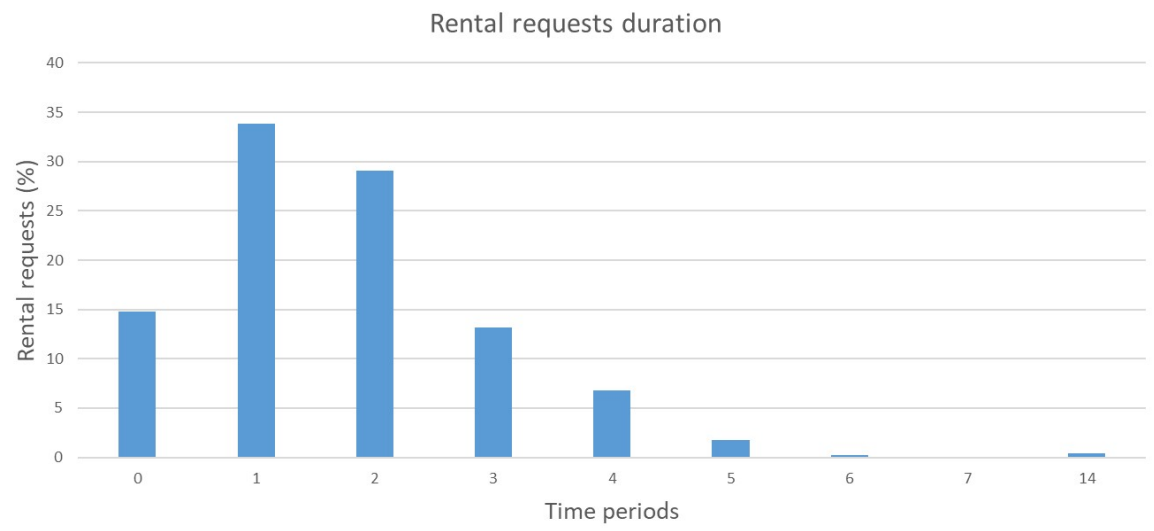

Figure 5.3: Distribution of rental requests duration

Lastly, regarding the groups of vehicles requested, their distribution also appears to be random and thus no group appears to be more requested than the rest.

\subsection{Methodological Tests}

To solve the bi-objective mathematical function, several methods were tested. Firstly, the model was tested using a single objective function at a time. This method did not prove to be efficient because, as expected in the case of the environmental objective function, the optimal value would 
always be zero, not performing any rentals, since it aims to minimize the environmental impacts and there is no constraint to ensure that a minimum value of demand must be met. Table 5.2 shows the instances tested and the respective results when considering a financial objective function and an environmental objective function.

Table 5.2: Results of solving a single objective function at a time

\begin{tabular}{|c||cc|}
\hline Instance & Financial OF & Environmental OF \\
\hline \hline 10 & 68442.1 & 0 \\
11 & 5126230 & 0 \\
12 & 73712.3 & 0 \\
13 & 5526310 & 0 \\
28 & 81394.6 & 0 \\
29 & 6294720 & 0 \\
\hline
\end{tabular}

Then, the weighted sum method was tested. However, the results showed that this is not the most appropriate method due to the large difference between the magnitude of the units considered in each objective function (Euros and $\mathrm{gCO}_{2}$ ). As the magnitude of the environmental solution is much greater than the magnitude of the financial solution, even with very low environmental weights, the results obtained end up being null - Table 5.3. This method was tested using an algorithm that iteratively ran the model with the different weights in the range $[0 ; 1]$ with a predefined increment between iterations. Table 5.3 shows two examples: one with a 0.05 increment and the other with a 0.01 increment.

Table 5.3: Results of the weighted sum method

\begin{tabular}{|r||rrrr|}
\hline Instance & $\begin{array}{r}\text { Financial } \\
\text { weight }\end{array}$ & $\begin{array}{r}\text { Environmental } \\
\text { weight }\end{array}$ & $\begin{array}{r}\text { Financial } \\
\text { solution (€) }\end{array}$ & $\begin{array}{r}\text { Environmental } \\
\text { solution (gCO })\end{array}$ \\
\hline \hline 31 & 1.00 & 0.00 & 5851950 & $1.56 \mathrm{E}+14$ \\
31 & 0.95 & 0.05 & 0 & 0 \\
31 & $(\ldots)$ & $(\ldots)$ & $(\ldots)$ & $(\ldots)$ \\
31 & 0.00 & 1.00 & 0 & 0 \\
\hline 27 & 1.00 & 0.00 & 4697580 & $2.85 \mathrm{E}+14$ \\
27 & 0.99 & 0.01 & 340390 & $3.09 \mathrm{E}+11$ \\
27 & 0.98 & 0.02 & 71830 & $4.95 \mathrm{E}+10$ \\
27 & 0.97 & 0.03 & 0 & 0 \\
27 & $(\ldots)$ & $(\ldots)$ & $(\ldots)$ & $(\ldots)$ \\
27 & 0.96 & 0.04 & 0 & 0 \\
\hline
\end{tabular}

To overcome this obstacle, the implementation of a normalizing value to be applied in the environmental component was studied. Even so, this value is extremely difficult to define and after some tests, it was found that there is no single normalizing value suitable for all instances.

Finally, the epsilon constraint method was tested. Due to time constraints, each iteration was defined as having a maximum of 600 seconds, that is, 10 minutes. The method was applied to the 
38 instances referenced in the previous section and a summary of these results can be found in Table 5.4.

The average time per iteration, the percentage of optimal values obtained, and the average mixed-integer programming (MIP) gap are included in Table 5.4. The percentage of optimal values consists of the number of iterations in which the optimal value was reached divided by the total number of iterations performed. The MIP gap (the difference between the best integer solution obtained and the upper bound of the optimal value to be divided by the best integer solution obtained) regards to the total number of iterations performed. The tables containing the complete results of these tests are presented in Appendix A.

Table 5.4: Results of the epsilon constraint method

\begin{tabular}{|c||ccc|}
\hline Objective Function (OF) & Avg. iteration time (sec) & Optimal Values (\%) & Avg. MIP gap (\%) \\
\hline \hline Financial OF & 321.41 & 68.32 & 0.000216 \\
Environmental OF & 553.66 & 15.27 & 0.035095 \\
\hline
\end{tabular}

Both versions of the epsilon method (using the financial objective function or the environmental objective function) were applied to 38 instances with a number of iterations ranging from 10 to 45. These data results are compiled in Table A.1 in Appendix A. For all tests, the epsilon constraint method using the financial function as an objective function lasted a total of 348049 seconds (approx. 96 hours), while using the environmental function as an objective function lasted a total of 586592 seconds (approx. 163 hours).

Using the financial function as the objective function and the environmental function as a constraint has thus proved to be better in terms of time and results obtained. Even in cases where the optimal value has not been reached, the MIP gap is relatively low (average MIP gap of $0.000507 \%$ ). For this reason, the epsilon constraint method considering the financial function as an objective function and the environmental function as a constraint will be used considered in the next analyses.

Results of instance number 7 (the larger instance) are not contained in Table 5.4, which therefore contains only the values for 37 instances. These results are not included because in some of iterations (3) the MIP gap is significantly higher when compared with the rest of the results Table A.3 in Appendix A. Thus, to not distort the average results obtained in all other instances, instance 7 results are considered outliers and therefore not contained in Table 5.4.

As explained before, the analysed instances are built so that there are pairs of instances where all characteristics are similar, except for the scale factor (the difference is that one instance has a certain number of rentals and budget and the other has the same value multiplied by 100). Thus, analysing the average iteration time (Figure 5.4) and the MIP gap (Figure 5.5) for both situations, it is possible to conclude that the average iteration time and the MIP gap are lower in average when the scale factor is larger. Although time differences are significant, the gap values are remarkably small for both scale factors - the y-axis of Figure 5.5 describes a super reduced scale. The pairs of instances represented on the horizontal axis of Figures 5.4 and 5.5 were ordered by the increasing 
size, calculated as the multiplication of the number of rental requests by the number of vehicle groups.

The justification for this may rest in the way the solver performs the branch-and-bound tree search. The scale factor increase results on an admissible solution set much wider. That fact can lead the search for the optimal value to explore more nodes and, thus, taking more time, or to reach the node with the optimal value more quickly, and thus being more efficient. In this specific case, it appears that it allows the search for the optimal solution to happen in a much more efficient way.

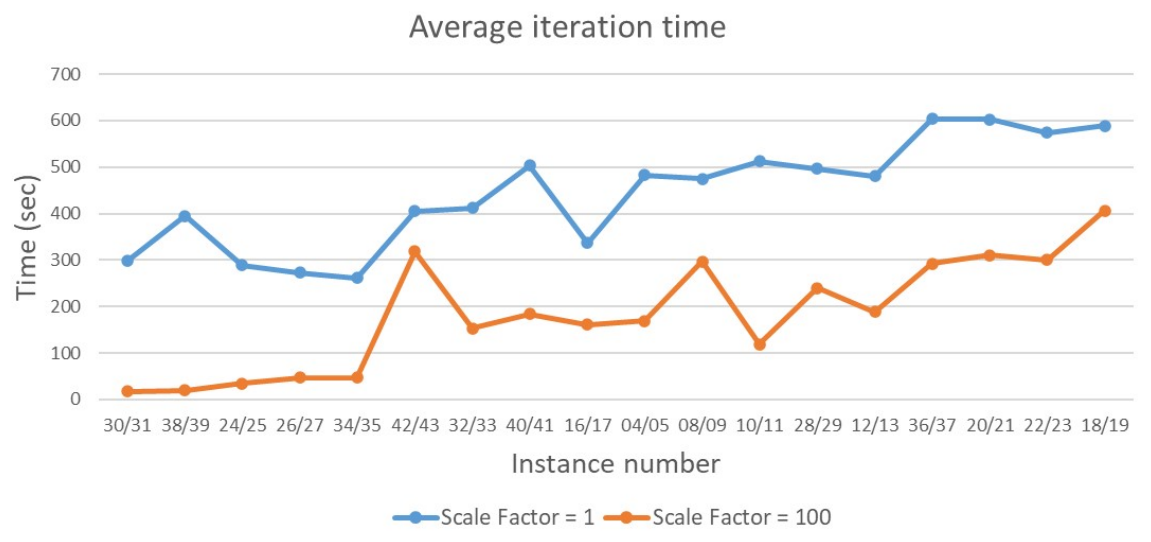

Figure 5.4: Average iteration time for different scale factors

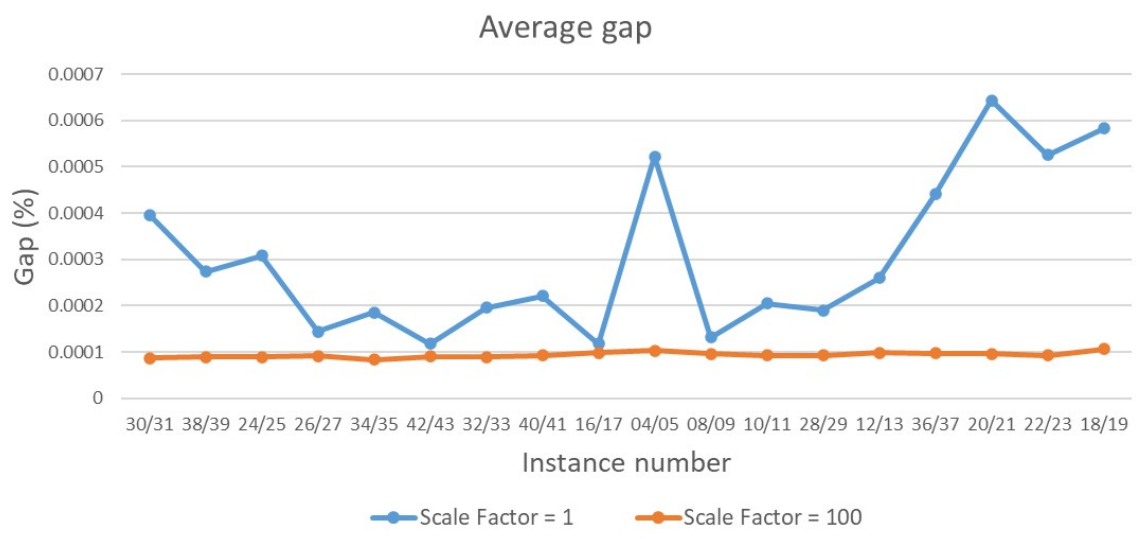

Figure 5.5: Average gap for different scale factors

Figures 5.6 and 5.7 show the average iteration time depending on the number of rentals and groups, respectively. The radius of the bubbles is proportional to $(R \times G)$, where $\mathrm{R}$ is the number of rentals and $\mathrm{G}$ is the number of vehicle groups, which has been used as a measure of instance size. Analysing both figures, it is possible to conclude that the time to solve increases as expected with size; however, the number of rentals appears to have more influence on the average iteration time. 


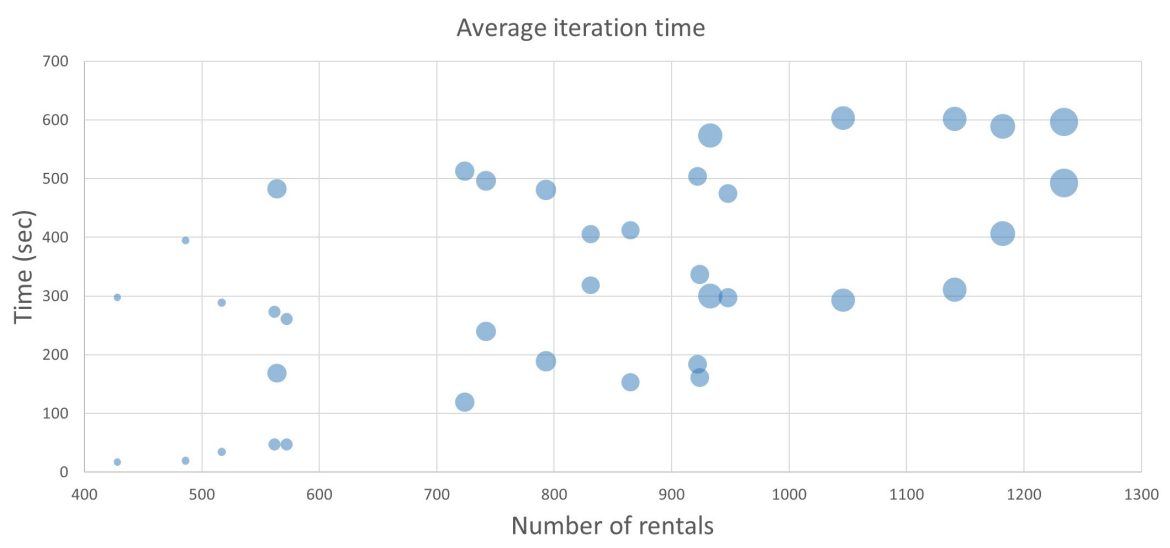

Figure 5.6: Average iteration time depending on the number of rentals

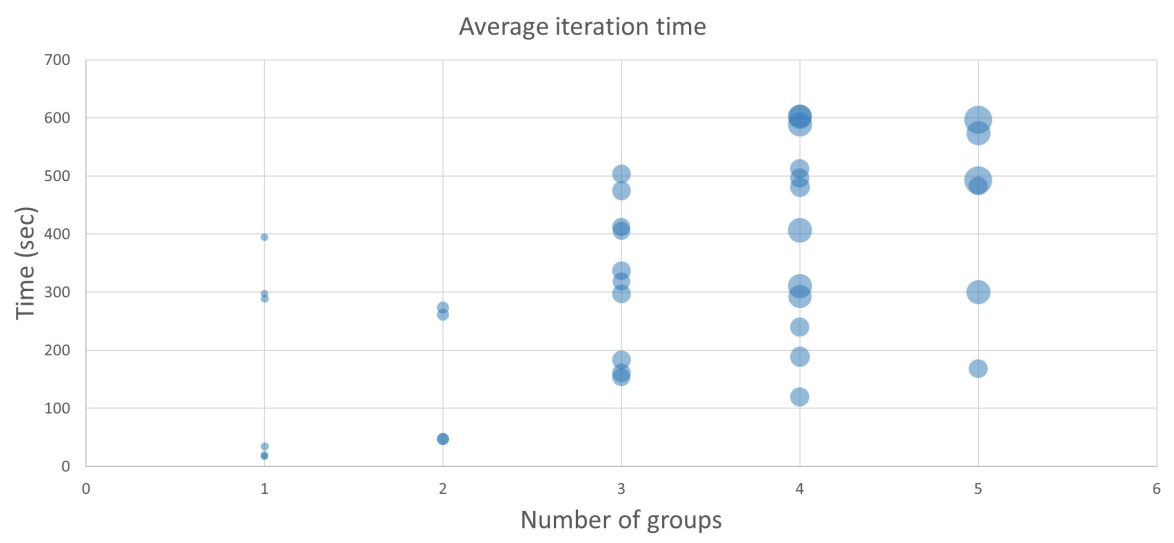

Figure 5.7: Average iteration time depending on the number of vehicle groups

The number of iterations defines the size of the epsilon vector. Figure 5.8 shows that the average iteration time has no relation to the chosen epsilon size. Even so, the total time per instance is bigger if the epsilon size increases (Figure 5.9) as would be expected, since bigger epsilon size values imply more iterations performed per instance. Due to time constraint reasons, the use of epsilon constraint with an epsilon size of 30 was defined. 


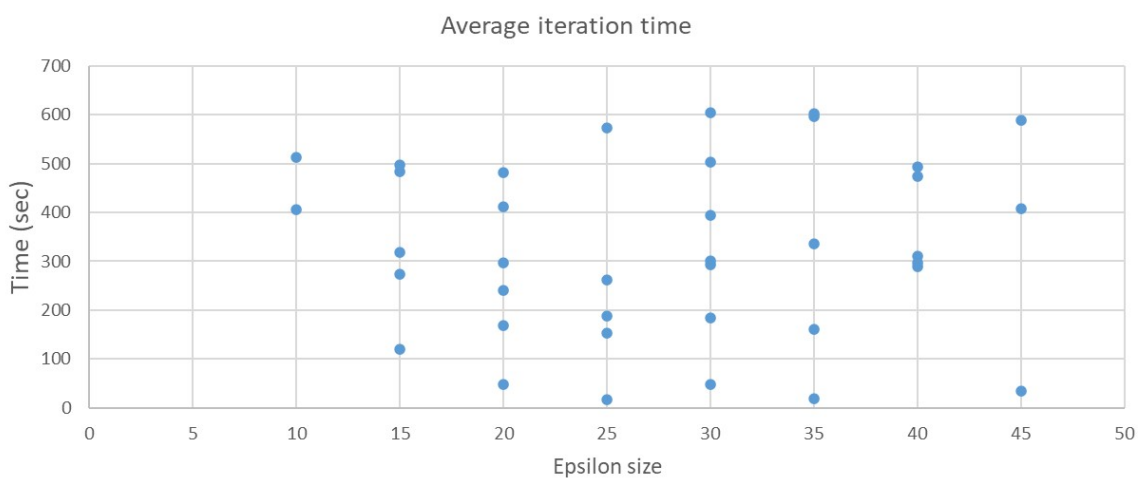

Figure 5.8: Average iteration time depending on the epsilon size

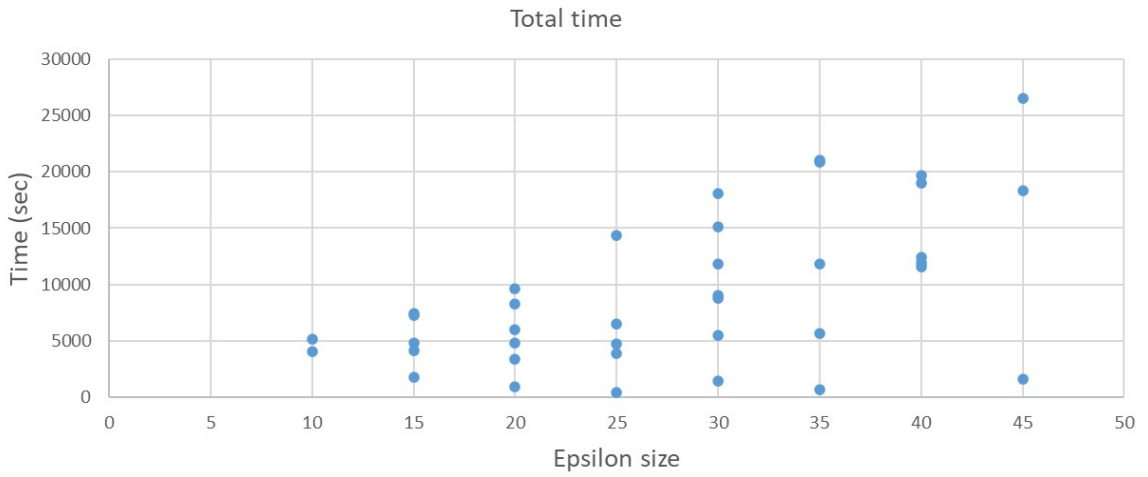

Figure 5.9: Total time per instance depending on the epsilon size

Summing up, the most fit parametrization of the method to be used in the following tests and analyses has the following characteristics:

- The financial objective is used as the objective function whereas the environmental function is a constraint with a bound changing iteratively;

- 30 iterations will be used per analysis. For each iteration, the epsilon value constraints the environmental function. The epsilon values change iteratively according to the expression $\frac{E V}{E S} \times N$ where $E V$ represents the environmental value obtained in the preliminary iteration, $E S$ stands for the Epsilon size, and $N$ represents the iteration number;

- Maximum time of 10 minutes per iteration (with a resulting maximum of 300 minutes per instance run).

The algorithms were developed in the programming language C++ in Visual Studio 2017 and were run on a HP Z820 Workstation computer with 128GB of RAM memory, and with 2 CPUs (Xeon E5-2687W 0 @ 3.10 GHz). The MIP Solver used was CPLEX 12.8.0. 


\subsection{Analyses and Insights}

In this section, the analysis tests are presented and the respective results are analysed and discussed. These tests are essentially of an environmental and managerial nature.

Regarding tests of an environmental nature, the influence of incentives for the use of electric vehicles is first analysed. These incentives aim to understand how this influences the types of vehicles used in rentals and the consequent variations in environmental impacts. After that, the use of cleaner energy sources is studied. This test is carried out since the electric energy influences the impacts in the production and disposal phases, but it is also used as fuel by BEVs and PHEVs. Due to the current high production of electric vehicles, it is important to understand the impacts that arise from recycling batteries. To do so, tests are carried out considering different scenarios with different disposal impacts. A sensitivity analysis on fuel production is also performed since this parameter combines several stages (such as oil extraction, oil transportation, refining, and transportation to gasoline pumps), which is why it is arduous to estimate.

From a management point of view, the first test conducted regards homogeneous fleets and aims to understand the model results in the impossibility of making upgrades. Then, variations in demand are tested, since it leads to different choices of price levels and thus significantly influences financial results. To reproduce an illustrative situation of market competitors, the influence of price changing is also analysed. Finally, the significance of the initial available budget is tested since, in all businesses, a greater or lesser investment capacity tends to be quite decisive in the overall financial results.

In Table 5.5, the instances utilized for each test are presented.

Table 5.5: Instances utilized

\begin{tabular}{|c||lccc|}
\hline Test number & \multicolumn{1}{c|}{ Test name } & Instance number & $\begin{array}{c}\text { Number } \\
\text { requests }\end{array}$ & $\begin{array}{c}\text { of } \\
\text { Vehicle } \\
\text { groups }\end{array}$ \\
\hline \hline 5.3 .1 & $\begin{array}{l}\text { Incentives for using electric } \\
\text { vehicles }\end{array}$ & 12 & 793 & 4 \\
5.3 .2 & Use of renewable sources of & & & \\
energy & 36 & 1046 & 4 \\
5.3 .3 & Electric vehicles disposal & 10 & 724 & 4 \\
5.3 .4 & Fuel production & 11 & 724 & 4 \\
5.3 .5 & Homogeneous fleets & 30 & 428 & 1 \\
5.3 .7 & Total demand variation & 29 & 742 & 4 \\
5.3 .8 & Demand variation by group & 13 & 793 & 4 \\
5.3 .9 & Market competition & 28 & 742 & 4 \\
\hline
\end{tabular}

All instances were chosen because they present the number of groups of vehicles suitable for the tests to be carried out. In fact, in all tests, 4 groups of vehicles are used (ICE, Hybrid, PHEV, and $\mathrm{BEV}$ ) except in the test of homogeneous fleets where only one group is considered for each scenario. The number of rental requests was also considered, favoring the instances with the least number of rentals, to reduce the computation time required, and considering all instances have a realistic size. Finally, the choice of repeated instances was avoided whenever possible. 
The results were obtained by running once the method presented in Chapter 4 alongside the parametrization defined in Section 5.2. A summary of these analyses is then presented at the end of the chapter with the main conclusions and managerial insights obtained.

\subsubsection{Incentives for Using Electric Vehicles}

One of the obstacles to the utilization of electric vehicles is related to their high cost, not only related to the purchase of the car but also to changing batteries, if needed. Thus, the use of incentives can be important to overcome the price obstacle. In this test, the impact of reducing the purchase price of electric vehicles is studied. The same percentage of discount is applied to the costs of leasing, ownership, and prices. Three scenarios are tested:

1. Buying, leasing and ownership costs and prices according to original instance's values;

2. Buying, leasing and ownership costs and prices: $25 \%$ discount for BEVs;

3. Buying, leasing and ownership costs and prices: $50 \%$ discount for BEVs.

Analysing the Pareto front in Figure 5.10, no major differences are visible in the three scenarios. In fact, scenario 1 proves to be slightly better than scenario 2 and 3 because, for each environmental impact value, it presents a higher profit.

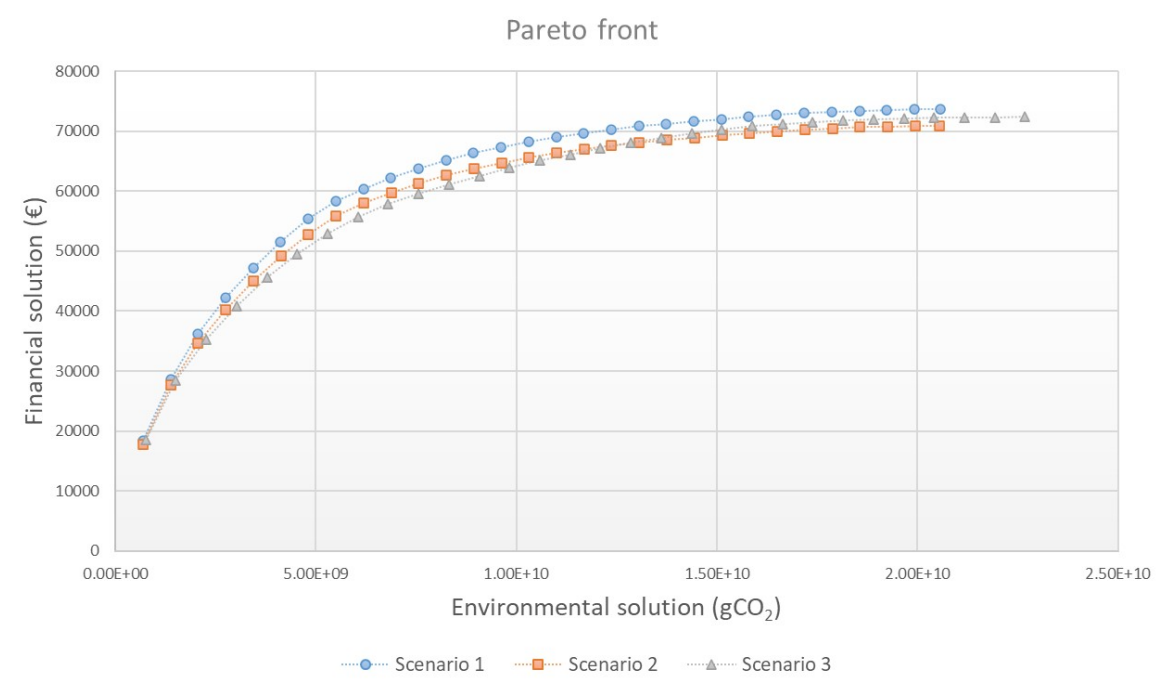

Figure 5.10: Incentives for using electric vehicles: Pareto front

Figure 5.11 contains all the environmental impacts, namely production, disposal, emissions resulting from fuel consumption (both for own and leased vehicles), utilization, and emissions related to empty transfers (distinguishing between empty transfers performed by truck or by a single driver). The horizontal axis of Figure 5.11 shows values in the interval $[1 ; 90]$ representing the 30 iterations performed in each of the scenarios, considering the scenarios in ascending order. 
The most significant impacts are related to vehicle production and fuel. Disposal impacts, as verified in the literature review, are practically negligible when compared to the remaining impacts. On the other hand, emissions related to the utilization of vehicles are not meaningful due to the reduced time horizon considered. These impacts are similar in scenarios 1 and 2, while in scenario 3 , it is possible to observe an increase in emissions regarding the fuel for owned vehicles.

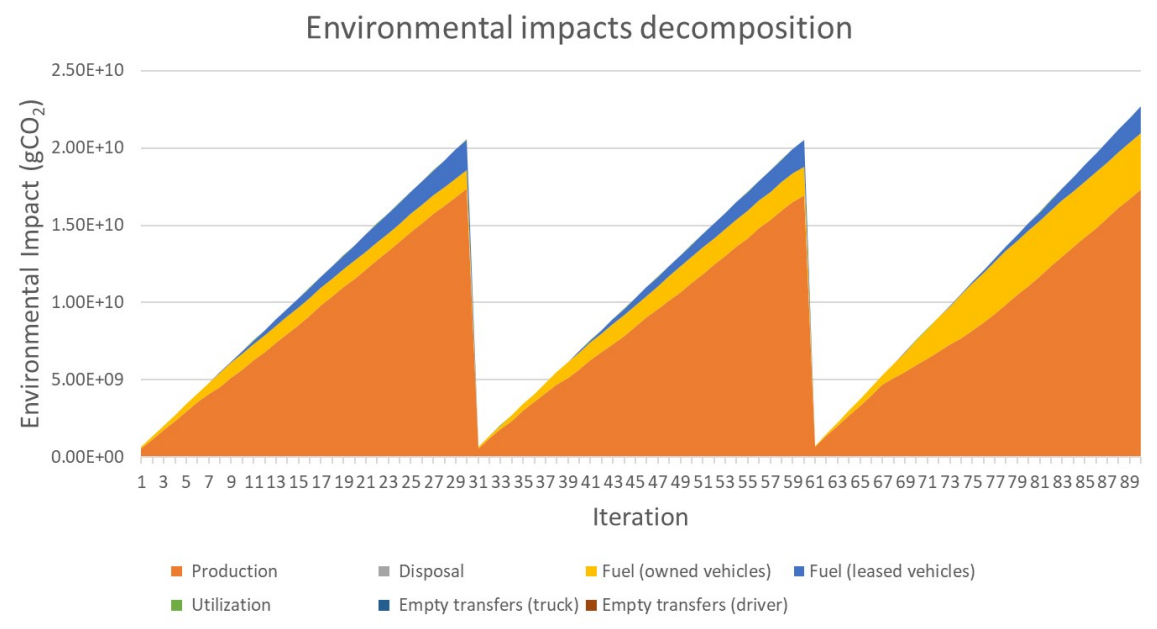

Figure 5.11: Incentives for using electric vehicles: Environmental impacts decomposition

In scenario 3, incentives are greater and this leads to the acquisition of more electric vehicles. These, as will also be shown further in this chapter, are highly polluting due to the value related to electricity generation emissions estimated in Chapter 3 - $485 \mathrm{gCO} 2 / \mathrm{kWh}$. This value is considerably high as it represents the World average. For example, by multiplying fuel production by fuel consumption, it is concluded that ICE vehicles have emissions of $45 \mathrm{gCO}_{2} / \mathrm{km}$ while BEVs have emissions of approximately $94 \mathrm{gCO}_{2} / \mathrm{km}$. These values justify the greater environmental impacts in scenario 3 .

Through a deeper look at the financial component of the solution, it is worth noting that this higher profit is essentially due to a reduction in costs. In every iteration, the revenues are greater in scenario 1 - Figure 5.12. The x-axis in Figure 5.12 represents the number of iterations. The direction of the environmental constraint relaxation is consistent with the increase in the number of iterations, that is, the greater the number of the iteration is, the greater the relaxation of the environmental constraint. 


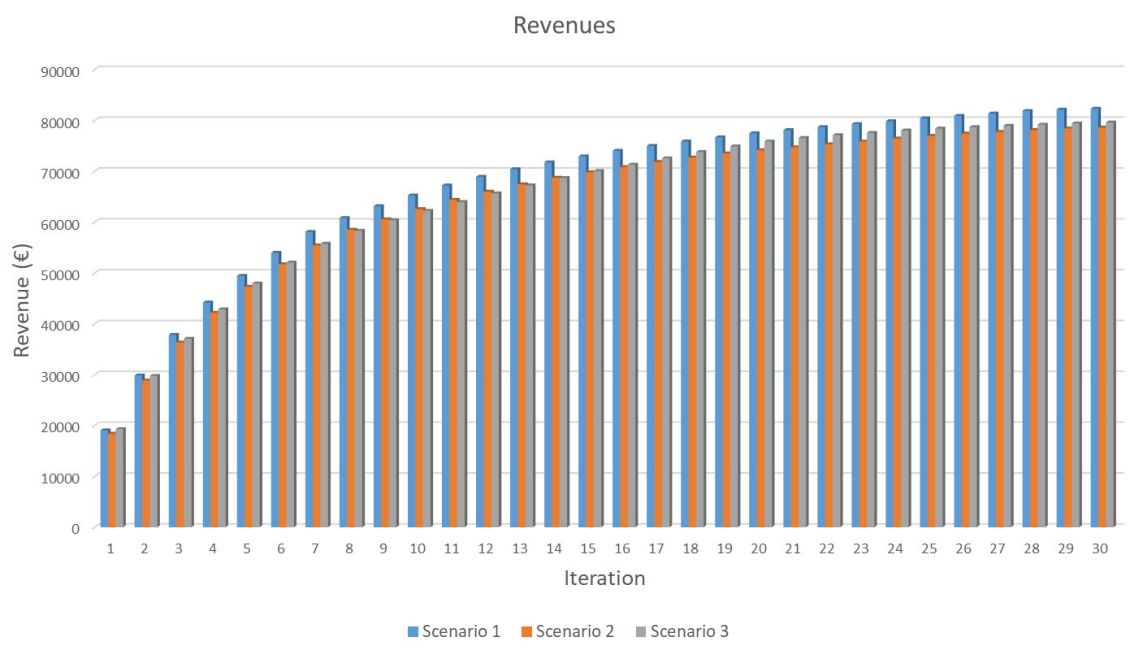

Figure 5.12: Incentives for using electric vehicles: Revenues

In global, costs are lower in scenario 2 and even lower in scenario 3 - Figure 5.13. The x-axis in Figure 5.13 represents the number of iterations performed in all scenarios, each one containing 30 iterations. Scenarios are presented in ascending order. There is, however, a component that deserves a detailed analysis: the upgrade costs. The budget is maintained but the price of electric vehicles drops considerably. Thus, the model privileges the purchase of these vehicles and their subsequent offer as an upgrade in a rental request. As it allows the purchase of more vehicles, it will also allow the acceptance of a greater percentage of booking requests, as shown in Figure 5.14. The acceptance rate is the quotient between the number of accepted rental requests and the total number of requests.

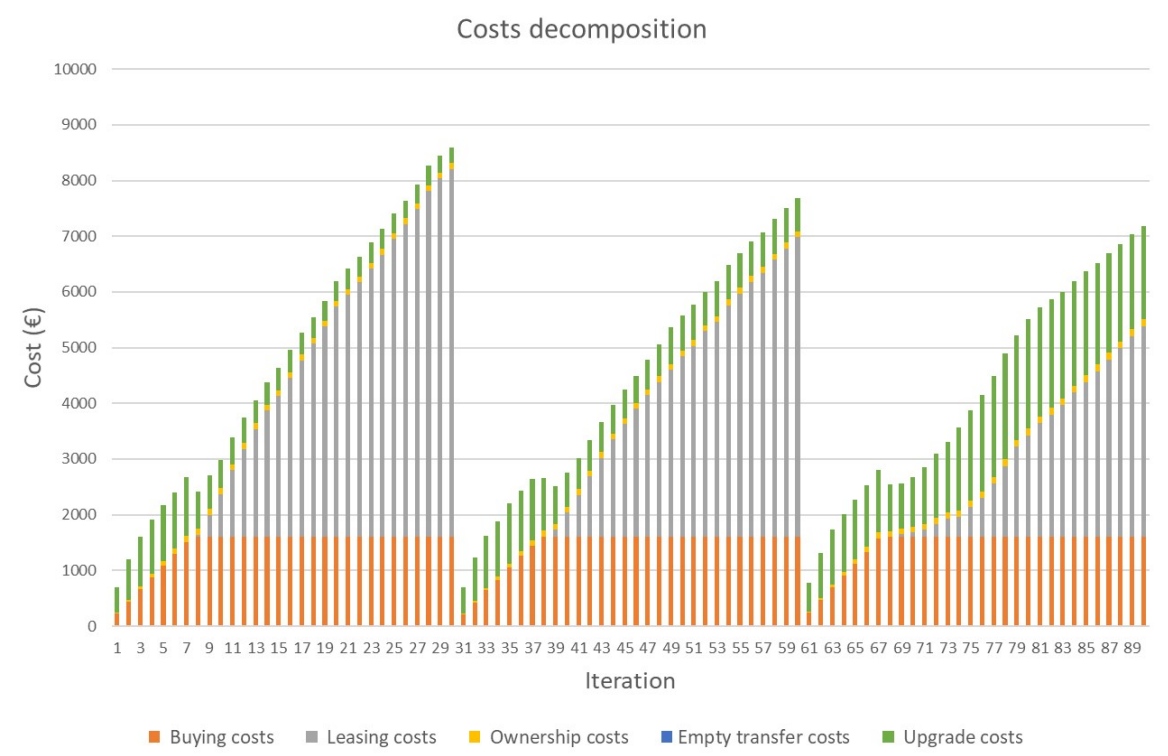

Figure 5.13: Incentives for using electric vehicles: Costs decomposition 


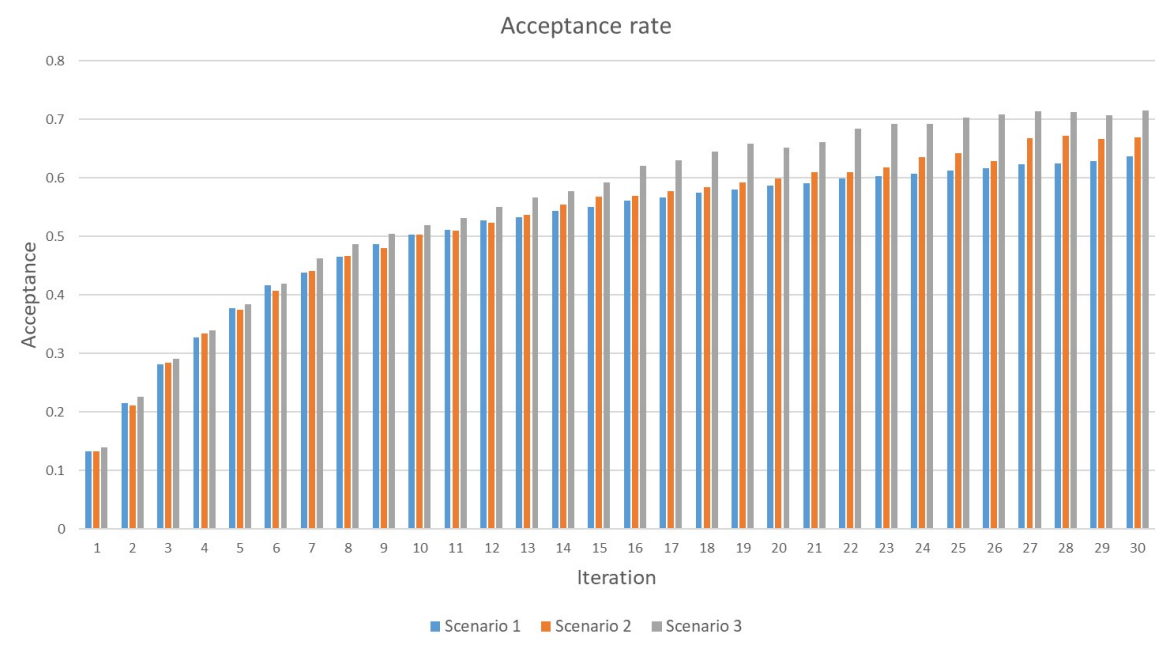

Figure 5.14: Incentives for using electric vehicles: Acceptance rate

In Table 5.6, it is possible to verify that this solution privileges the purchase of electric vehicles instead of vehicles of other groups. All values regard the last iteration for each scenario, that is, where the environmental constraint is most relaxed (i.e. it corresponds to a single objective solution when considering the financial objective function).

Table 5.6: Purchased vehicles by group

\begin{tabular}{|c||ccc|}
\hline Vehicle group & Scenario 1 & Scenario 2 & Scenario 3 \\
\hline \hline BEV & 98 & 239 & 640 \\
PHEV & 58 & 0 & 0 \\
Hybrid & 163 & 115 & 0 \\
ICE & 87 & 94 & 0 \\
\hline
\end{tabular}

The use of incentives for using electric vehicles does not lead to a reduction in environmental impacts. The tests carried out show that the impacts end up being even greater in scenario 3 where the incentives are the highest. The reduction in electric vehicle buying costs allows the purchase of more BEVs and the following offer of them as an upgrade, thus managing to meet a higher percentage of rental requests.

\subsubsection{Use of Renewable Sources of Energy}

The electric energy source is fundamental in determining emissions since it is linked not only to the production and disposal of vehicles but also to the fuel consumption, in the case of electric vehicles and PHEV. To simulate the use of cleaner energy sources, the maximum and minimum values presented in Table 3.1 were retrieved. The following three scenarios are tested:

1. Electricity generation emissions from Europe $\left(303 \mathrm{gCO}_{2} / \mathrm{kWh}\right)$; 
2. Electricity generation emissions from the World average ( $\left.485 \mathrm{gCO}_{2} / \mathrm{kWh}\right)$;

3. Electricity generation emissions from Oceania $\left(651 \mathrm{gCO}_{2} / \mathrm{kWh}\right)$.

Figure 5.15 shows a considerable difference in the environmental solutions and scenario 3 proves to be the worst from an environmental standpoint, as expected. Even so, the three Pareto fronts tend roughly to the same financial solution, showing that in financial terms the results are very similar. This is an interesting result, as it is possible to keep financial performance and improve in environmental impact.

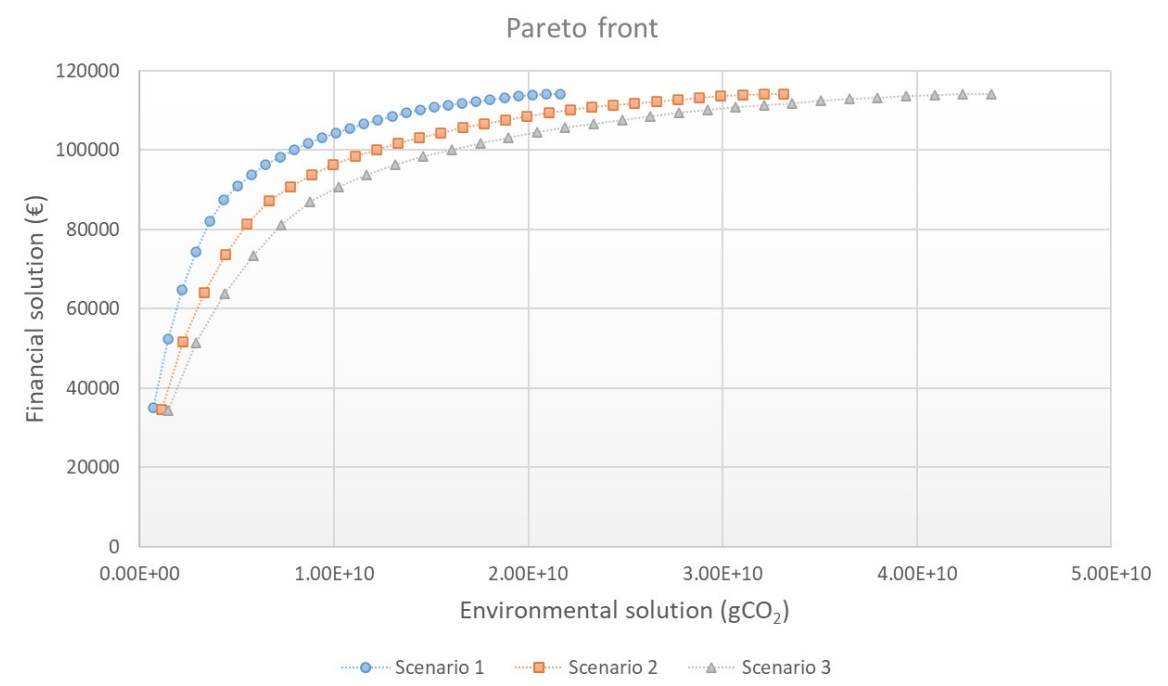

Figure 5.15: Use of renewable sources of energy: Pareto front

Analysing Table 5.7, it is also possible to verify that the electricity generation emissions variation (in percentage) translates into a similar variation in the final environmental solution. All values regard the last iteration of each scenario.

Table 5.7: Emissions variation

\begin{tabular}{|c||cc|}
\hline Emissions $\left(\mathbf{g C O}_{\mathbf{2}} \mathbf{/ k W h}\right)$ and variation & Environmental solution $\left(\mathbf{g C O}_{\mathbf{2}}\right)$ & Variation \\
\hline \hline $303(-37.53 \%)$ & $2.16 \mathrm{E}+10$ & $-34.73 \%$ \\
$485($ Baseline $)$ & $3.32 \mathrm{E}+10$ & 0 (Baseline) \\
$651(+34.23 \%)$ & $4.38 \mathrm{E}+10$ & $+32.10 \%$ \\
\hline
\end{tabular}

These similarities in terms of environmental variation follow this apparent proportionality ratio due to the main emissions factor and their dependence on the use of electricity. Vehicle production is the most significant environmental impact, as shown in Figure 5.16. As already discussed in Section 3.1, the impacts of vehicle production are equivalent to the sum of the energy consumed in the car components production, and the subsequent energy consumed in the assembly process. In both cases, the required energy is estimated in units of energy per units of mass $(\mathrm{kJ} / \mathrm{kg})$. Production emissions are then expected to follow the variation due to electricity dependency. The 
horizontal axis in Figures 5.16 and 5.17 shows the 30 iterations performed in each of the scenarios, considering the scenarios in ascending order.

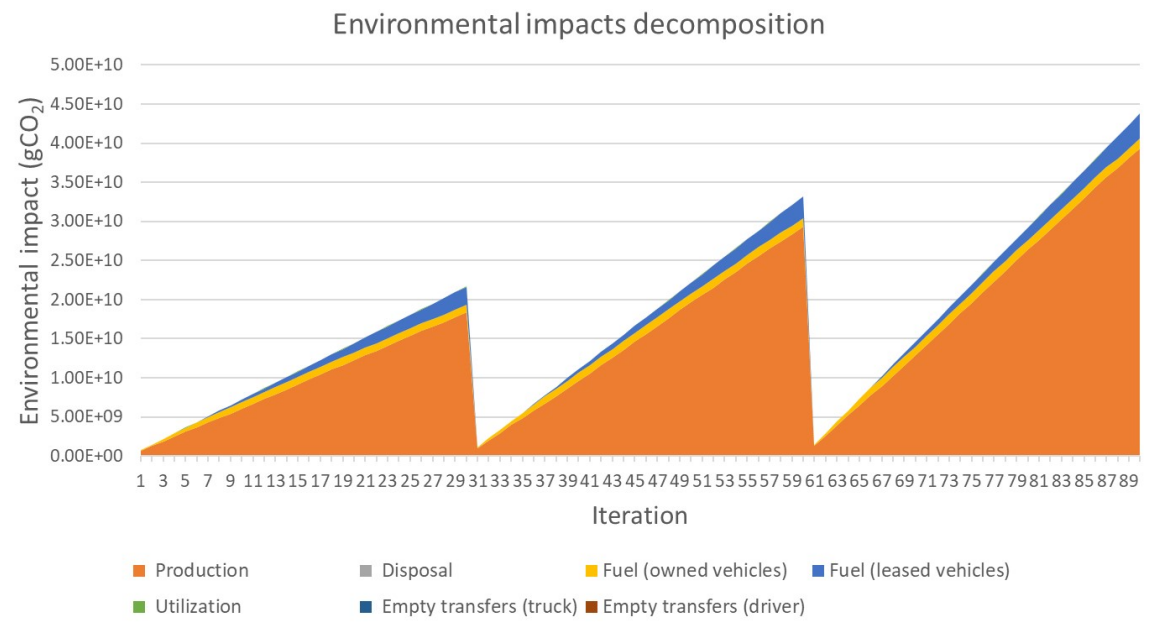

Figure 5.16: Use of renewable sources of energy: Environmental impacts decomposition

Analysing the remaining impacts in Figure 5.17, it is possible to verify that the variation is not so linear. This happens because, depending on the type of vehicle, the fuel used is different. Thus, in the case of BEVs and PHEVs, fuel emissions increase but for the ICE and Hybrid vehicles, they remain the same. If this test had been carried out on a homogeneous fleet with only electric vehicles, growth in fuel emissions would be expected as the ones that occurred in production.

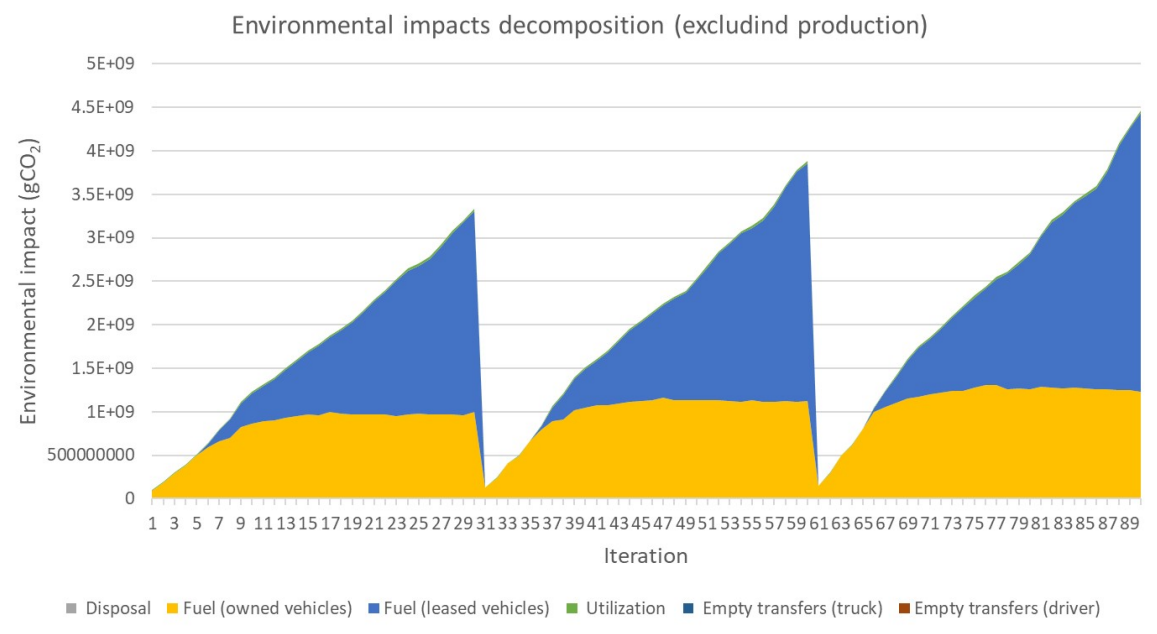

Figure 5.17: Use of renewable sources of energy: Environmental impacts decomposition (excluding production)

The tests carried out show that the source of electric energy plays a major role in the environmental solution due essentially to the impacts related to the production of the vehicles. The Pareto 
front (Figure 5.15) tends roughly to the same financial value in all scenarios, therefore, the source of electric energy does not affect the financial results obtained.

\subsubsection{Electric Vehicles Disposal}

To simulate the existing concern regarding the disposal of electric batteries, multiplicative factors are applied to the disposal impacts of electric vehicles. Hybrid vehicles also have an electric motor, although with less capacity than electric cars. Therefore, in all tests, $1 / 10$ of the same factor is also applied for both hybrid vehicles (Hybrid and PHEV). Five scenarios are tested:

1. Disposal impacts according to original instance's values defined in Chapter 3;

2. Multiplicative factor $=5000$;

3. Multiplicative factor $=50000$;

4. Multiplicative factor $=500000$;

5. Multiplicative factor $=5000000$.

Analysing the Pareto front in Figure 5.18, it is possible to conclude that as the disposal impact increases, the final impacts are greater, and the financial solutions are successively smaller for the same impact. The Pareto front grows asymptotically to the same financial result in all cases, only changing the slope.

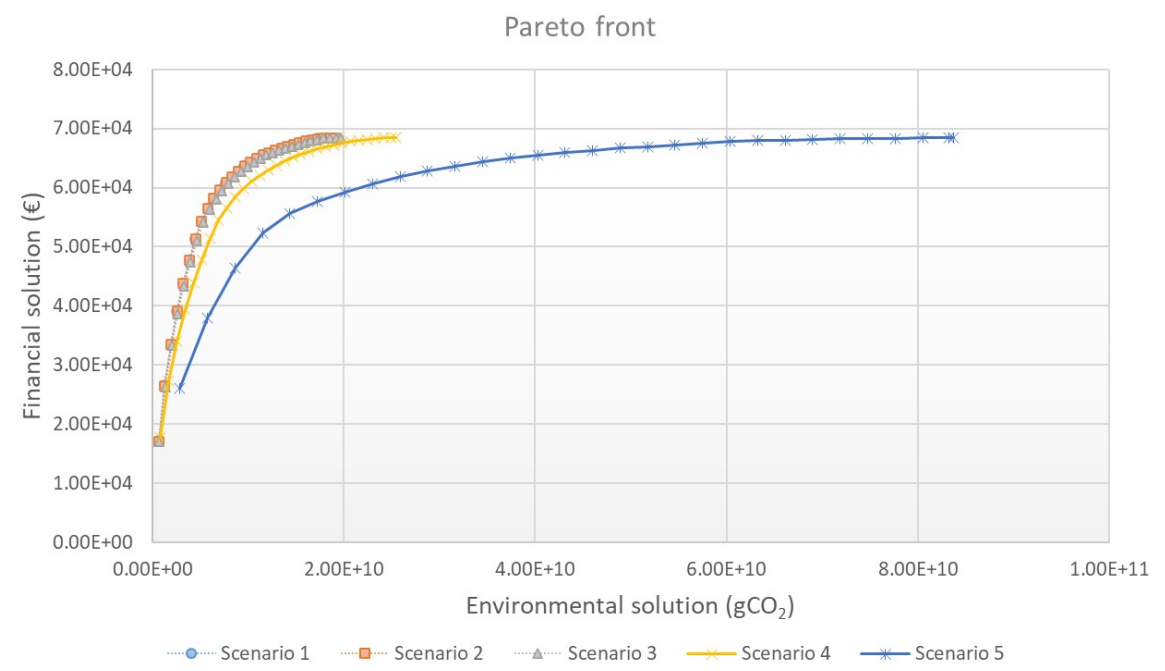

Figure 5.18: Electric vehicles disposal: Pareto front

Table 5.8 shows the fleet composition for an identical environmental solution $\left(1.40 \mathrm{E}+10 \mathrm{gCO}_{2}\right)$. Since Pareto fronts evolve differently in each scenario, the number of the iteration in which that scenario reaches the environmental value considered will also be different. Thus, the iteration in 
which each scenario reaches the environmental value considered is shown in Table 5.8. It shows that the number of electric vehicles purchased decreases considerably as the impact of the disposal of its batteries is increased. The budget that is not spent on this type of vehicle, is redirected to the remaining vehicle groups.

Table 5.8: Purchased vehicles for the same environmental impact

\begin{tabular}{|c||c||cccc|}
\hline Scenarios & Iteration & ICE & Hybrid & PHEV & BEV \\
\hline \hline 1 & 22 & 166 & 131 & 65 & 48 \\
2 & 22 & 165 & 132 & 66 & 47 \\
3 & 22 & 165 & 132 & 66 & 47 \\
4 & 17 & 187 & 135 & 69 & 29 \\
5 & 5 & 252 & 87 & 98 & 0 \\
\hline
\end{tabular}

Table 5.9 shows the fleet composition in the last iteration of each scenario, where no major changes between the three scenarios are identified. This happens due to the epsilon value used. As explained in Section 5.2, the epsilon values change iteratively according to the expression $\frac{E V}{E S} \times N$ where $E V$ represents the environmental value obtained in the preliminary iteration, $E S$ stands for the Epsilon size, and $N$ represents the iteration number. In the final iteration $(E S=N)$ the epsilon value coincides with the environmental value retrieved from the preliminary iteration and, thus, the relaxation of the environmental constraint is maximum.

Table 5.9: Purchased vehicles at final iteration

\begin{tabular}{|c||cccc|}
\hline Scenarios & ICE & Hybrid & PHEV & BEV \\
\hline \hline 1 & 194 & 127 & 49 & 48 \\
2 & 201 & 124 & 49 & 46 \\
3 & 204 & 120 & 48 & 48 \\
4 & 196 & 124 & 49 & 49 \\
5 & 196 & 124 & 49 & 49 \\
\hline
\end{tabular}

The test conducted shows that, in scenarios where the impact of disposal is greater, the use of electric vehicles is avoided in the initial iterations, due to a tighter environmental constraint. However, in the final iterations where relaxation is greatest, the fleets proved to be similar in all scenarios.

From a financial standpoint, an increase in disposal impacts does not affect the best financial solution obtained. It is visible in the Pareto front (Figure 5.18) that all curves grow asymptotically to the same financial solution with different slopes.

\subsubsection{Fuel Production}

Fuel production is a very difficult impact to estimate because it includes factors such as oil extraction, oil transportation, refining, and transportation to gasoline pumps. This impact is estimated 
in Chapter 3, corresponding to the value used in scenario 2. Therefore, a sensitivity analysis is performed in this section, reproducing smaller and greater impacts, respectively, preserving the same difference for the baseline value - scenarios 1 and 3 . Three scenarios are tested:

1. Fuel production $=500 \mathrm{gCO}_{2} / 1$;

2. Fuel production $=750 \mathrm{gCO}_{2} / 1$;

3. Fuel production $=1000 \mathrm{gCO}_{2} / 1$.

Analysing the Pareto front in Figure 5.19, it is possible to verify the existence of a few differences between the three observed scenarios. The main difference regards the maximum emissions achieved, which are higher where fuel production has the greatest impact.

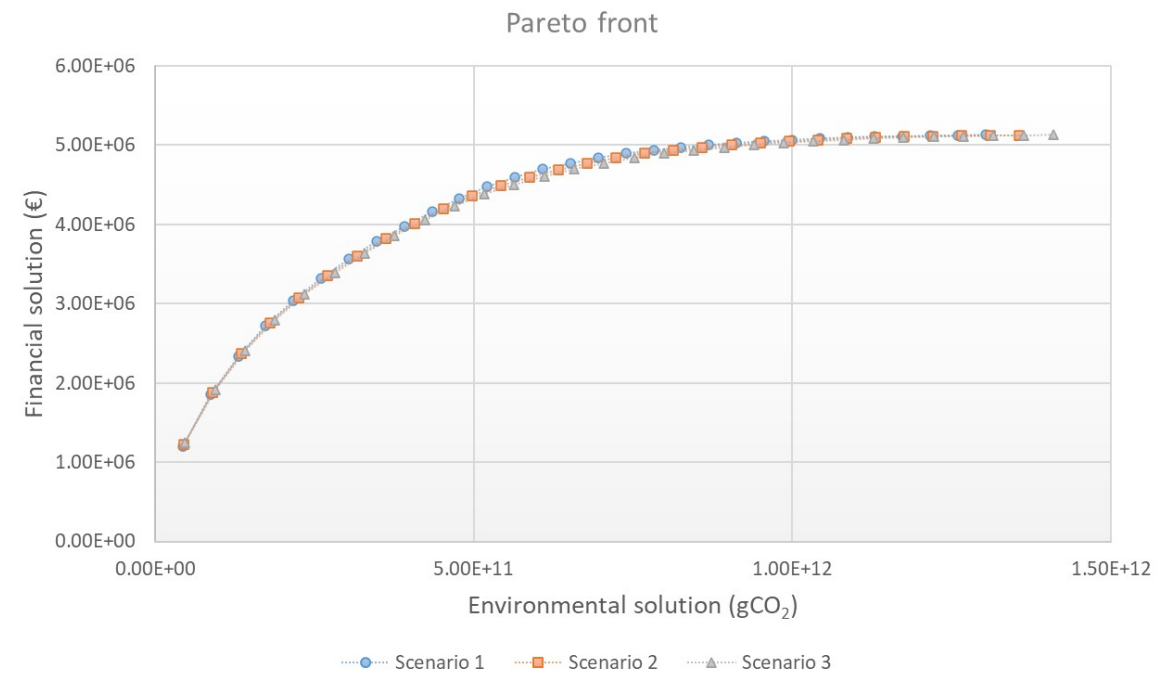

Figure 5.19: Fuel Production: Pareto front

Analysing the environmental impacts in Figure 5.20, it is possible to verify that the increase in the environmental impacts regards the fuel, not only from leased but also from owned vehicles. The fuel production impact increase is not proportional to the increase in the environmental solution due to the existence of vehicles of different types. In fact, this increase affects ICE vehicle emissions, but not the BEV. The horizontal axis in Figure 5.20 shows the 30 iterations performed in each of the scenarios, considering the scenarios in ascending order. 


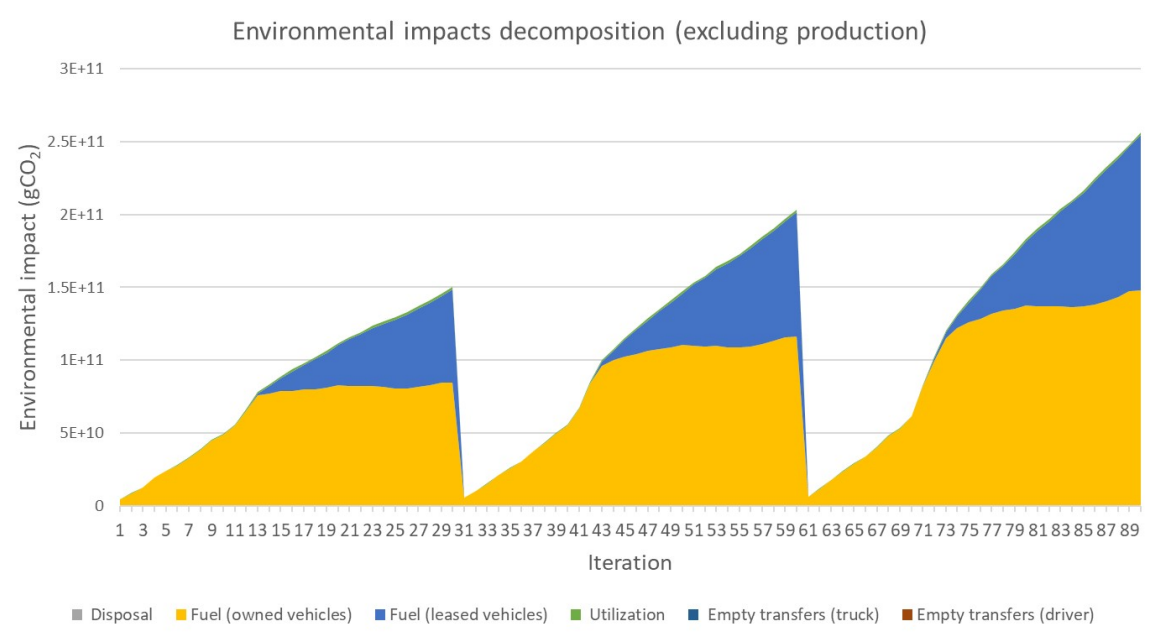

Figure 5.20: Fuel Production: Environmental impacts decomposition (excluding production)

The fuel production impact increase leads to an increase in the environmental solution while, from a financial point of view, there are no relevant deviations to report regarding the tests performed.

\subsubsection{Homogeneous Fleets}

One of the car rental strategies regarding the capacity-pricing problem is the offer of a vehicle of a higher class for the price of the lower class, that is, offering upgrades. A very interesting analysis to do is to test the model's behavior when only homogeneous fleets are available, and thus upgrades are no longer offered. In this analysis, four scenarios are tested:

1. Fleet containing only ICE vehicles;

2. Fleet containing only Hybrid vehicles;

3. Fleet containing only PHEVs;

4. Fleet containing only BEVs.

In financial terms, the results prove to be better when using a fleet with only ICE vehicles, that is, the lowest level group, as shown in Figure 5.21. This was awaited since, as these vehicles are cheaper than the other vehicle groups, it is possible to purchase more vehicles in this scenario compared to the others. It is then possible to accept more rental requests, as will be shown later. 


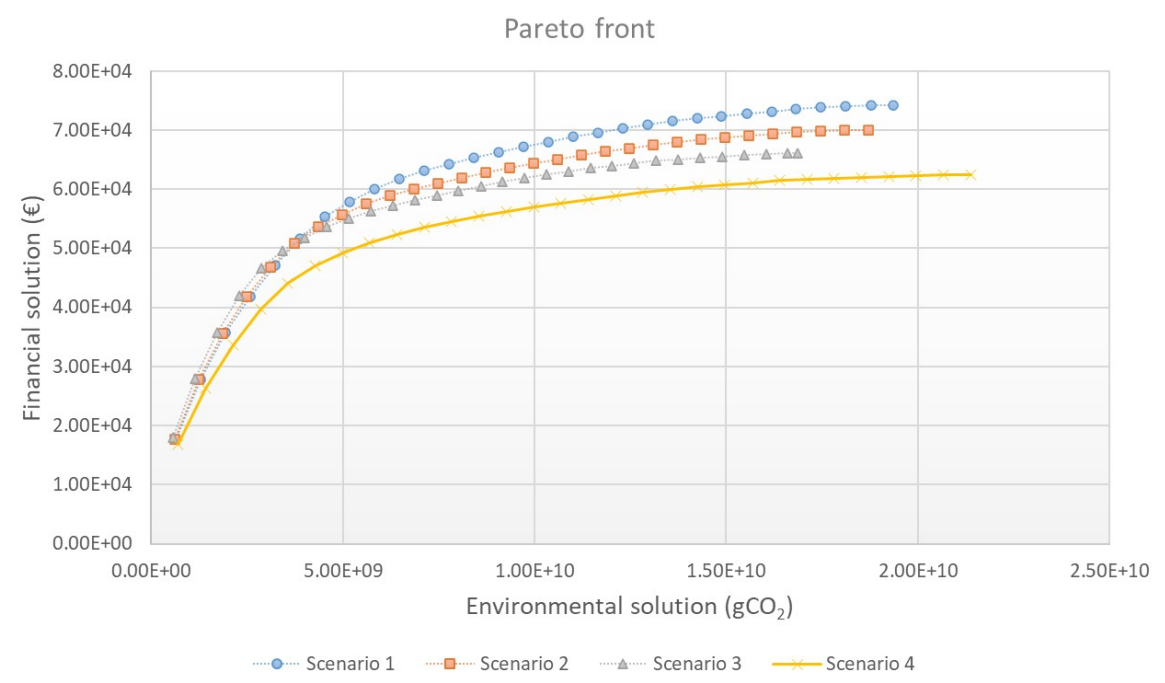

Figure 5.21: Homogeneous fleets: Pareto front

Analysing the revenues in Figure 5.22 and the acceptance rate in Figure 5.23, it is possible to conclude that revenues are higher in scenario 1 because, although ICE vehicles are cheaper (both for the company when buying them and for the customer when renting them), the purchase of vehicles by the company is highly limited by the available budget. More vehicles are bought and, therefore, it is possible to accept more rental requests, thus achieving a higher profit. It is also possible to lease vehicles - and that happens - but the model privileges the purchase of vehicles as it is more profitable, as will be further explained in this chapter.

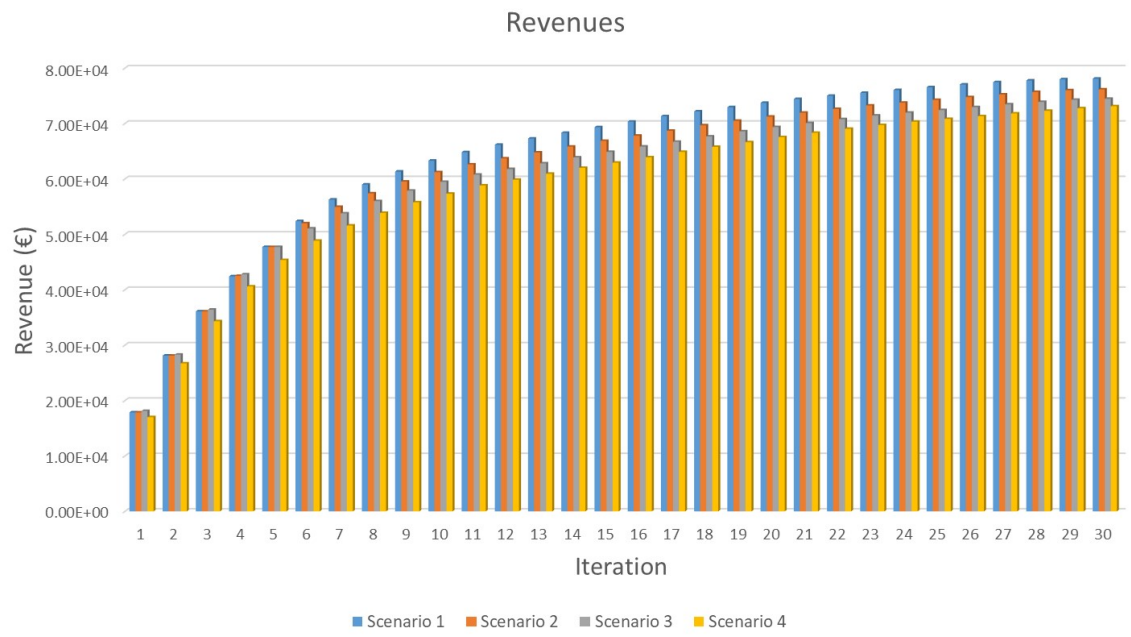

Figure 5.22: Homogeneous fleets: Revenues 


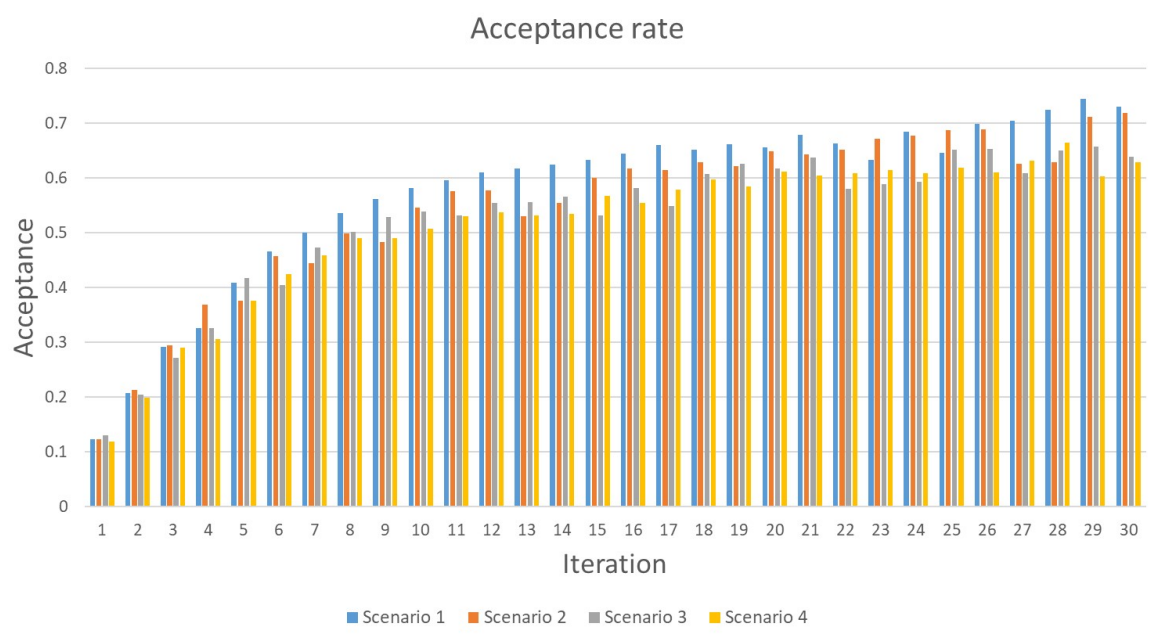

Figure 5.23: Homogeneous fleets: Acceptance rate

From an environmental point of view, scenario 4 (fleet containing only BEVs) proves to be more polluting, as shown in Figures 5.24 and 5.25. The horizontal axis in Figures 5.24 and 5.25 shows values in the interval $[1 ; 120]$ representing the 30 iterations performed in each of the scenarios, considering the scenarios in ascending order. The electricity generation emissions regard the average value of the World, therefore, this high value may justify these higher emissions verified in scenario 4, although fewer vehicles have been purchased. Donateo et al. also verified this fact, concluding that electric vehicles only become environmentally friendly if their energy comes from renewable or cleaner sources [14]. The estimation of the impact value per liter of fuel produced may also partly justify these differences.

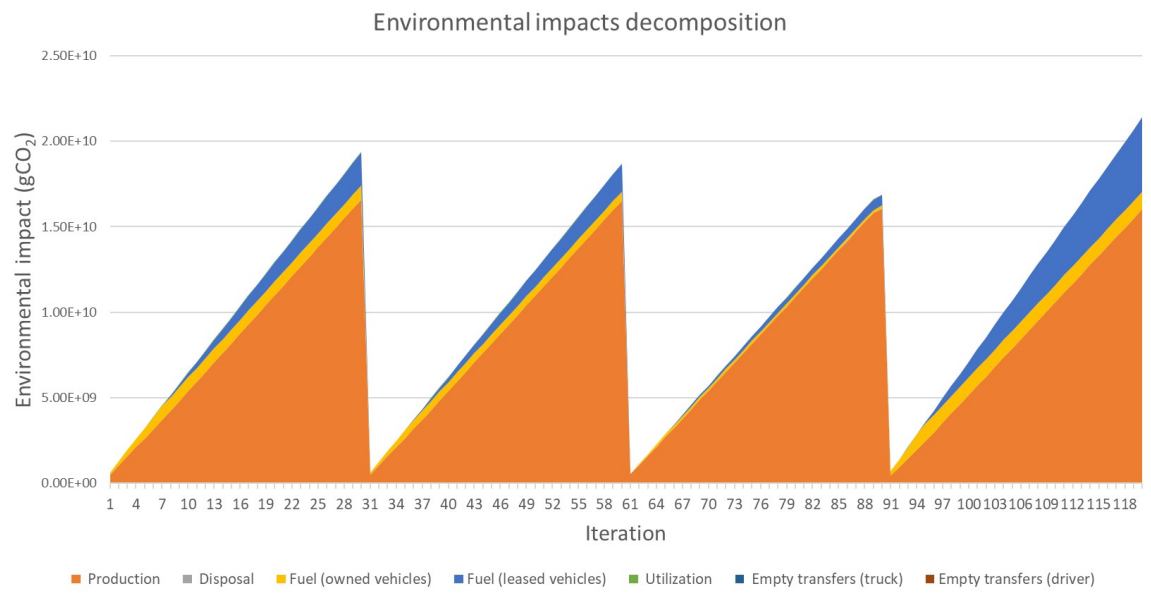

Figure 5.24: Homogeneous fleets: Environmental impacts decomposition 


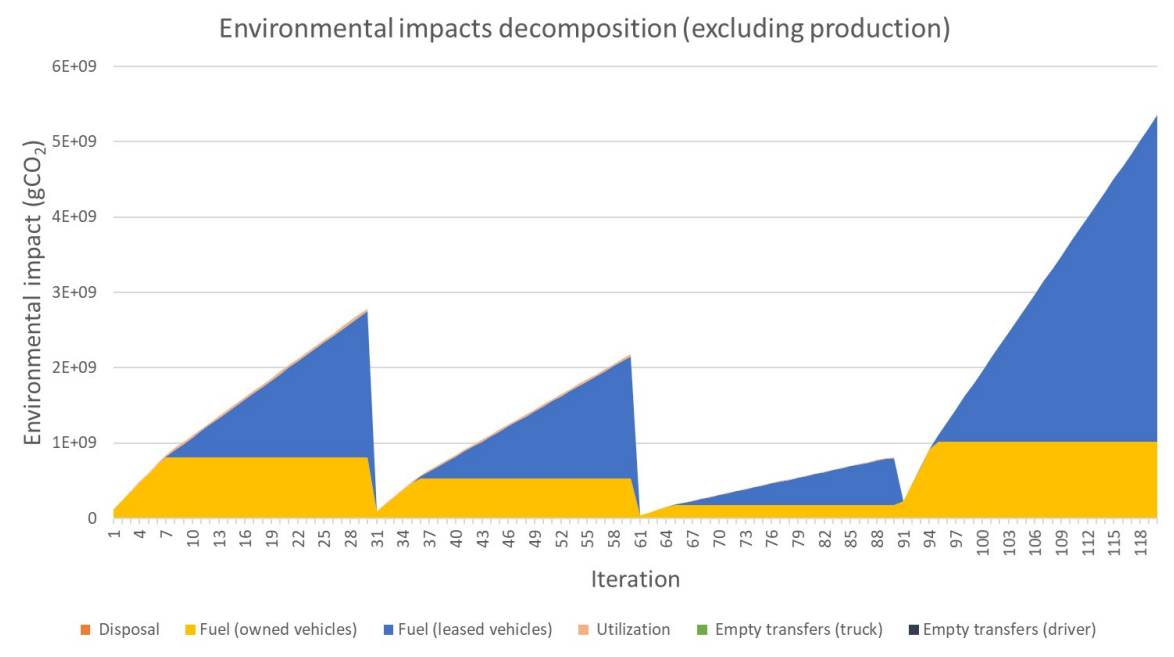

Figure 5.25: Homogeneous fleets: Environmental impacts decomposition (excluding production)

These tests sustain that the use of a homogeneous fleet containing only ICE vehicles is the most profitable from a financial point of view. Since ICE vehicles are the lowest group vehicle, they are also cheaper when comparing to the remaining vehicle groups. Therefore, there is a bigger capacity to buy more vehicles. Thus, more vehicles are purchased and, consequently, more rental requests are accepted. From an environmental standpoint, a fleet containing BEVs proves to be more polluting due to the high emission values of electricity production even though it is a smaller fleet when compared to the other scenarios.

\subsubsection{Total Demand Variation}

Demand plays an important role in this mathematical model as it is directly related to the price level chosen and thus influences revenues. Five scenarios are tested in this analysis:

1. Decrease in demand: $-40 \%$;

2. Decrease in demand: $-20 \%$;

3. Demand according to original instance's value;

4. Increase in demand: $+20 \%$;

5. Increase in demand: $+40 \%$.

Analysing the Pareto front in Figure 5.26, the results prove to be better, from a financial point of view, with higher demand since it leads to greater price levels chosen and thus revenues are also higher. 


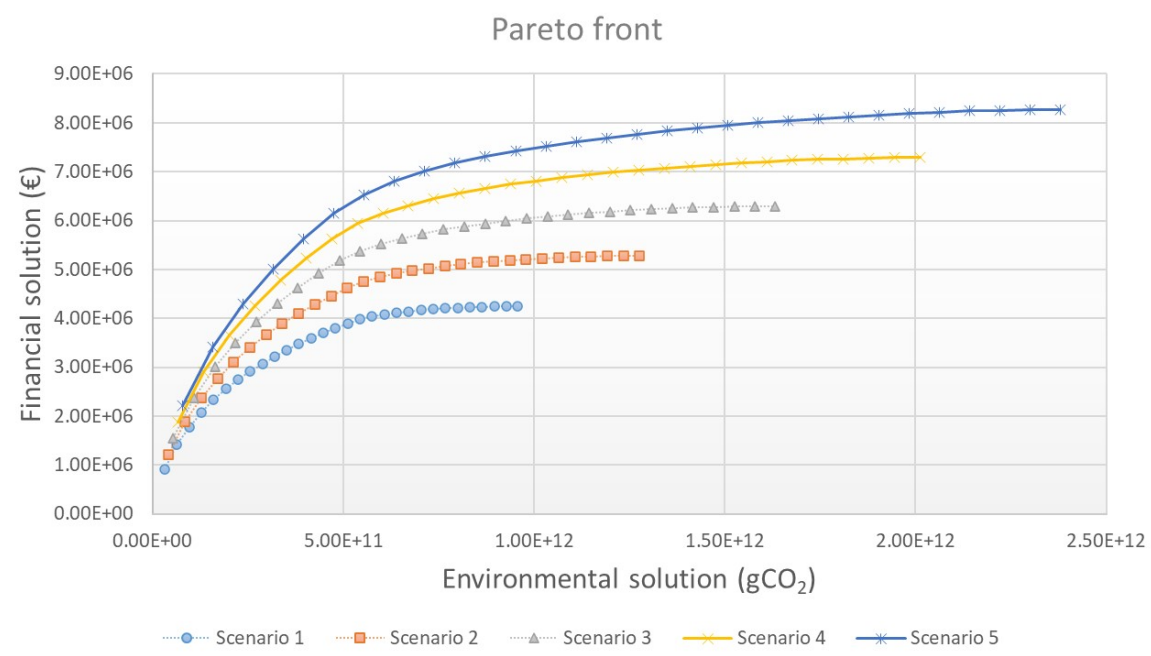

Figure 5.26: Total demand variation: Pareto front

Figure 5.27 shows that more rentals are accepted as demand increases. Even so, this increase in the number of accepted rental requests does not translate into a higher acceptance rate. In fact, in general, the acceptance of the rental is lower as demand increases, as shown in Figure 5.28. The justification for this is related to budget constraints. Due to the unavailability of more budget, the fleet size does not increase in the same way that the rental requests do, causing a lack of offer.

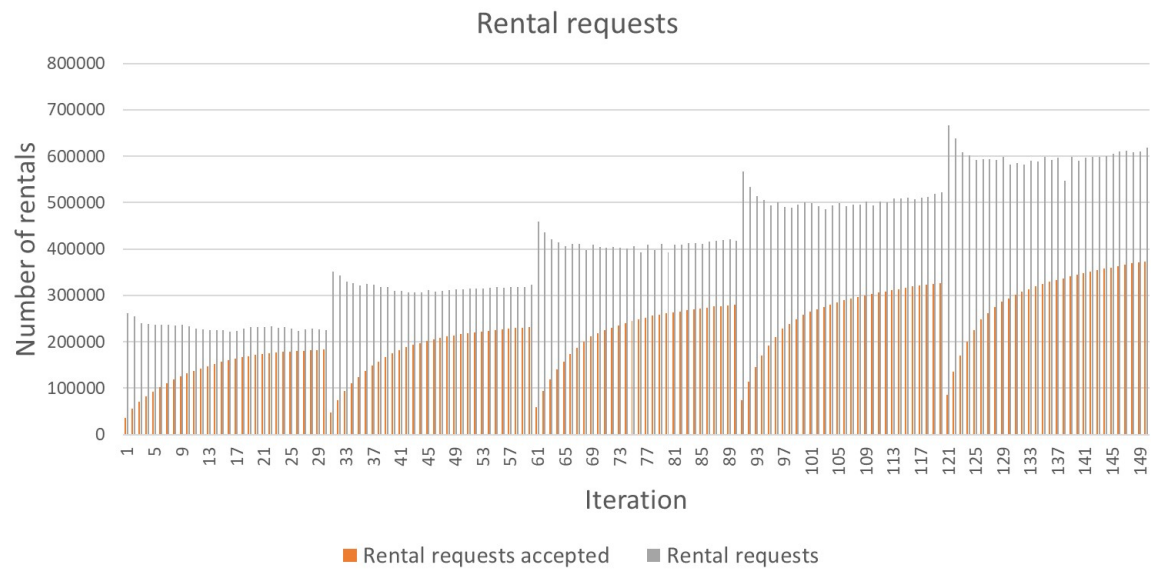

Figure 5.27: Total demand variation: Rental requests 


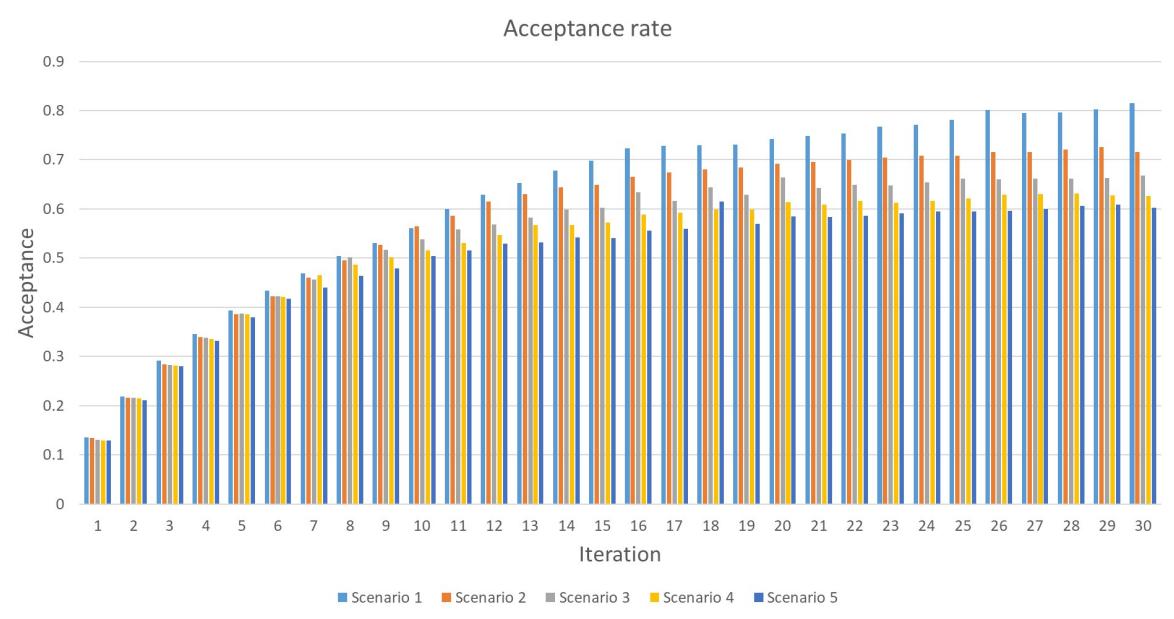

Figure 5.28: Total demand variation: Acceptance rate

Tables 5.10 and 5.11 represent the environmental and financial solutions obtained in the last iterations of each scenario, which aims to understand how a certain percentage change in demand influences financial and environmental results. It is possible to verify that the environmental solution deviation is the closest to the deviation in demand, although the financial results also follow this variation but not so precisely.

Table 5.10: Total demand variation: Emissions variation

\begin{tabular}{|c||cc|}
\hline Demand variation (\%) & Environmental solution $\left(\mathbf{g C O}_{2}\right)$ & Variation (\%) \\
\hline \hline-40 & $9.58 \mathrm{E}+11$ & -41.33 \\
-20 & $1.28 \mathrm{E}+12$ & -21.75 \\
- & $1.63 \mathrm{E}+12$ & - \\
+20 & $2.01 \mathrm{E}+12$ & +23.31 \\
+40 & $2.38 \mathrm{E}+12$ & +45.81 \\
\hline
\end{tabular}

Table 5.11: Total demand variation: Financial results variation

\begin{tabular}{|c||cc|}
\hline Demand variation (\%) & Financial solution (euros) & Variation (\%) \\
\hline \hline-40 & $4.24 \mathrm{E}+06$ & -32.59 \\
-20 & $5.29 \mathrm{E}+06$ & -16.04 \\
- & $6.29 \mathrm{E}+06$ & - \\
+20 & $7.29 \mathrm{E}+06$ & +15.80 \\
+40 & $8.28 \mathrm{E}+06$ & +31.47 \\
\hline
\end{tabular}

The tests carried out in this section show that the increase in demand leads to better financial results, as it influences the choice of higher price levels. The environmental impacts are higher 
when the demand increases since a greater number of rentals are performed, despite a lower acceptance rate. Both financial and environmental results tend to follow the variation in demand, although with a more straightforward impact in the environmental solution.

\subsubsection{Demand Variation by Group}

Unlike in the previous analyses, the variation in demand may not be uniform for all types of vehicles. Indeed, certain vehicles can be subjected to higher demand than others. Thus, in this test, scenarios were created representing increases in demand by vehicle group and not globally. The following scenarios are tested:

1. Demand according to original instance's value;

2. Increase in demand for BEVs: $+20 \%$;

3. Increase in demand for BEVs: $+40 \%$;

4. Increase in demand for PHEVs: $+20 \%$;

5. Increase in demand for PHEVs: $+40 \%$;

6. Increase in demand for Hybrid vehicles: $+20 \%$;

7. Increase in demand for Hybrid vehicles: $+40 \%$;

From a financial standpoint, the increase in demand for Hybrid vehicles proves to be more advantageous (Figure 5.29) since the financial solution is higher in scenario 7. These results are interesting since it was expected that the increase in demand for higher-class vehicles would lead to better financial results, as they are more expensive. However, the vehicle groups required are not homogeneous. Regardless of the type of vehicle, the increase in demand always leads to better financial results. 


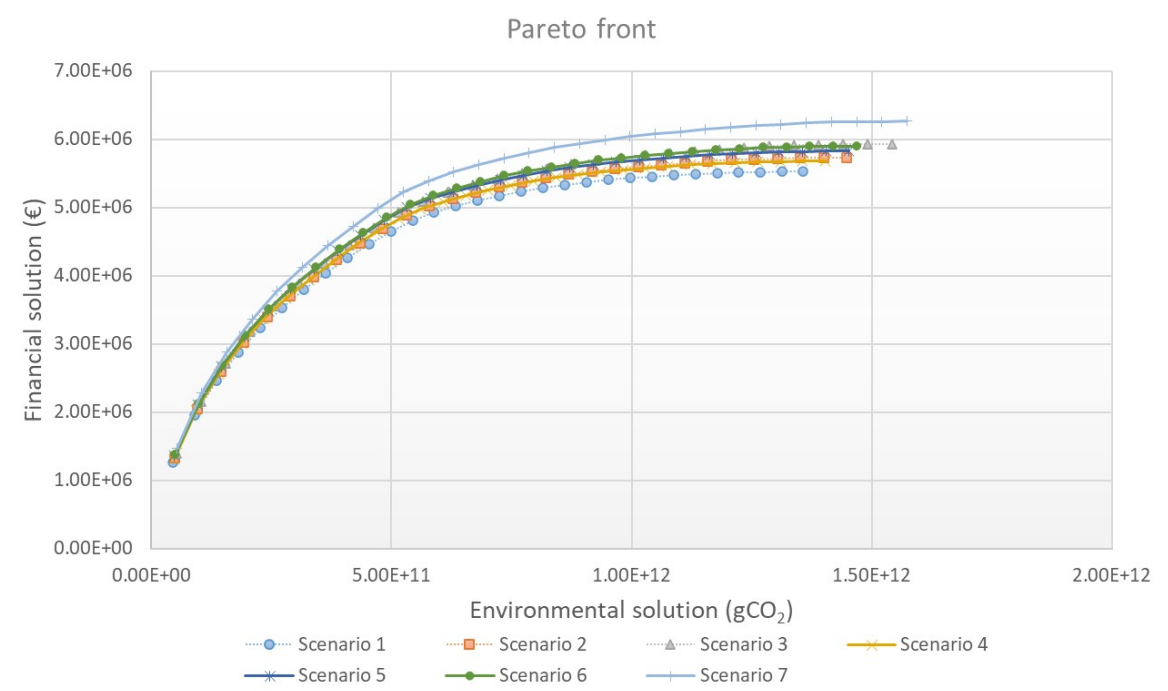

Figure 5.29: Demand variation by group: Pareto front

Figure 5.30 shows the vehicle groups required. Hybrid vehicles are the most requested and, thus, the increase in demand for this type of vehicle ends up being the most significant financially because it affects a greater number of rental requests.

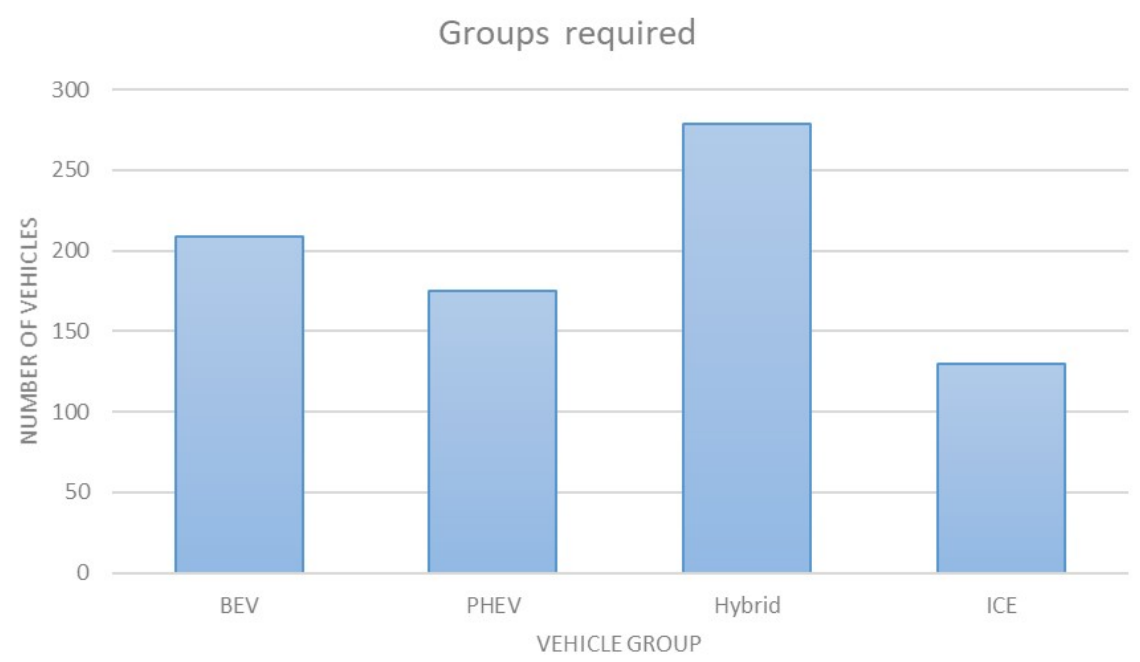

Figure 5.30: Demand variation by group: Groups required

Analysing Figures 5.31 and 5.32 it is possible to verify that emissions also increase according to the increase in demand. The impacts are always greater the greater the demand for a specific group of vehicles. The horizontal axis in Figures 5.31 and 5.32 shows the 30 iterations performed in each of the scenarios, considering the scenarios in ascending order. 


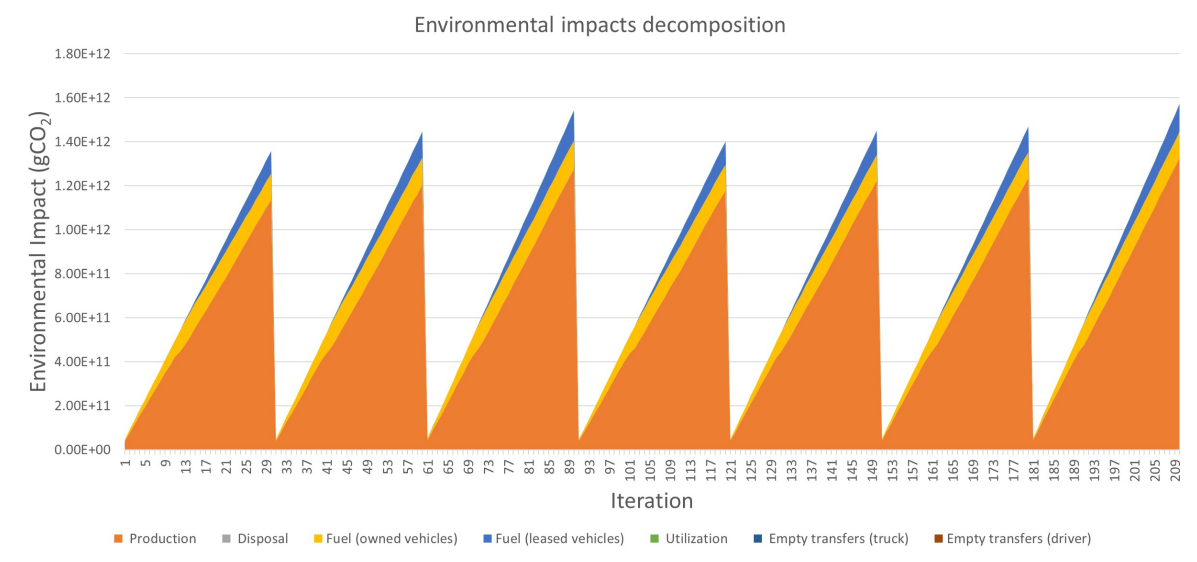

Figure 5.31: Demand variation by group: Environmental impacts decomposition

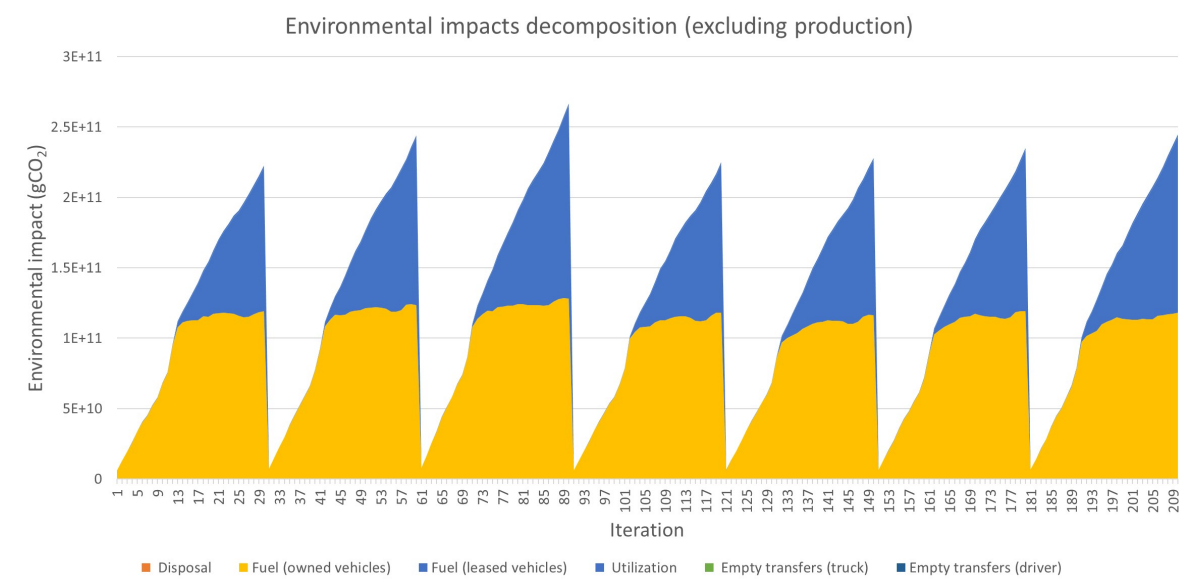

Figure 5.32: Demand variation by group: Environmental impacts decomposition (excluding production)

This analysis shows that demand influences financial results in a positive way (greater demand for a certain type of vehicle leads to better financial results being achieved). The financial results emerging from the increase in demand for a certain group of vehicles are influenced by the distribution of preferences for the required vehicle groups. In this analysis, the financial results were better when greater demand occurred in Hybrid vehicles since these were already the most required group in rental requests. Therefore, the increase in demand ends up affecting a greater number of effective requests.

\subsubsection{Market Competition}

One of the most important decisions in this business is related to price setting. Its increase or decrease can be quite decisive in the financial results of a company since a very high price can drive customers away and a very low price may not be profitable. Thus, this analysis aims to study 
the effect on revenues and the respective environmental impacts of increasing or decreasing prices. Three scenarios are tested:

1. Decrease in prices: $-10 \%$;

2. Prices according to original instance's values;

3. Increase in prices: $+10 \%$.

Analysing the Pareto front in Figure 5.33 and the data in Table 5.12, it is possible to conclude that this increase/decrease in prices has an approximately linear effect on financial results. The data in Table 5.12 regards the last iteration of each scenario. Moreover, in all scenarios and for the same environmental solution, the financial results prove to be better the higher the prices. This is expected since, as prices are higher, fewer rentals will be needed to achieve the same profit that would be achieved with lower prices. The fulfillment of fewer rentals then leads to a reduction in environmental impacts, concerning the same financial result.

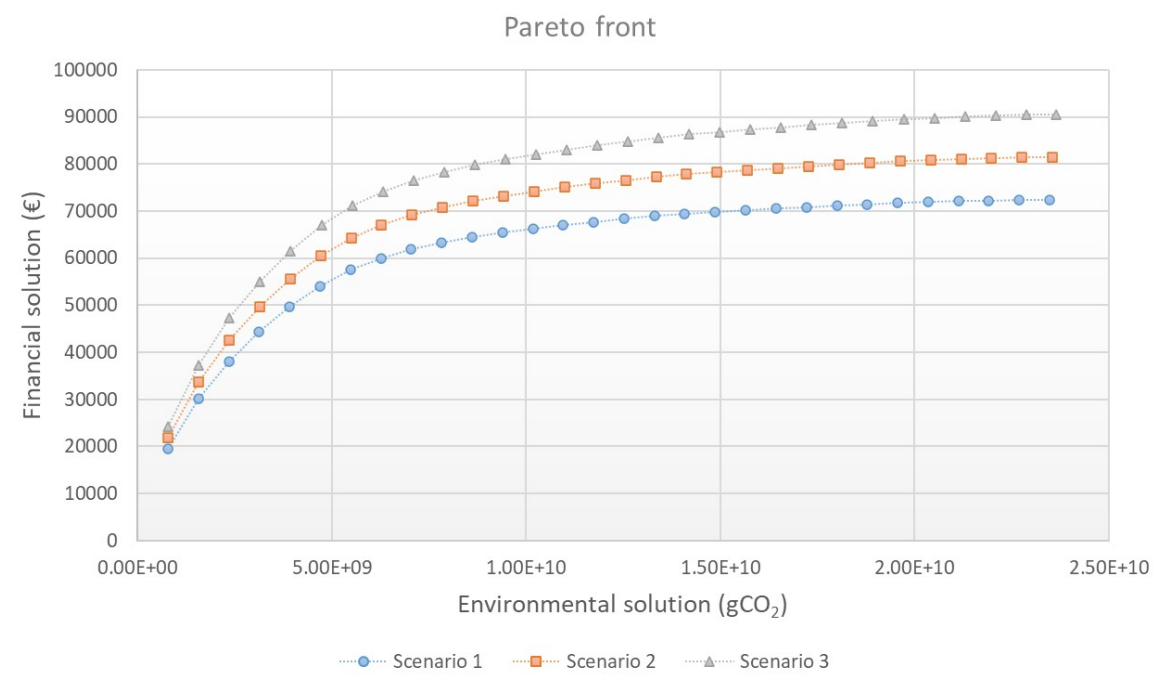

Figure 5.33: Market competition: Pareto front

Table 5.12: Financial results variations

\begin{tabular}{|c||cc|}
\hline Scenarios & Financial solution (Euros) & Variation (\%) \\
\hline \hline 1 & 72319.30 & -11.51 \\
2 & 81395.60 & - \\
3 & 90477.50 & +11.16 \\
\hline
\end{tabular}

Analysing the financial component more deeply, it is also concluded that this increase in profit is linked to the increase in revenues (Figure 5.34) since costs remain constant, as shown in Figure 5.35. The horizontal axis in Figure 5.35 shows the 30 iterations performed in each of the scenarios, considering the scenarios in ascending order. 


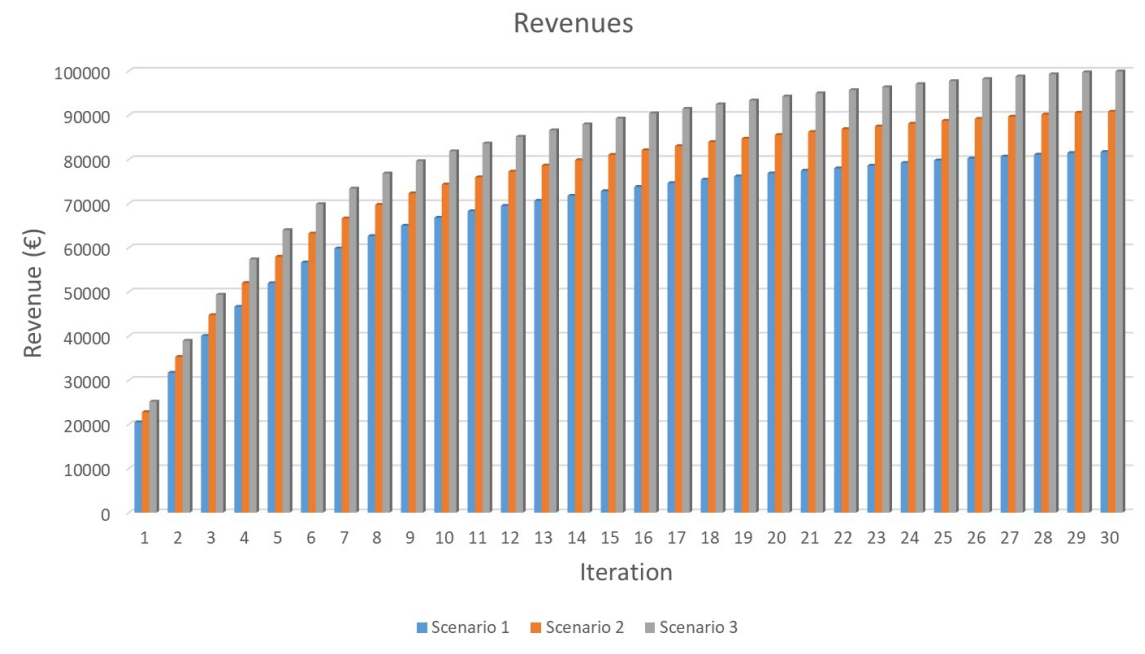

Figure 5.34: Market competition: Revenues

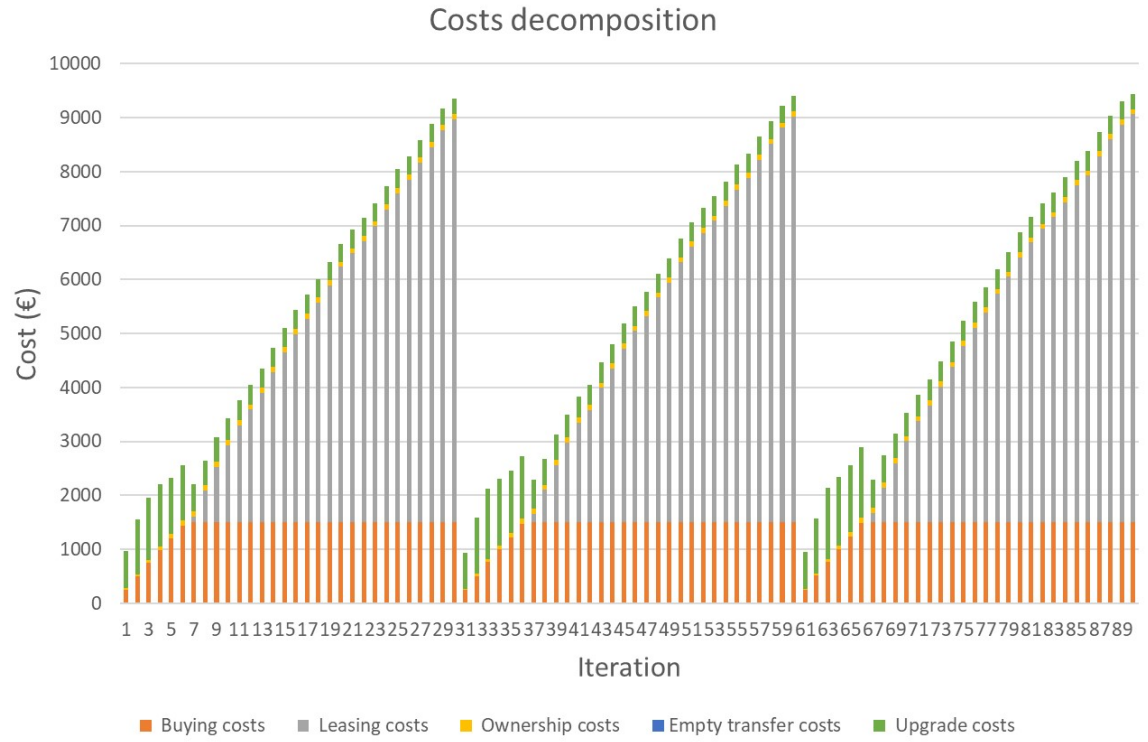

Figure 5.35: Market competition: Costs decomposition

The analysis of the price variation shows that the financial results tend to follow the same variation of the price. This similar variation occurred because the demand was maintained and this led to a similar number of accepted rentals - Figure 5.36. The horizontal axis in Figure 5.36 shows the 30 iterations performed in each of the scenarios, considering the scenarios in ascending order. 


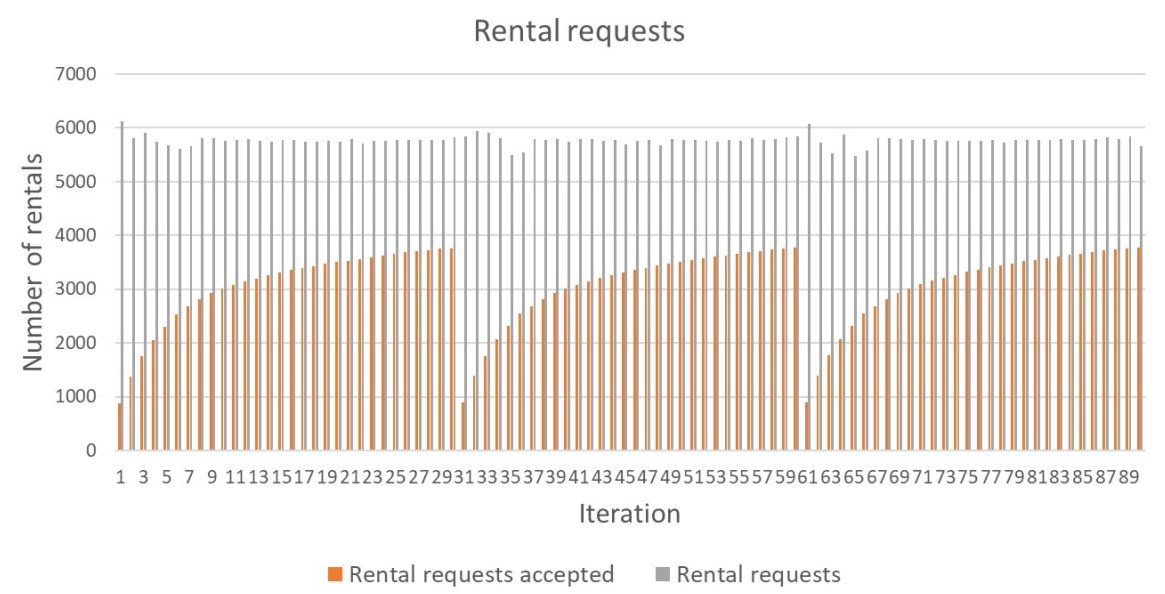

Figure 5.36: Market competition: Rental requests

In this analysis, the variation was small $(+/-10 \%)$ and this may have been relevant in the proportional increase in profits. If the price increase was higher, demand would be expected to be lower and the financial results would not follow the price increase the same way.

\subsubsection{Available Budget}

The available budget is a significant factor in any business and has been critical in most of the previous analyses. Especially in the car rental capacity-pricing problem, the greater or lesser capacity of a company to buy assets can be quite decisive in the financial profitability of the same company. Thus, to test the influence of the budget, several scenarios are tested:

1. Lower budget (original budget $\times 0.5$ );

2. Budget according to original instance's value;

3. Higher budget (original budget $\times 2$ );

4. Higher budget (original budget $\times 3$ );

5. Hypothetical infinite budget (original budget $\times 100$ ).

Analysing the Pareto front in Figure 5.37, a positive correlation between the initial available budget and the financial results is significant. From an environmental standpoint, the results prove to be better, regarding the same financial result, the larger the available budget. Considering the last iteration of each scenario, the environmental result is very similar in all scenarios except the last one, which aims to represent a hypothetical infinite budget situation. 


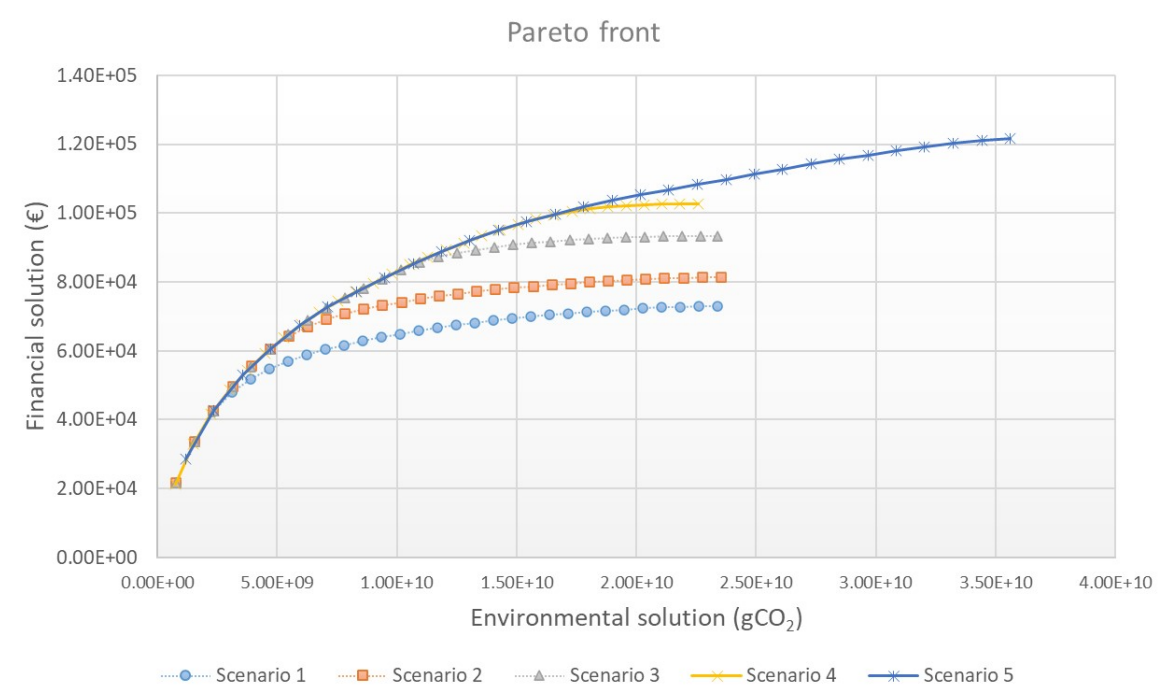

Figure 5.37: Available budget: Pareto front

After a deeper look at the financial component, it is possible to see that, in general, revenues increase when the available budget is higher, which means that more rental requests have been accepted - Figure 5.38. Analysing the costs decomposition in Figure 5.39, they are successively lower, except in the last scenario. Even so, there is a common factor in all scenarios: the model gives preference to the purchase of vehicles and only then leases to fill the lack of fleet and thus fulfill more rental requests. This is precisely the reason that leads to cost reduction over scenarios 1, 2, 3, and 4. The budget increases and allows the model to buy more vehicles. The larger own fleet vehicles allow more rental requests to be accepted but, at the same time, allow a reduction in costs since ownership costs are lower than the leasing ones.

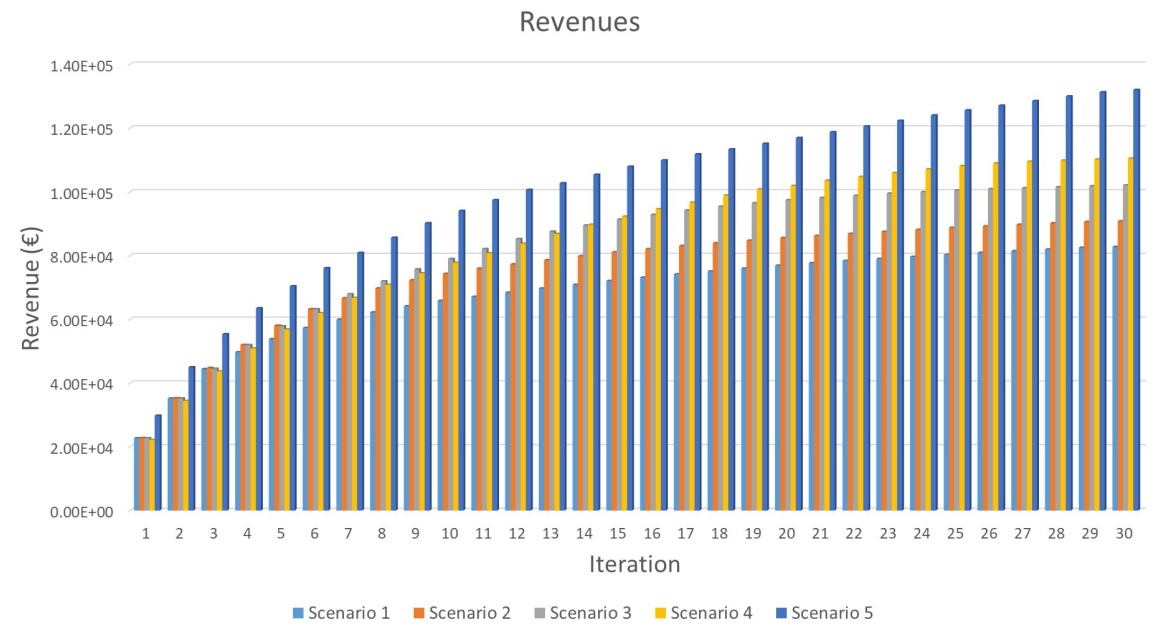

Figure 5.38: Available budget: Revenues 
The horizontal axis in Figures 5.39, 5.40 and 5.41 shows the 30 iterations performed in each of the scenarios, considering the scenarios in ascending order.

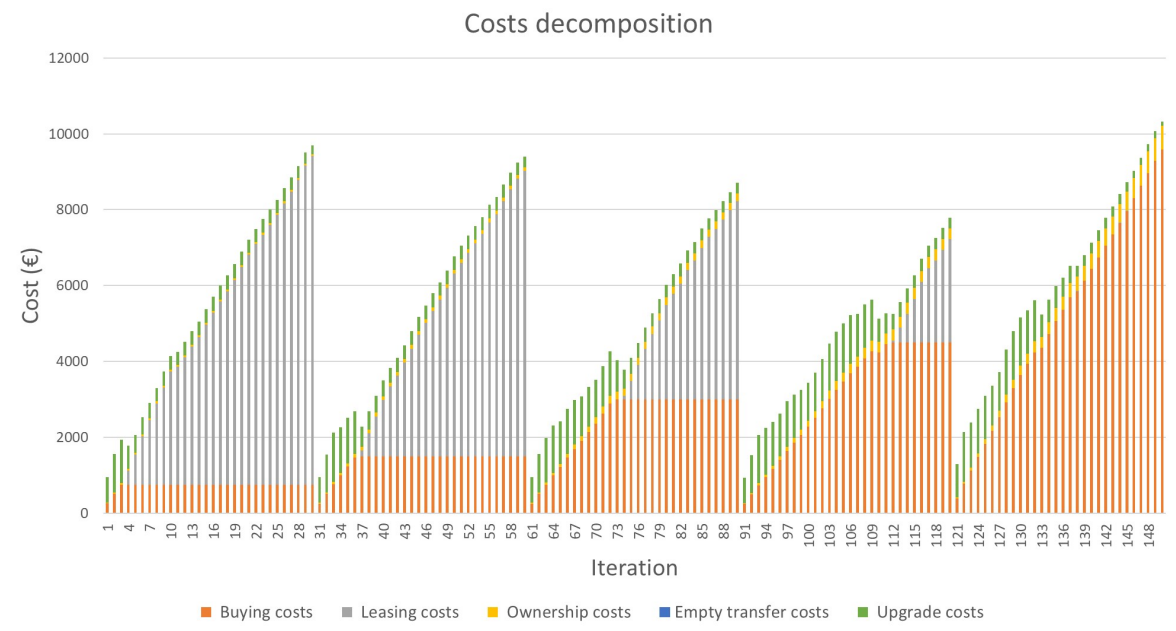

Figure 5.39: Available budget: Costs decomposition

The use of leased vehicles is practically residual in scenario 5 - Figure 5.40. It still occurs because, despite having a higher budget to spend, a greater demand in a specific peak may not justify the purchase of vehicles since it implies ownership costs throughout all time horizon and a high one-time cost.

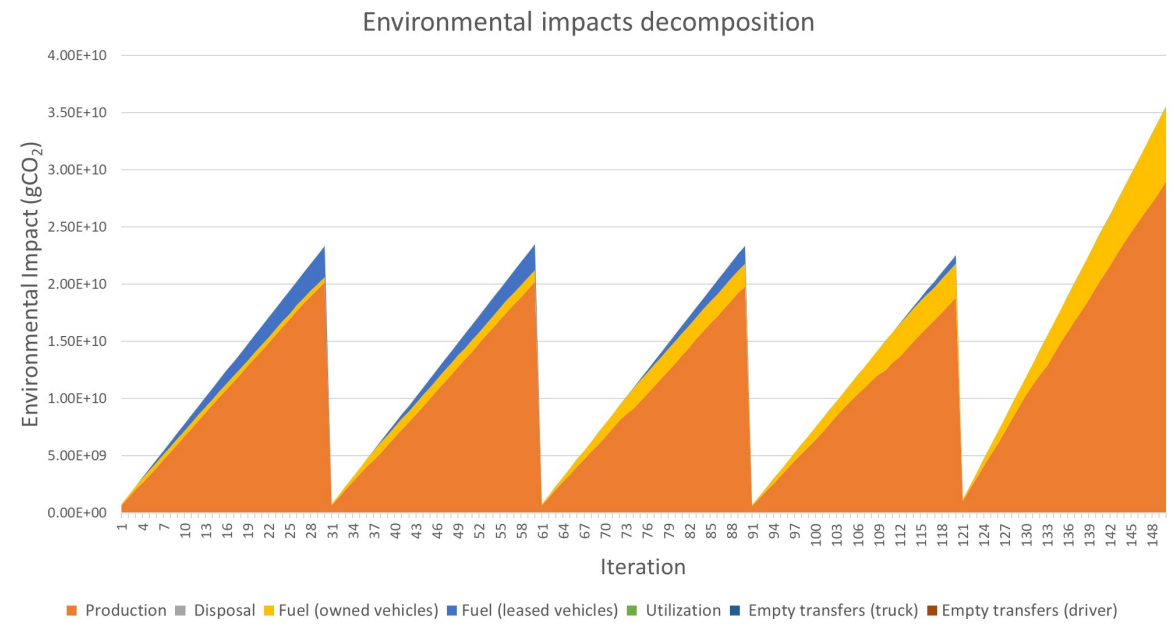

Figure 5.40: Available budget: Environmental impacts decomposition

It is also in the last scenario that the model has the highest environmental impact values, justified by a greater capacity to purchase vehicles and the resulting receptivity to comply with rental requests. In fact, in the last scenario, $100 \%$ of rental requests are fulfilled, a unique case in all tests performed - Figure 5.41. 


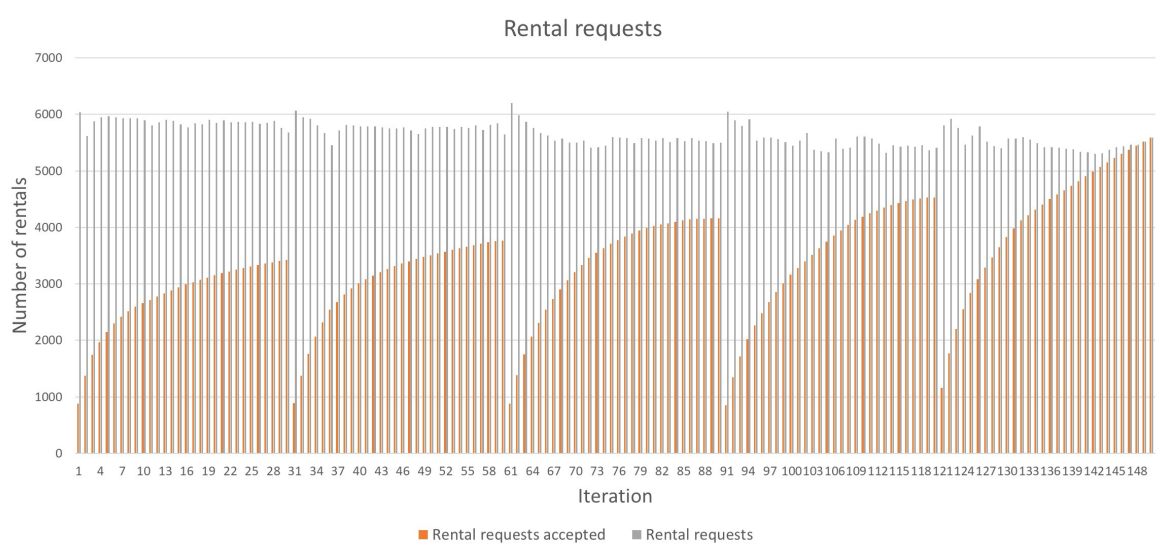

Figure 5.41: Available budget: Rental requests

The tests carried out considering different budgets conclude that the financial results are better the larger the budget available. This happens because, with a larger budget available, the model favors the purchase of more vehicles rather than leasing them. Buying vehicles prove to be more financially lucrative and thus, the profits obtained are greater. The environmental impact is considerably higher in scenario 5, allowing to conclude that it depends essentially on the size of the fleet and not so much on the operational optimization that can be made of its use.

\subsection{Summary}

Throughout this chapter, several topics were covered with a special focus on the conclusions and insights retrieved from the analyses performed. However, before analysing the results, it was important to understand what input data was used in the model - the instances - as well as how this data was handled - the method. To do so, rental request analyses were performed for all the considered instances. The analyses conclude that the rental requests are preferably shortterm as the check-out time period is highly concentrated at the beginning of the time horizon. Then, the methodological tests were performed. The use of the epsilon constraint method with a financial function as an objective function and an environmental function as a constraint was defined. Furthermore, an epsilon size of 30 was also established.

Finally, all the analysis tests performed and respective results were discussed. Firstly, incentives for using electric vehicles did not translate into an effective decrease in $\mathrm{CO}_{2}$ emissions. At the same time, the source of electrical energy proved to be significant in the environmental results due to its strong correlation with the production phase of the vehicle. Moreover, the increased impact of disposal on electric vehicles has not been shown to affect the financial results obtained. For the same environmental solution value, the financial result was lower the greater the impact of disposal, as the model avoids the purchase of electric vehicles and redirects the available budget for the purchase of other vehicle groups. However, in the final iterations of each scenario, where the relaxation of the environmental constraint is greater, the model did not restrict the purchase of 
electric vehicles, therefore, all scenarios obtained very similar financial results. The use of electric vehicles has proven that a reduction in environmental impacts is only achieved if the source of electricity is renewable or cleaner.

From a more managerial standpoint, it is verified that the model results tend to follow changes in demand: from an environmental point of view, it follows these changes in a very similar way (a $40 \%$ decrease in demand leads to a $41.33 \%$ decrease in the environmental results) and from a financial point of view, this variation is not so linear but it is also relevant (a $40 \%$ decrease in demand leads to a $32.59 \%$ decrease in financial results). When considering a variation in demand by vehicle groups, it is highly linked to the distribution of the percentages of vehicles required by rental requests, which is an intrinsic characteristic of the instances. Moreover, the price variation proved to have an almost linear influence on financial results (an increase of $10 \%$ in prices leads to an increase of $11.16 \%$ in profits) showing that the prices currently set in the instances can be increased (at least by $10 \%$ ) without causing a decrease in demand. Finally, the available budget proved to be crucial in the financial results, since the larger the budget, the greater the profit achieved. This test proved the model's predisposition to buy vehicles instead of leasing, although leasing also occurs on a residual basis. Furthermore, only with a hypothetically infinite budget, the model proved to be able to accept all rental requests.

These analyses also proved that empty transfers are not very common, as already mentioned in the literature review. Finally, it was possible to conclude that all Pareto fronts have the same behavior: higher growth at the beginning with asymptotic growth at the final stage. That is, in the final stage of all Pareto curves, its derivative is lower and tends to zero. Thus, profit increases little even though with a significant increase regarding the emissions. Analysing all the Pareto fronts studied, it is possible to conclude that, on average, with a decrease of $16.10 \%$ of the financial results, it is possible to obtain a decrease of $65.33 \%$ in $\mathrm{CO}_{2}$ emissions.

All conclusions drawn are based on the model implemented and are therefore limited to the model's limitations. No model is a perfect reflection of reality. Nevertheless, they can be very useful for drawing conclusions that are useful and applicable to real situations. 


\section{Chapter 6}

\section{Conclusions and Future Work}

In this work, environmental concerns were incorporated into a mathematical model related to the capacity-pricing problem in the car rental business, resulting in a bi-objective model. The Life Cycle Assessment method was applied not only to vehicles but also to fuel, to define environmental parameters and the corresponding objective. Four types of vehicles were considered: internal combustion engine vehicles, hybrids, hybrids plug-in, and electric vehicles. Several methods of solving multi-objective problems were addressed and the epsilon constraint method is developed and applied to this problem and to the bi-objective mathematical model. The results obtained allowed us to conclude that the source of electric energy is significant in environmental results. In addition to this, environmental and financial results tend to follow changes in demand and a small variation in prices influences financial results almost linearly. The available budget proves to be crucial in the model's capacity to accept rental requests while environmental results depend essentially on the size of the fleet. Moreover, the results show a predisposition to buy vehicles instead of resorting to its leasing, while empty transfers are not very common.

Analysing the environmental impacts obtained in all the tests carried out, it is possible to conclude the emissions related to the use of the vehicles is always practically negligible when compared with the production or the impacts of the fuel. This is due to the relatively short time horizon considered - 12 time units. Thus, the increase in the time horizon, although it may lead to a higher computational effort required, will also lead to more consistent results.

Another important guideline regarding future work is related to the gases considered. $\mathrm{CO}_{2}$ is the main gas emitted when considering the transport sector, but other gases should be the focus of attention and concern as well. Nitrous oxide $\left(\mathrm{N}_{2} \mathrm{O}\right)$ is dangerous to human health. Moreover, it is responsible for acid rain that also affects agriculture [15]. Each greenhouse gas has a global warming potential (GWP) different over different time horizons. It is a measure of how much energy the emissions of 1 ton of a gas will absorb over a given period of time, relative to the emissions of 1 ton of carbon dioxide $\mathrm{CO}_{2}$. Table 6.1 shows the GWP of some greenhouse gases. It is possible to verify that the $\mathrm{N}_{2} \mathrm{O}$ has a 100 -year GWP of 298 while $\mathrm{CO}_{2}$ has a 100 -year GWP of 1 . 
Table 6.1: GHGs global warming potential [21]

\begin{tabular}{|c||c|}
\hline Greenhouse Gas & 100-year GWP \\
\hline \hline Carbon dioxide $\left(\mathrm{CO}_{2}\right)$ & 1 \\
Methane $\left(\mathrm{CH}_{4}\right)$ & 25 \\
Nitrous oxide $\left(\mathrm{N}_{2} \mathrm{O}\right)$ & 298 \\
\hline
\end{tabular}

Table 6.2 contains the emissions associated with fuel combustion, over $100 \mathrm{~km}$, considering a petrol car with a consumption of $5.87 \mathrm{~kg} \mathrm{1} / 100 \mathrm{~km}$. Analysing the table, it is possible to notice that emissions related to carbon dioxide represent the largest percentage of emissions while all others are almost negligible.

Table 6.2: Emissions associated with fuel combustion, over $100 \mathrm{~km}$ [33]

\begin{tabular}{|c||c|}
\hline Substance & Quantity (kg) \\
\hline \hline Carbon dioxide $\left(\mathrm{CO}_{2}\right)$ & 20 \\
Carbon monoxide $(\mathrm{CO})$ & 0.58 \\
Nitrous oxide $\left(\mathrm{N}_{2} \mathrm{O}\right)$ & 0.004 \\
Sulfur dioxide $\left(\mathrm{SO}_{2}\right)$ & 0.0029 \\
Nitrogen oxide $(\mathrm{NOx})$ & 0.13 \\
Soot & 0.0014 \\
Volatile organic compound (VOC) & 0.083 \\
\hline
\end{tabular}

Table 6.2 shows that $\mathrm{N}_{2} \mathrm{O}$ emissions are much lower than $\mathrm{CO}_{2}$ emissions. However, combining the data from the two tables, it is possible to verify that, even though $\mathrm{N}_{2} \mathrm{O}$ emissions are low, they end up being relevant. For example, by multiplying the emissions in Table 6.2 with the GWP in Table 6.1, we obtain the following:

Table 6.3: Multiplication of GWP by the emissions

\begin{tabular}{|c||ccc|}
\hline Substance & Quantity $(\mathbf{k g})$ & 100-year GWP & Quantity $(\mathbf{k g}) \times$ 100-year GWP \\
\hline \hline Carbon dioxide $\left(\mathrm{CO}_{2}\right)$ & 20 & 1 & 20 \\
Nitrous oxide $\left(\mathrm{N}_{2} \mathrm{O}\right)$ & 0.004 & 298 & 1.192 \\
\hline
\end{tabular}

Table 6.3 shows that emissions may seem negligible at the outset but can prove to be quite important when considering the GWP. Therefore, if global emissions are analysed also considering the GWP, the calculation of environmental impacts will be more realistic and will lead to more consistent analyses and results.

Finally, the last guideline for future work is related to the method used. Testing NSGA-II, one of the most recognized genetic algorithms and the most complex model of all addressed in the literature review, can be interesting to validate the results of the epsilon constraint method. 


\section{Appendix A}

\section{Methodological Tests Results}

In this appendix, the tables with the detailed results of the methodological tests are presented.

Table A.1 contains the general information of the instances used in both tests and the number of iterations that will be used in each one.

Tables A.2 and A.3 contain the results of epsilon constraint with objective financial function, while Table A. 4 contains the results of epsilon constraint with environmental objective function. 
Table A.1: Instances data and number of iterations tested

\begin{tabular}{|c|c|c|c|c|c|}
\hline Instance & Rentals & Groups & $(\mathbf{R} \times \mathbf{G})$ & Scale factor & Iterations \\
\hline 30 & 428 & 1 & 428 & 1 & 20 \\
\hline 31 & 428 & 1 & 428 & 100 & 25 \\
\hline 38 & 486 & 1 & 486 & 1 & 30 \\
\hline 39 & 486 & 1 & 486 & 100 & 35 \\
\hline 24 & 517 & 1 & 517 & 1 & 40 \\
\hline 25 & 517 & 1 & 517 & 100 & 45 \\
\hline 26 & 562 & 2 & 1124 & 1 & 15 \\
\hline 27 & 562 & 2 & 1124 & 100 & 20 \\
\hline 34 & 572 & 2 & 1144 & 1 & 25 \\
\hline 35 & 572 & 2 & 1144 & 100 & 30 \\
\hline 42 & 831 & 3 & 2493 & 1 & 10 \\
\hline 43 & 831 & 3 & 2493 & 100 & 15 \\
\hline 32 & 865 & 3 & 2595 & 1 & 20 \\
\hline 33 & 865 & 3 & 2595 & 100 & 25 \\
\hline 40 & 922 & 3 & 2766 & 1 & 30 \\
\hline 41 & 922 & 3 & 2766 & 100 & 30 \\
\hline 16 & 924 & 3 & 2772 & 1 & 35 \\
\hline 17 & 924 & 3 & 2772 & 100 & 35 \\
\hline 04 & 564 & 5 & 2820 & 1 & 15 \\
\hline 05 & 564 & 5 & 2820 & 100 & 20 \\
\hline 08 & 948 & 3 & 2844 & 1 & 40 \\
\hline 09 & 948 & 3 & 2844 & 100 & 40 \\
\hline 10 & 724 & 4 & 2896 & 1 & 10 \\
\hline 11 & 724 & 4 & 2896 & 100 & 15 \\
\hline 28 & 742 & 4 & 2968 & 1 & 15 \\
\hline 29 & 742 & 4 & 2968 & 100 & 20 \\
\hline 12 & 793 & 4 & 3172 & 1 & 20 \\
\hline 13 & 793 & 4 & 3172 & 100 & 25 \\
\hline 36 & 1046 & 4 & 4184 & 1 & 30 \\
\hline 37 & 1046 & 4 & 4184 & 100 & 30 \\
\hline 20 & 1141 & 4 & 4564 & 1 & 35 \\
\hline 21 & 1141 & 4 & 4564 & 100 & 40 \\
\hline 22 & 933 & 5 & 4665 & 1 & 25 \\
\hline 23 & 933 & 5 & 4665 & 100 & 30 \\
\hline 18 & 1182 & 4 & 4728 & 1 & 45 \\
\hline 19 & 1182 & 4 & 4728 & 100 & 45 \\
\hline 06 & 1234 & 5 & 6170 & 1 & 35 \\
\hline 07 & 1234 & 5 & 6170 & 100 & 40 \\
\hline
\end{tabular}


Table A.2: Epsilon constraint method - financial objective function results (1)

\begin{tabular}{|c|c|c|c|c|}
\hline Instance & Avg. iteration time (sec) & Total Time (sec) & Optimal & Optimal values (\%) \\
\hline 30 & 298 & 5950 & 11 & 55.00 \\
\hline 31 & 17 & 431 & 25 & 100.00 \\
\hline 38 & 395 & 11848 & 12 & 40.00 \\
\hline 39 & 19 & 681 & 35 & 100.00 \\
\hline 24 & 289 & 11545 & 23 & 57.50 \\
\hline 25 & 35 & 1561 & 45 & 100.00 \\
\hline 26 & 273 & 4099 & 10 & 66.67 \\
\hline 27 & 47 & 948 & 20 & 100.00 \\
\hline 34 & 261 & 6531 & 18 & 72.00 \\
\hline 35 & 47 & 1411 & 30 & 100.00 \\
\hline 42 & 406 & 4057 & 6 & 60.00 \\
\hline 43 & 319 & 4779 & 12 & 80.00 \\
\hline 32 & 412 & 8244 & 14 & 70.00 \\
\hline 33 & 153 & 3837 & 25 & 100.00 \\
\hline 40 & 504 & 15112 & 19 & 63.33 \\
\hline 41 & 184 & 5518 & 28 & 93.33 \\
\hline 16 & 337 & 11783 & 30 & 85.71 \\
\hline 17 & 161 & 5646 & 34 & 97.14 \\
\hline 04 & 483 & 7241 & 6 & 40.00 \\
\hline 05 & 169 & 3372 & 18 & 90.00 \\
\hline 08 & 475 & 18989 & 26 & 65.00 \\
\hline 09 & 297 & 11886 & 35 & 87.50 \\
\hline 10 & 513 & 5127 & 4 & 40.00 \\
\hline 11 & 119 & 1791 & 15 & 100.00 \\
\hline 28 & 496 & 7443 & 9 & 60.00 \\
\hline 29 & 240 & 4797 & 19 & 95.00 \\
\hline 12 & 481 & 9614 & 10 & 50.00 \\
\hline 13 & 189 & 4720 & 24 & 96.00 \\
\hline 36 & 603 & 18096 & 1 & 3.33 \\
\hline 37 & 293 & 8777 & 26 & 86.67 \\
\hline 20 & 602 & 21069 & 1 & 2.86 \\
\hline 21 & 310 & 12416 & 35 & 87.50 \\
\hline 22 & 574 & 14343 & 3 & 12.00 \\
\hline 23 & 300 & 9007 & 27 & 90.00 \\
\hline 18 & 589 & 26498 & 3 & 6.67 \\
\hline 19 & 407 & 18302 & 31 & 68.89 \\
\hline 06 & 597 & 20879 & 2 & 5.71 \\
\hline 07 & 493 & 19701 & 17 & 42.50 \\
\hline
\end{tabular}


Table A.3: Epsilon constraint method - financial objective function results (2)

\begin{tabular}{|c|c|c|c|}
\hline Instance & Avg. gap (\%) & Non optimal & Non optimal avg. gap (\%) \\
\hline 30 & 0.000396 & 9 & 0.000767 \\
\hline 31 & 0.000087 & 0 & - \\
\hline 38 & 0.000273 & 18 & 0.000399 \\
\hline 39 & 0.000089 & 0 & - \\
\hline 24 & 0.000308 & 17 & 0.000598 \\
\hline 25 & 0.000088 & 0 & - \\
\hline 26 & 0.000144 & 5 & 0.000273 \\
\hline 27 & 0.000091 & 0 & - \\
\hline 34 & 0.000186 & 7 & 0.000415 \\
\hline 35 & 0.000083 & 0 & - \\
\hline 42 & 0.000118 & 4 & 0.000163 \\
\hline 43 & 0.000091 & 3 & 0.000159 \\
\hline 32 & 0.000195 & 6 & 0.000426 \\
\hline 33 & 0.000089 & 0 & - \\
\hline 40 & 0.000221 & 11 & 0.000449 \\
\hline 41 & 0.000092 & 2 & 0.000185 \\
\hline 16 & 0.000118 & 5 & 0.000281 \\
\hline 17 & 0.000098 & 1 & 0.000268 \\
\hline 04 & 0.000523 & 9 & 0.000816 \\
\hline 05 & 0.000102 & 2 & 0.000200 \\
\hline 08 & 0.000132 & 14 & 0.000205 \\
\hline 09 & 0.000096 & 5 & 0.000124 \\
\hline 10 & 0.000205 & 6 & 0.000278 \\
\hline 11 & 0.000092 & 0 & - \\
\hline 28 & 0.000190 & 6 & 0.000337 \\
\hline 29 & 0.000092 & 1 & 0.000118 \\
\hline 12 & 0.000259 & 10 & 0.000422 \\
\hline 13 & 0.000098 & 1 & 0.000195 \\
\hline 36 & 0.000440 & 29 & 0.000452 \\
\hline 37 & 0.000097 & 4 & 0.000147 \\
\hline 20 & 0.000643 & 34 & 0.000659 \\
\hline 21 & 0.000096 & 5 & 0.000136 \\
\hline 22 & 0.000525 & 22 & 0.000584 \\
\hline 23 & 0.000093 & 3 & 0.000148 \\
\hline 18 & 0.000583 & 42 & 0.000618 \\
\hline 19 & 0.000106 & 14 & 0.000173 \\
\hline 06 & 0.000839 & 33 & 0.000884 \\
\hline 07 & 574.9739411 & 23 & 999.9546154 \\
\hline
\end{tabular}


Table A.4: Epsilon constraint method - environmental objective function results

\begin{tabular}{|c|c|c|c|c|c|}
\hline Instance & Avg. it. time (sec) & Total time (sec) & Optimal & Optimal values (\%) & Avg. gap (\%) \\
\hline 30 & 477 & 9530 & 5 & 25.00 & 0.003285 \\
\hline 31 & 226 & 5644 & 23 & 92.00 & 0.000113 \\
\hline 38 & 478 & 14341 & 9 & 30.00 & 0.002840 \\
\hline 39 & 316 & 11070 & 28 & 80.00 & 0.000118 \\
\hline 24 & 523 & 20907 & 7 & 17.50 & 0.002744 \\
\hline 25 & 439 & 19756 & 31 & 68.89 & 0.000210 \\
\hline 26 & 559 & 8385 & 2 & 13.33 & 0.001492 \\
\hline 27 & 499 & 9972 & 9 & 45.00 & 0.000267 \\
\hline 34 & 559 & 13973 & 4 & 16.00 & 0.002355 \\
\hline 35 & 562 & 16869 & 6 & 20.00 & 0.014897 \\
\hline 42 & 605 & 6050 & 0 & 0.00 & 0.002060 \\
\hline 43 & 602 & 9036 & 0 & 0.00 & 0.190747 \\
\hline 32 & 569 & 11375 & 2 & 10.00 & 0.001522 \\
\hline 33 & 599 & 14965 & 1 & 4.00 & 0.000782 \\
\hline 40 & 586 & 17586 & 2 & 6.67 & 0.004399 \\
\hline 41 & 603 & 18087 & 0 & 0.00 & 0.087132 \\
\hline 16 & 523 & 18291 & 8 & 22.86 & 0.000717 \\
\hline 17 & 602 & 21067 & 0 & 0.00 & 0.233307 \\
\hline 04 & 563 & 8451 & 2 & 13.33 & 0.023421 \\
\hline 05 & 521 & 10420 & 6 & 30.00 & 0.000562 \\
\hline 08 & 582 & 23266 & 4 & 10.00 & 0.022792 \\
\hline 09 & 593 & 23728 & 1 & 2.50 & 0.075959 \\
\hline 10 & 566 & 5663 & 1 & 10.00 & 0.003236 \\
\hline 11 & 605 & 9080 & 0 & 0.00 & 0.000598 \\
\hline 28 & 584 & 8756 & 1 & 6.67 & 0.004508 \\
\hline 29 & 606 & 12122 & 0 & 0.00 & 0.205274 \\
\hline 12 & 581 & 11617 & 2 & 10.00 & 0.001938 \\
\hline 13 & 605 & 15116 & 0 & 0.00 & 0.136815 \\
\hline 36 & 579 & 17384 & 3 & 10.00 & 0.022441 \\
\hline 37 & 602 & 18059 & 0 & 0.00 & 0.003276 \\
\hline 20 & 594 & 20773 & 1 & 2.86 & 0.024545 \\
\hline 21 & 598 & 23914 & 1 & 2.50 & 0.003082 \\
\hline 22 & 596 & 14907 & 2 & 8.00 & 0.002902 \\
\hline 23 & 605 & 18140 & 0 & 0.00 & 0.179312 \\
\hline 18 & 597 & 26872 & 1 & 2.22 & 0.009025 \\
\hline 19 & 600 & 27014 & 0 & 0.00 & 0.002211 \\
\hline 06 & 583 & 20391 & 2 & 5.71 & 0.027618 \\
\hline 07 & 600 & 24016 & 0 & 0.00 & 0.003840 \\
\hline
\end{tabular}




\section{Bibliography}

[1] Budget Direct. Car Insurance: Research Statistics. - Accessed: 28.04.2020

https://www.budgetdirect.com.au/car-insurance/research/

average-fuel-consumption-australia.html

[2] The Engineering ToolBox. Fuels - Densities and Specific Volume. Accessed: 28.04.2020 https://www.engineeringtoolbox.com/ fuels-densities-specific-volumes-d_166.html

[3] Kelley Blue Book. Hybrid Alternative Energy Car. - Accessed: 28.04.2020 https : / www . kbb.com/best-cars/top-10-best-plug-in-hybrid-cars-under-40000/

[4] Toyota. Toyota Prius. - Accessed: 04.03.2020 https://www.toyota.pt/new-cars/ prius-plugin/Prius-Brochure.json

[5] Toyota. Toyota Yaris. - Accessed: 04.03.2020 https://www.toyota.pt/new-cars/ yaris/Yaris-Brochure.json

[6] Auto Rental News. U.S. car rental revenue and fleet size comparision 2017. January 2017. - Accessed: 02.02.2020 https://www.autorentalnews.com/ rental-operations/305498/2017-car-rental-market-data-1

[7] Auto Rental News. U.S. car rental revenue and fleet size comparision $2018 . \quad$ January 2018. - Accessed: 02.02.2020 https://www.autorentalnews.com/ rental-operations/321011/2018-revenue-cars-in-service-snapshot

[8] MarketWatch. Car Rental Market 2019 Industry Analysis By Size, Share, Growth, Trends, Demand, Statistics, Key Players With Regional Forecast To 2023. September 2019. - Accessed: 02.02.2020 https: //www. marketwatch.com/press-release

[9] Aghaei, J. ; Amjady, N. ; Shayanfar, H.A.: Multi-objective electricity market clearing considering dynamic security by lexicographic optimization and augmented epsilon constraint method. In: Applied Soft Computing 11 (2011), Nr. 4, S. 3846 - 3858. - URL https://doi.org/10.1016/j.asoc.2011.02.022 
[10] Almarzooqi, A. ; Mnatsakanyan, A. ; Muruaga, E.: Management of Used Lithium Ion Batteries of EV in Dubai. (2019), S. 514-517. - URL https:// doi .org/10.1109/ ISC2 46665.2019 .9071665

[11] Blums ack, S. ; Samaras, C. ; Hines, P.: in: Power and Energy Society General Meeting - Conversion and Delivery of Electrical Energy Energy in the 21st Century. (2008). - URL http://dx.doi.org/10.1109/PES.2008.4596965

[12] Campanari, S. ; Manzolini, G. ; Iglesia, F. G. de la: Energy analysis of electric vehicles using batteries or fuel cells through well-to-wheel driving cycle simulations. In: Journal of Power Sources 186 (2009), Nr. 2, S. 464 - 477. - URL https://doi.org/ $10.1016 / j \cdot j$ jowsour.2008.09.115

[13] CARRoll, W.J. ; Grimes, R.C.: Evolutionary change in product management: experiences in the car rental industry. In: Interfaces 25 (Sept.-Oct. 1995), Nr. 5, S. 84 - 104. - URL http://dx.doi.org/10.1287/inte.25.5.84

[14] Donateo, T. ; Ingrosso, F. ; Licci, F. ; Laforgia, D.: A method to estimate the environmental impact of an electric city car during six months of testing in an Italian city. In: Journal of Power Sources 270 (2014/12/15), S. 487 - 98. - URL http: //dx.doi.org/ $10.1016 / j \cdot j$ jowsour.2014.07.124

[15] Gagnon, L. ; Belanger, C. ; Uchiyama, Y.: Life-cycle assessment of electricity generation options: The status of research in year 2001. In: Energy Policy 30 (2002), Nr. 14, S. 1267-1278. - URL https://doi.org/10.1016/S0301-4215(02)00088-5

[16] Guerriero, F. ; Olivito, F.: Modelling and solving a car rental revenue optimisation problem. In: International Journal of Mathematics in Operational Research 3 (2011), Nr. 2, S. 198 - 218. - URL http://dx.doi.org/10.1504/IJMOR.2011.038911

[17] GuO, W. ; LI, Z. ; ZhAO, D. ; Wong, T.: A k-nearest-neighbors Pareto rank assignment strategy and compound crossover operator based NSGA-II and its applications on multiobjective optimization functions. Berlin, Germany, 2008, S. 142 - 51. - URL http : / / dx . doi.org/10.1007/978-3-540-92137-0_16

[18] Hooftman, N. ; Oliveira, L. ; Messagie, M. ; Coosemans, T. ; Van Mierlo, J.: Environmental Analysis of Petrol, Diesel and Electric Passenger Cars in a Belgian Urban Setting. In: Energies 9 (2016), Nr. 2, S. 84 (24 pp.) -. - URL http: / / dx. doi .org/10 . $3390 /$ en 9020084

[19] IEA: CO2 Emissions from Fuel Combustion 2019. (2019). - URL https: / /www . iea. org/reports/co2-emissions-from-fuel-combustion-2019

[20] LANE, B.: Lyfe cycle assessment of vehicle fuels and technologies. In: London Borough of Camden (March 2006). - URL https://www. nextgreencar.com/content/WGC_ LCA_SUMMARY_10_03_2006_vP.pdf 
[21] LI, S. ; LI, N. ; GaO, Y. ; LI, J.: Vehicle Cycle Environmental Impacts Assessment of a China Passenger Car. Piscataway, NJ, USA, 2012, S. 1889 - 92. - URL http: / / dx . doi . org/10.1109/iCBEB.2012.466

[22] Mahesh, K. ; Nallagownden, P. ; Elamvazuthi, I.: Advanced Pareto Front NonDominated Sorting Multi-Objective Particle Swarm Optimization for Optimal Placement and Sizing of Distributed Generation. In: Energies 9 (2016), Nr. 12. - URL https:// doi . org/10.3390/en9120982

[23] Maravall, D. ; LOPE, J. de: Multi-objective dynamic optimization with genetic algorithms for automatic parking. In: Soft Computing 11 (2007), Nr. 3, S. 249 - 57. - URL http: //dx.doi.org/10.1007/s00500-006-0066-6

[24] Marler, R.T. ; Arora, J.S.: J. Survey of multi-objective optimization methods for engineering. In: Struct Multidisc Optim 26 (2004), S. 369-395. - URL https: //doi.org/10.1007/s00158-003-0368-6

[25] Marler, R.T. ; ArorA, J.S.: The weighted sum method for multi-objective optimization: new insights. In: Structural and Multidisciplinary Optimization 41 (2010), Nr. 6, S. 853 62. - URL http://dx.doi.org/10.1007/s00158-009-0460-7

[26] Mavrotas, G.: Effective implementation of the epsilon-constraint method in MultiObjective Mathematical Programming problems. In: Applied Mathematics and Computation 213 (2009), S. 455-465. - URL https: / / doi.org/10.1016/j.amc.2009.03.037

[27] Mota, B. ; Gomes, M.I. ; A.C. ; Barbosa-PovoA, A.P.: Sustainable supply chains: An integrated modeling approach under uncertainty. In: Omega 77 (2018), S. 32 - 57. - URL https://doi.org/10.1016/j.omega.2017.05.006

[28] Oliveira, B.B. ; Carravilla, M.A. ; Oliveira, J.F.: "Capacity-Pricing Model: car rental instances", Mendeley Data, v1. 2017. - URL http://dx.doi.org/10.17632/ g49smv7nh8.1

[29] Oliveira, B.B. ; Carravilla, M.A. ; Oliveira, J.F.: Fleet and revenue management in car rental companies: A literature review and an integrated conceptual framework. In: Omega 71 (2017), S. 11 - 26. - URL https://doi.org/10.1016/j.omega.2016. 08.011

[30] Oliveira, B.B. ; Carravilla, M.A. ; Oliveira, J.F.: Integrating pricing and capacity decisions in car rental: A matheuristic approach. In: Operations Research Perspectives 5 (2018), S. 334 -356. - URL https://doi.org/10.1016/j.orp.2018.10.002

[31] Oliveira, B.B. ; Carravilla, M.A. ; Oliveira, J.F.: A co-evolutionary matheuristic for the car rental capacity-pricing stochastic problem. In: European Journal of Operational 
Research 276 (2019), Nr. 2, S. 637 - 655. - URL https://doi.org/10.1016/j. ejor.2019.01.015

[32] Orlov, A. ; Kallbekken, S.: The impact of consumer attitudes towards energy efficiency on car choice: Survey results from Norway. In: Journal of Cleaner Production 214 (2019/03/20), S. 816-22. - URL http://dx.doi.org/10.1016/j. jclepro.2018. 12.326

[33] Ribeiro, C. ; Ferreira, J.V. ; PARtidario, P.: Life cycle assessment of a multi-material car component. In: International Journal of Life Cycle Assessment 12 (2007), Nr. 5, S. 336 -45. - URL http://dx.doi.org/10.1065/lca2006.12.304

[34] Sheng, Z. ; Xiangtao, Z.: Multi-objective optimization for pure electric vehicle during a car-following process. Piscataway, NJ, USA, 2019, S. 2884 - 8. - URL http: / / dx. doi. org/10.23919/ChicC.2019.8865537

[35] Simoes, C.L. ; Sa, R. Figueiredo de ; Ribeiro, C.J. ; Bernardo, P. ; Pontes, A.J. ; BERNARDO, C.A.: Environmental and economic performance of a car component: assessing new materials, processes and designs. In: Journal of Cleaner Production 118 (2016/04/01), S. 105 - 17. - URL http://dx.doi.org/10.1016/j.jclepro.2015.12.101

[36] Vasconcelos, A.S. ; Martinez, L.M. ; Correia, G.H.A. ; Guimaraes, D.C. ; FARIAS, T.L.: Environmental and financial impacts of adopting alternative vehicle technologies and relocation strategies in station-based one-way carsharing: an application in the city of Lisbon, Portugal. In: Transportation Research, Part D: Transport and Environment 57 (December 2017), S. 350 - 62. - URL http://dx.doi.org/10.1016/j.trd.2017. 08.019

[37] Wikströma, M. ; ERIKSSON, L. ; HANSSON, L.: Introducing plug-in electric vehicles in public authorities. In: Research in Transportation Business Management (2016), Nr. 18, S. 29 -37. - URL https://doi.org/10.1016/j.rtbm.2016.01.009 